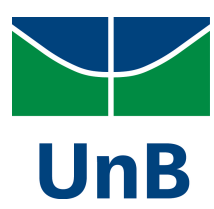

Universidade de Brasília - UnB

Programa de Pós-Graduação de Administração - PPGA

Wendy Sidon Meira de Oliveira

Spillover de Volatilidades e Ações de Empresas com

Governança Corporativa de Alta Qualidade 



\section{Spillover de Volatilidades e Ações de Empresas com Governança Corporativa de Alta Qualidade}

Dissertação apresentada no curso de Mestrado Acadêmico do Programa de Pós-Graduação em Administração, na área de concentração de Finanças e Métodos Quantitativos, da Universidade de Brasília como requisito para obtenção do grau de Mestre.

Orientador: Prof. Adj. José Carneiro da Cunha Oliveira Neto

Brasília

Julho, 2016 

Wendy Sidon Meira de Oliveira

Spillover de Volatilidades e Ações de Empresas com Governança Corporativa de Alta Qualidade/ Wendy Sidon Meira de Oliveira. - Brasília, Julho, 2016125 p.; $30 \mathrm{~cm}$.

Orientador: Prof. Adj. José Carneiro da Cunha Oliveira Neto

Dissertação (Mestrado) - Universidade de Brasília - UnB

Programa de Pós-Graduação de Administração - PPGA, Julho, 2016.

1. Spillover. 2. Governança Corporativa. 3. Volatilidade. I. Prof. Adj. José Carneiro da Cunha Oliveira Neto. II. Universidade de Brasília. III. Faculdade de Administração, Ciências Contábeis e Economia. IV. Título. 


\title{
Spillover de Volatilidades e Ações de Empresas com Governança Corporativa de Alta Qualidade
}

\begin{abstract}
Dissertação apresentada no curso de Mestrado Acadêmico do Programa de Pós-Graduação em Administração, na área de concentração de Finanças e Métodos Quantitativos, da Universidade de Brasília como requisito para obtenção do grau de Mestre.
\end{abstract}

Trabalho aprovado. Brasília, Julho, 2016

Prof. Adj. José Carneiro da Cunha Oliveira Neto

Faculdade de Economia, Administração e

Contabilidade

Universidade de Brasília - UnB

Prof. Tit. Herbert Kimura

Faculdade de Economia, Administração e

Contabilidade

Universidade de Brasília - UnB

Prof. Associado Osvaldo Cândido

Faculdade de Economia, Administração e

Contabilidade

Universidade Católica de Brasília 
À Deus, por me conceder sabedoria nas escolhas dos melhores caminhos, coragem pra acreditar, força pra não desistir e proteção pra me amparar.

Ao meu pai, que se foi durante a fase de desenvolvimento deste trabalho e que deixará eternas saudades, pelo amor que me mostrou e pela confiança que sempre dedicou na minha capacidade.

À minha mãe, pelo apoio, amor, confiança e motivação incondicional.

Às minhas irmãs, pelo incentivo direto ou indireto.

À minha filha, pela espera, por compreender minhas ausências e por me impulsionar em direção às vitórias em cada desafio. 



\section{Agradecimentos}

Agradeço à DEUS por ter concedido a oportunidade de cursar e concluir o mestrado e por ter colocado pessoas tão especiais ao meu lado.

A meus pais, Lamir e Joilda, meu eterno agradecimento. Sempre acreditaram em minha capacidade. Sempre me fortaleceram e me incentivaram a encarar novos desafios e, em cada um deles, fazer o meu melhor. Obrigada pelo amor incondicional!

À pequena Cindy, que, nos últimos dois anos, foi compreensiva e ao mesmo tempo me inspirou a querer ser mais que fui até hoje! Minha 'mola propulsora', obrigada por fazer parte desta realização!

Às minhas irmãs, Christine e Stephanie, agradeço imensamente, pois, a seu modo, sempre se orgulharam de mim e confiaram em meu trabalho. Obrigada pela confiança!

Aos meus amigos, Bira, Elisângela, Guga e Miriam, por só quererem o meu bem e me valorizarem tanto como pessoa. Obrigada pela amizade!

Ao Prof. André Nunes Maranhão, meu agradecimento especial, por sua tão dedicada orientação e participação no desenvolvimento deste trabalho. Graças à sua parceria, amizade, paciência, compreensão, apoio, este trabalho pôde ser concretizado. Obrigada por ter ajudado tanto a fazer deste sonho uma realidade. Obrigada por cada minuto dedicado a este estudo!

A meus amigos do mestrado, pelos momentos divididos juntos, especialmente ao Fernando, à Maísa e ao Daniel, que se tornaram verdadeiros amigos e tornaram mais leve minha caminhada. Foi bom demais poder contar com vocês! Obrigada!

Aos membros da banca examinadora da dissertação, Prof. Dr. José Carneiro da Cunha Oliveira Neto, Prof. Dr. Herbert Kimura, Prof. Dr. Osvaldo Cândido pela disponibilidade e interesse na participação. Muito obrigada!

Ao Prof. Dr. Rodrigo Penaloza e ao Prof. Dr. Pedro Henrique Melo Albuquerque, pelas contribuições realizadas a esse trabalho durante o exame de qualificação.

Aos funcionárias da Secretaria do PPGA/UnB, especialmente à Edvânia, pela disponibilidade, simpatia e gentileza. Obrigada pela ajuda!

Agradeço enormemente, também, ao Banco do Brasil, pelo apoio concedido por meio de bolsa de estudos, sem a qual seria impossível frequentar aulas e desenvolver os trabalhos necessários à conclusão do curso. Agradeço também aos colegas de trabalho pela compreensão e incentivo. Obrigada a todos pelo apoio!

Sozinho ninguém vence!... OBRIGADA A TODOS! 



\section{Resumo}

Existe uma crescente preocupação com o valor e a credibilidade das empresas no mercado, o que pode ser traduzido em conceitos de governança corporativa. Desde seus desenvolvimentos teóricos tendo por base a teoria dos jogos, em particular teoria de agente principal, estudos tem identificado agregação de valor de mercado associados a empresas de boa governança, nesse ponto outras questões passam a ser colocadas, como por exemplo, se governança pode reduzir os efeitos de transbordamento de volatilidades de outros tipos de ativos. O transbordamento de volatilidade, medido por meio de correlações condicionais é um estudo recente em finanças, os modelos utilizados e testes aplicados buscam identificar sua existência e precedência estatística.

Neste estudo, foram utilizados os retornos: Ibovespa, como controle para o aspecto estritamente negocial, IGC-X e IGC-NM como retornos com diferentes graus de governança corporativa. Utilizando 48 taxas de câmbios foram criados retornos representativos por meio de análise de componentes principais para três diferentes proxies de choques cambiais, o primeiro utilizando todas as 48 taxas de câmbio, a segunda utilizando as taxas de câmbio exceto o Dólar e a terceira sendo apenas o retorno do Dólar. Um procedimento semelhante foi realizado utilizando 17 bolsas de valores internacionais, contudo criando apenas uma proxy para choques de mercados financeiros internacionais.

Por meio de modelos GARCH multivariados foram estimadas as correlações condicionais em 9 diferentes modelos combinando sempre um índice Bovespa (Ibovespa, IGC-X ou IGC-NM) com um dos três tipos de choque cambial e o choque de mercados financeiros internacionais. A existência e direção dos transbordamentos de volatilidade de choques cambias, choques de mercados financeiros internacionais e índices Bovespa foram testadas por meio de testes de causalidade de Granger de segunda ordem.

Como principais resultados temos a comprovada existência de transbordamentos de choques cambiais e de mercados financeiros para índices Bovespa, sendo que essas correlações apresentam dinâmica temporal, com transbordamentos sempre na direção dos choques para os índices Bovespa. Os transbordamentos cambiais apresentam na maior parte do período amostral uma correlação condicional negativa enquanto os transbordamentos de mercados financeiros internacionais apresentam uma correlação condicional positiva. O Dólar apresentou o maior transbordamento cambial para qualquer índice Bovespa, a magnitude de choques cambiais e de mercados financeiros internacionais é equivalente. Por fim os índices de governança corporativa apresentaram menores transbordamentos à medida que o grau de governança corporativa aumenta para os choques cambiais e de mercados financeiros internacionais testados.

Palavras-chave: Governança Corporativa, GARCH Multivariados, Spillover de volatilidade, Choques Cambiais, Choques de Mercados Financeiros Internacionais.. 



\section{Abstract}

There is growing concern about the value and credibility of the companies in the market, which can be translated into concepts of corporate governance. Since its theoretical developments based on the theory of games, in particular theory principal-agent, studies have identified market value addition associated with good governance companies, this point other issues are now placed, for example, it can governance reduce the effects of overflow volatilities of other types of assets. The spillover of volatility, measured by means of conditional correlations is a recent study in finance, the models used and the tests seek to identify their existence and statistical precedence.

In this study, the returns were used: Ibovespa, as control for strictly business aspect, IGC-X and IGC-NM as returns with different levels of corporate governance. Using 48 exchange rates representative returns were created through principal component analysis for three different proxies exchange rate shocks, the first using all 48 exchange rates, the second using exchange rates other than the dollar and third being only the return of the dollar. A similar procedure was carried out using 17 international stock exchanges, but creating just a proxy to shocks of international financial markets. Through multivariate GARCH models were estimated conditional correlations in 9 different models combining always Bovespa index (Ibovespa, IGC-X or IGCNM) with one of three types of exchange rate shock and the shock of the international financial markets. The existence and direction of spillovers of volatility of forward exchange shocks, international financial market shocks and Bovespa were tested by Granger causality test of second order.

The main results have proven the existence of spillovers from exchange rate and financial markets shocks to Bovespa index, and these correlations have temporal dynamics, with spillovers always in the direction of the shocks to the Bovespa. The exchange spillovers have most of the sample period a negative conditional correlation as spillovers from international financial markets have a positive conditional correlation. The Dollar experienced the largest exchange for any overflow Bovespa index, the magnitude of exchange rate shocks and international financial markets is equivalent. Finally the corporate governance indices showed lower spillovers as the level of corporate governance increases to exchange rate and international financial markets shocks tested.

Keywords: Corporate Governance, Multivariate GARCH, Volatility Spillover, Exchange rate shock, International financial market shock. 



\section{Lista de ilustrações}

Figura 1 - Construção de Índices . . . . . . . . . . . . . . . . . . . . . . . . 75

Figura 2 - Modelos Estimados . . . . . . . . . . . . . . . . . . 75

Figura 3 - Gráfico de Retorno e Volatilidade do Ibovespa . . . . . . . . . . . 78

Figura 4 - Retorno e Volatilidade do IGC-NM . . . . . . . . . . . . . 78

Figura 5 - Retorno e Volatilidade do IGC-X . . . . . . . . . . . . . . . . . 79

Figura 6 - Análise Exploratória dos Dados - Índices Bovespa . . . . . . . . . . . . 79

Figura 7 - Histograma de Retorno e Volatilidade do Ibovespa . . . . . . . . . . . 80

Figura 8 - Histograma de Retorno e Volatilidade do IGC-NM . . . . . . . . . . 80

Figura 9 - Histograma de Retorno e Volatilidade do IGC-X . . . . . . . . . . . 80

Figura 10 - Resultados do Teste Jarque Bera _ . . . . . . . . . . . . . . . . 80

Figura 11 - Resultados do Teste de Bartlet e Estatística KMO . . . . . . . . . . 81

Figura 12 - Análise Exploratória dos Dados - IND1, IND2, IND3 e Dólar . . . . . . . . 81

Figura 13 - Histograma de Retorno e Volatilidade do IND1 . . . . . . . . . . . . . 82

Figura 14 - Histograma de Retorno e Volatilidade do IND2 . . . . . . . . . . . . . . 82

Figura 15 - Histograma de Retorno e Volatilidade do IND3 . . . . . . . . . . . . . 82

Figura 16 - Histograma de Retorno e Volatilidade do Dólar . . . . . . . . . . . . . . 82

Figura 17 - Resultados do Teste Jarque Bera para IND1, IND2, IND3 e Dólar . . . . . . 82

Figura 18 - Matriz de Correlação Contemporânea dos Retornos . . . . . . . . . . . 83

Figura 19 - Matriz de Correlação Contemporânea das Volatilidades . . . . . . . . . 83

Figura 20 - Teste LM para Autocorrelação de Retornos e Volatilidade - Índices Bovespa 84

Figura 21 - Teste LM para Autocorrelação de Retornos e Volatilidade - Índices e Dólar . 84

Figura 22 - Funções de Autocorrelação - Ibovespa . . . . . . . . . . . . . . . . . 84

Figura 23 - Funções de Autocorrelação - IGC-NM … . . . . . . . . . . . 85

Figura 24 - Funções de Autocorrelação - IGC-X . . . . . . . . . . . . . . . . 85

Figura 25 - Funções de Autocorrelação - IND1 ‥ . . . . . . . . . . . . 85

Figura 26 - Funções de Autocorrelação - IND2 . . . . . . . . . . . . . . . . . . . . . . . . . . 85

Figura 27 - Funções de Autocorrelação - IND3 . . . . . . . . . . . . . . . 86

Figura 28 - Funções de Autocorrelação - Dólar … . . . . . . . . . . . . . 86

Figura 29 - Parâmetros BEKK e Teste LM - Modelo 1 . . . . . . . . . . . . . . 87

Figura 30 - Teste de Causalidade de Granger de Segunda Ordem e Gráfico de Correlações Condicionais - Modelo 1 . . . . . . . . . . . . . . . . . . . . 87

Figura 31 - Parâmetros BEKK e Teste LM - Modelo $2 \ldots \ldots$. . . . . . . . 88

Figura 32 - Teste de Causalidade de Granger de Segunda Ordem e Gráfico de Correlações Condicionais - Modelo $2 \ldots \ldots \ldots$. . . . . . . . . . 88

Figura 33 - Parâmetros BEKK e Teste LM - Modelo 3 . . . . . . . . . . . . . . . 89 
Figura 34 - Teste de Causalidade de Granger de Segunda Ordem e Gráfico de Correlações Condicionais - Modelo 3 . . . . . . . . . . . . . . . . . . . . 90 90

Figura 35 - Parâmetros BEKK e Teste LM - Modelo 4 . . . . . . . . . . . . . . . . 91

Figura 36 - Teste de Causalidade de Granger de Segunda Ordem e Gráfico de Correlações Condicionais - Modelo 4 . . . . . . . . . . . . . . . . . . . 9 91

Figura 37 - Parâmetros BEKK e Teste LM - Modelo 5 . . . . . . . . . . . . . . . 92

Figura 38 - Teste de Causalidade de Granger de Segunda Ordem e Gráfico de Correlações Condicionais - Modelo 5 . . . . . . . . . . . . . . . 92

Figura 39 - Parâmetros BEKK e Teste LM - Modelo 6 . . . . . . . . . . . . . . . . 93

Figura 40 - Teste de Causalidade de Granger de Segunda Ordem e Gráfico de Correlações Condicionais - Modelo 6 . . . . . . . . . . . . . . . . . 94

Figura 41 - Parâmetros BEKK e Teste LM - Modelo 7 . . . . . . . . . . . . . . 95

Figura 42 - Teste de Causalidade de Granger de Segunda Ordem e Gráfico de Correlações Condicionais - Modelo 7 . . . . . . . . . . . . . . 95

Figura 43 - Parâmetros BEKK e Teste LM - Modelo 8 . . . . . . . . . . . . . . 96

Figura 44 - Teste de Causalidade de Granger de Segunda Ordem e Gráfico de Correlações Condicionais - Modelo 8 . . . . . . . . . . . . . . . . 96

Figura 45 - Parâmetros BEKK e Teste LM - Modelo 9 . . . . . . . . . . . . . . . . 97

Figura 46 - Teste de Causalidade de Granger de Segunda Ordem e Gráfico de Correlações Condicionais - Modelo 9 . . . . . . . . . . . . . . . . . . 97

Figura 47 - Comparativos - Correlações Condicionais por Índices Bovespa . . . . . . . 99

Figura 48 - Teste T para Correlaçãoes Condicionais . . . . . . . . . . . . . . . . 100

Figura 49 - Comparativos - Correlações Condicionais . . . . . . . . . . . . . . . . 100

Figura 50 - Teste T para Correlaçãoes Condicionais . . . . . . . . . . . . . . . . 101

Figura 51 - Estatísicas Exploratórias - Correlaçãoes Condicionais . . . . . . . . . . . 101

Figura 52 - Resultados dos Testes ADF para Índices Bovespa . . . . . . . . . . . . . 119

Figura 53 - Resultados dos Testes ADF para os Índices Criados . . . . . . . . . . . . 119

Figura 54 - Resultados da ACP - Câmbio . . . . . . . . . . . . . . . . . . 121

Figura 55 - Resultados da ACP - Câmbio sem Dólar . . . . . . . . . . . . . . 121

Figura 56 - Resultados da ACP - Bolsas . . . . . . . . . . . . . . . . . 122

Figura 57 - MGARCH-BEKK(1,1) - Modelo $1 \ldots \ldots$. . . . . . . . . 123

Figura 58 - MGARCH-BEKK $(1,1)-$ Modelo $5 \ldots \ldots \ldots$. . . . . . . . . 123

Figura 59 - MGARCH-BEKK $(1,1)$ - Modelo $6 \ldots \ldots$. . . . . . . . . . . . 124

Figura 60 - MGARCH-BEKK(1,1) e MGARCH-BEKK $(2,1)$ - Modelo 8 . . . . . . . . 124

Figura 61 - Estatísticas Exploratórias - Correlações Condicionais . . . . . . . . . . 125 


\section{Lista de tabelas}

Tabela 1 - Resumo das diferenças de comportamento das ACFs e PACF dos modelos. . 54

Tabela 2 - Referências para Estatística KMO . . . . . . . . . . . . . . 73

Tabela 3 - Identificação das possíveis ordens dos modelos. . . . . . . . . . . . . . . . . . . . . . . . . . . .

Tabela 4 - Taxas de câmbios utilizadas. . . . . . . . . . . . . 115

Tabela 5 - Bolsas de valores utilizadas . . . . . . . . . . . . . 117 



\section{Sumário}

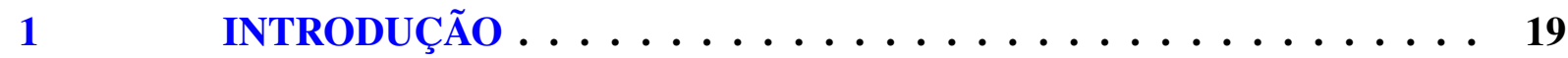

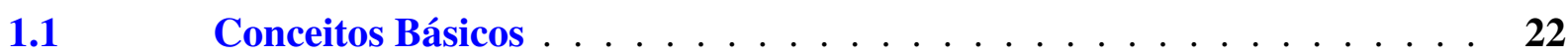

1.1.1 Índices da BM\&FBovespa $\ldots \ldots \ldots \ldots \ldots \ldots \ldots \ldots$

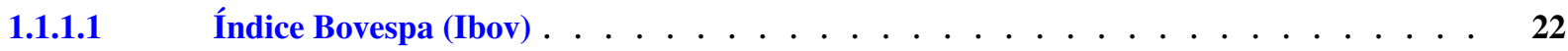

1.1.1.2 Índice Governança Corporativa - Novo Mercado (IGC-NM) $\ldots \ldots \ldots \ldots$

1.1.1.3 Índice de Ações com Governança Corporativa Diferenciada (IGC-X) $\ldots \ldots \ldots$

1.1.2 Retornos e Volatilidade . . . . . . . . . . . . . . . . . . . . . . 24

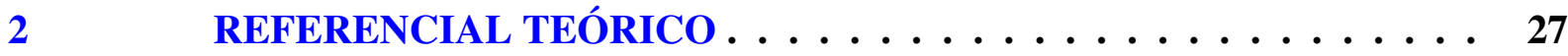

$2.1 \quad$ Aspectos da Governança Corporativa $\ldots \ldots \ldots \ldots$

2.1.1 Conflitos de Agência . . . . . . . . . . . . . . . . . . . 27

2.1.2 A Governança Corporativa e seus Impactos no Desempenho das Empresas 28

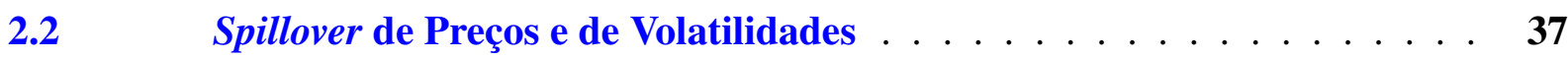

2.2.1 Preços de Ações e Taxas de Câmbio . . . . . . . . . . . . . . . . . 37

2.2.2 Spillover entre Volatilidade dos Preços de Ações e das Taxas de Câmbio . 40

2.2.3 Volatilidade entre Índices do Mercado Financeiro . . . . . . . . . . . 42

$2.3 \quad$ Spillovers, Governança Corporativa e os Efeitos Lead-Lag . . . . . . . 45

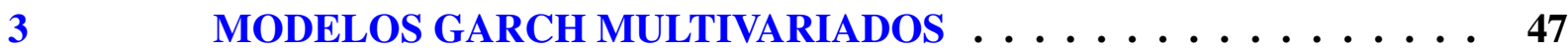

3.1 O Modelo GARCH Multivariado $\ldots \ldots \ldots \ldots \ldots$

3.2 Modelos MGARCH Baseados em GARCH Univariados . . . . . . . . 49

3.2.1 Modelo CCC . . . . . . . . . . . . . . . . . . . . . . . . . 49

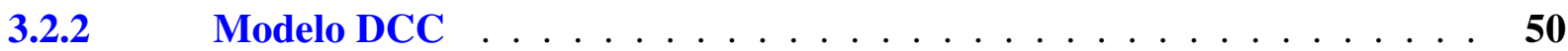

3.3 Modelos GARCH Multivariados Estruturais $\ldots \ldots \ldots \ldots \ldots$

3.3.1 Modelo Diagonal VEC $\ldots \ldots \ldots \ldots \ldots \ldots \ldots$

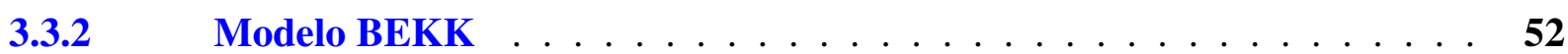

$3.4 \quad$ Identificação das Ordens dos Modelos GARCH $\ldots \ldots \ldots \ldots \ldots$

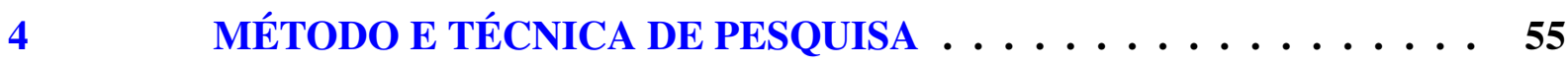

$4.1 \quad$ Teste de Causalidade de Engle-Granger $\ldots \ldots \ldots \ldots \ldots$

$4.2 \quad$ Teste de Causalidade de Granger de Segunda Ordem . . . . . . . . . 57

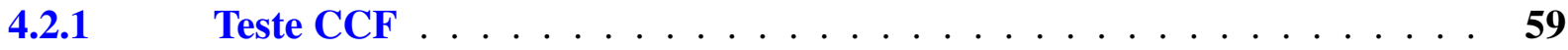

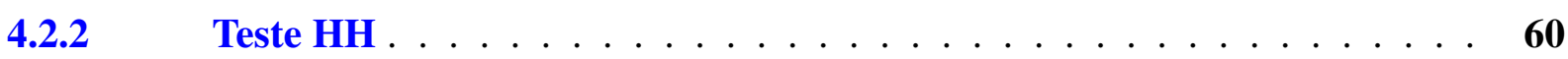

4.3 Análise de Componentes Principais e Estudo de Outliers Multivariados . 62

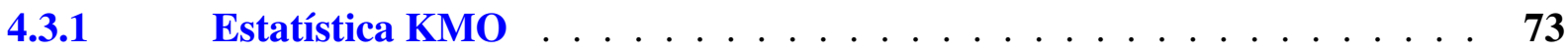

4.3.2 Teste Bartlett $\ldots \ldots \ldots \ldots \ldots \ldots \ldots \ldots \ldots \ldots$ 
4.4 Descrição dos Modelos, Construção de Índices e Testes Utilizados . . . . 74

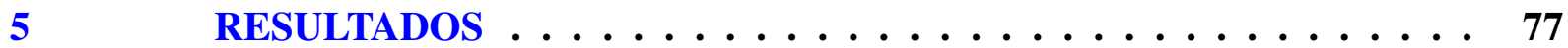

5.1 Descrição das Séries e Estatísticas Exploratórias . . . . . . . . . . . 77

$5.2 \quad$ Análise de Componentes Principais e Construção de Índices . . . . . . . 81

$5.3 \quad$ Estudo da Dinâmica Temporal . . . . . . . . . . . . . . . . . . 83

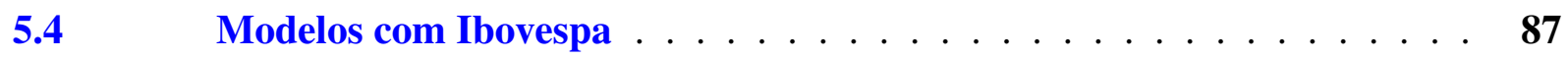

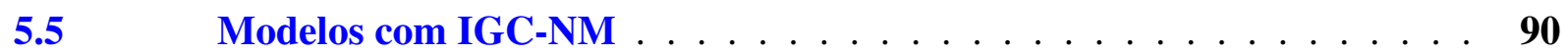

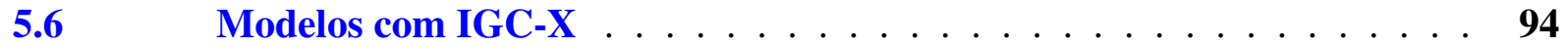

$5.7 \quad$ Análises Comparativas $\ldots \ldots \ldots \ldots \ldots$

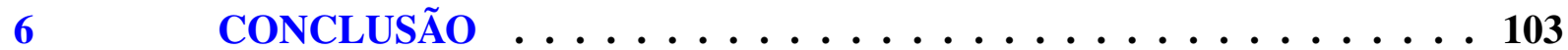

REFERÊNCIAS ............................ 105

$\begin{array}{ll}\text { APÊNDICES } & 113\end{array}$

APÊNDICE A - TABELA DE CÂMBIOS CONSIDERADOS . . . 115

APÊNDICE B - TABELA DE BOLSAS CONSIDERADAS . . . . 117

APÊNDICE C - TESTES DE ESTACIONARIEDADE . . . . . . 119

APÊNDICE D - ANÁLISE DE COMPONENTES PRINCIPAIS . . . 121

APÊNDICE E - MODELOS ESTIMADOS .......... 123

APÊNDICE F - ESTATÍSTICAS EXPLORATÓRIAS - CORRELAÇÕES

CONDICIONAIS ................ 125 


\section{Introdução}

Cada vez mais as corporações se preocupam com o valor e a credibilidade da empresa no mercado. Os investidores se tornam ainda mais exigentes quanto à boa governança corporativa das empresas. As boas práticas de governança podem ser consideradas vantagens competitivas, fornecendo alternativas eficazes aos mercados em momentos de pessimismo econômico ou onde as condições legais não trazem respaldo ao investidor. Além disso, vislumbram-se ganhos para a sociedade, que se beneficia diretamente com organizações mais estruturadas, transparentes e responsáveis.

A Governança Corporativa (GC), segundo definição do Instituto Brasileiro de Governança Corporativa (IBGC), é o sistema pelo qual as organizações são dirigidas, monitoradas e incentivadas, envolvendo os relacionamentos entre proprietários, conselho de administração, diretoria e órgãos de controle. Em uma definição mais genérica, a GC pode ser descrita como os mecanismos ou os princípios que governam o processo decisório dentro de uma empresa, ou ainda, um conjunto de regras que visam minimizar os problemas de agência (CARVALHO, 2002).

O investidor possui direitos sobre o investimento realizado por ele. Esses direitos são considerados críticos quando gerentes das empresas agem de acordo com seu próprio interesse. Dão aos seus investidores o poder de extrair dos gerentes retornos sobre seus investimentos. Acionistas recebem dividendos e podem retirar os diretores no caso de eles não darem resultados que paguem dividendos consideráveis, e credores não pagos possuem o poder de executar os bens das empresas. Sem esses direitos, investidores não seriam capazes de serem pagos, e assim empresas teriam dificuldade em receber financiamento externo (PORTA et al., 1998).

É possível pensar que a eficiência da governança corporativa está associada diretamente com a garantia de retorno do investimento. Essa afirmação está baseada fundamentalmente no conceito elaborado por Shleifer e Vishny (1997) sobre governança corporativa. Sendo assim tornase importante investigar a relação entre as práticas de GC adotadas pelas empresas e a valorização acionária da mesma. Suponha uma empresa que adota boas práticas de governança corporativa, com isso os acionistas obterão a garantia de que seus recursos serão utilizados de forma efetiva, afastando a insegurança causada pelos conflitos de agência (JENSEN; MECKLING, 1976). Logo, supomos que essas empresas terão valorização acionária elevada em razão do seu nível de GC.

Fazendo uma análise sob o ponto de vista do investidor externo, pode ser considerado importante uma análise sobre como o desempenho da firma está relacionado, ou não, com a variação cambial, por exemplo. Assim, há interesse em se fazer um estudo sobre o transbordamento ${ }^{1}$

$\overline{1}$ O conceito de spillover está relacionado à ideia de correlação, no caso de volatilidade condicional tem-se uma 
da volatilidade cambial e da volatilidade dos mercados financeiros internacionais com respeito à GC.

Por outro lado, há estudos preocupados com a relação entre preços de ações e taxas de câmbio em que se importaram com as variações em nível. Esses estudos evoluíram para tratar a volatilidade dos preços de ações e da taxa de câmbio, investigando portanto o transbordamento (spillover) de volatilidade em alguma direção: do câmbio para ações ou vice-versa. Nesse contexto, muitos modelos e testes passaram a ser implementados tanto para tratar a questão dessas variáveis em nível quanto em seu segundo momento. Classicamente, para analisar a volatilidade univariada os modelos mais utilizados são VAR, GARCH e suas várias especificações. Os modelos GARCH multivariados, por sua vez, criaram oportunidade de analisar efeitos cruzados de volatilidade (variâncias e correlações condicionais).

Esta dissertação tem por objetivo identificar se existe correlação entre fatores externos ao Brasil (volatilidade cambial e volatilidade dos mercados financeiros internacionais) e os índices de Governança Corporativa (IGC-NM e IGC-X) ou se existe correlação entre essas volatilidades e o Ibovespa. A partir dessa análise será testada a existência de causalidade de Granger de segunda ordem entre as variáveis (câmbios e bolsas de valores) e as variáveis que classificam a qualidade da governança (IGC-NM e IGC-X).

Um diferencial deste trabalho é o fato de que ainda não foi objeto de análise da academia brasileira, ou mesmo investigado de maneira integral por acadêmicos, a correlação existente entre volatilidades de choques externos (aqui considerados os câmbios e os mercados financeiros) e medidas de qualidade de governança corporativa (aqui considerados o IGC-NM e o IGC-X). Com base nessa investigação pode ser possível avaliar os impactos da Governança Corporativa em redução de risco (volatilidade).

A escolha por este tema deve-se à identificação com o assunto proposto, quanto à Governança Corporativa e quanto à modelos econométricos. Também se engloba nesta justificativa a realidade em que empresas investidoras, como fundos de pensão, por exemplo, que se vêm obrigadas a desenvolver mecanismos de análise sobre a possibilidade de investimento a fim de mitigar os riscos dos mesmos já que a legislação local, muitas vezes, não disponibiliza as condições necessárias.

Consideramos que há contribuição deste assunto para a sociedade pois o grau de governança corporativa, se desenvolvido adequadamente, refere-se à responsabilização da empresa sobre aspectos de transparência, prestação de contas, equidade das informações e consequente diminuição dos conflitos de interesse. Tudo isso pode acarretar em uma organização bem estruturada e perene, com responsabilidade sócio ambiental, o que culminaria em benefício direto à sociedade.

O presente estudo busca responder: 
1. se existe a possibilidade de construção de proxies para choques cambiais e choques de mercados financeiros internacionais;

2. se existem efeitos spillovers do câmbio com relação aos índices IGC-NM, IGC-X e Ibovespa;

3. se existem efeitos spillovers dos mercados financeiros internacionais com relação aos índices IGC-NM, IGC-X e Ibovespa;

4. se existe e qual o melhor modelo para estimar as variâncias e correlações condicionais;

5. se existe alguma causalidade, no sentido de Granger, para as correlações condicionais estimadas.

6. se há transbordamento entre volatilidade cambial e índices de Governança Corporativa;

7. se há transbordamento entre volatilidade de mercados financeiros internacionais e índices de Governança Corporativa;

8. qual desses transbordamentos é mais relevante com relação aos índices de governança?

9. maior qualidade de governança está associada a menores efeitos de transbordamento?

A presente pesquisa será bibliográfica com o objetivo geral de identificar os efeitos de spillover de volatilidade cambial e de volatilidade de mercados financeiros internacionais na volatilidade de ações de empresas com alta qualidade de governança corporativa.

No primeiro capítulo, conta um levantamento de referencial teórico com base nos estudos e publicações que abordam aspectos da governança corporativa, incluindo estudos sobre conflitos de agência. Além disso, o capítulo de fundamentação teórica traz à discussão estudos que tratam dos impactos da GC no desempenho das empresas. Em seguida esse capítulo trata de abordagens sobre a associação entre preços de ações e taxas de câmbio, terminando com os estudos encontrados que tratam da volatilidade dos preços de ações e taxas cambiais e mercados financeiros internacionais. No terceiro capítulo é apresentada a metodologia utilizada na pesquisa bibliográfica. O quarto capítulo aborda os resultados encontrados. O quinto e último capítulo apresenta as conclusões alcançadas mediante o presente trabalho de pesquisa. O estudo segue na descrição dos testes e critérios de informação que serão utilizados. Um capítulo para apresentação dos modelos GARCH multivariados subdivididos entre os estruturais e aqueles baseados em GARCH univariados. Sendo o último capítulo dedicado a apresentar a análise dos dados e estatísticas descritivas bem como os testes estatísticos, modelos estimados e, finalmente, o modelo GARCH multivariado selecionado. 


\subsection{Conceitos Básicos}

Alguns conceitos utilizados neste trabalho serão apresentados nesta seção. Ao que se refere aos conceitos que se relacionam com séries temporais, podem ser observados em Morettin (2008).

\subsection{1 Índices da BM\&FBovespa}

Os índices desenvolvidos pela BM\&FBovespa e que serão utilizados nesta dissertação são resultados de carteiras teóricas de ativos, elaboradas de acordo com os critérios estabelecidos em suas metodologias. Os índices da BM\&FBovespa utilizam procedimentos e regras constantes do Manual de Definições e Procedimentos dos Índices da BM\&FBovespa. Não estão incluídos no universo de ativos elegíveis das carteiras teóricas os BDRs e ativos de companhias em recuperação judicial ou extrajudicial, regime especial de administração temporária, intervenção ou que sejam negociados em qualquer outra situação especial de listagem (definidas no Manual de Definições e Procedimentos dos Índices da BM\&FBovespa).

Os índices que serão utilizados: Ibovespa, IGC-NM e IGC-X são compostos das ações e units exclusivamente de ações de companhias listadas na BM\&FBovespa que atendem aos critérios de inclusão específicos para cada um dos índices.

Ressalta-se que a participação dos ativos de uma companhia nos índices (considerando todas as espécies e classes de ações ou units que tenham como lastro tais ações da companhia, conforme o caso) não poderá ser superior a $20 \%$ (vinte por cento), quando de sua inclusão ou nas reavaliações periódicas. Caso isso ocorra, serão efetuados ajustes para adequar o peso dos ativos da companhia a esse limite, redistribuindo-se o excedente proporcionalmente aos demais ativos da carteira.

\subsubsection{1 Índice Bovespa (Ibov)}

O objetivo do Ibovespa é ser o indicador do desempenho médio das cotações dos ativos de maior negociabilidade e representatividade do mercado de ações brasileiro. O Ibovespa é um índice de retorno total (É um indicador que procura refletir não apenas as variações nos preços dos ativos integrantes do índice no tempo, mas também o impacto que a distribuição de proventos por parte das companhias emissoras desses ativos teria no retorno do índice). Serão selecionados para compor o Ibovespa os ativos que atendam cumulativamente aos critérios abaixo:

- Estar entre os ativos elegíveis que, no período de vigência das 3 (três) carteiras anteriores, em ordem decrescente de Índice de Negociabilidade (IN), representem em conjunto $85 \%$ (oitenta e cinco por cento) do somatório total desses indicadores;

- Ter presença em pregão de 95\% (noventa e cinco por cento) no período de vigência das 3 (três) carteiras anteriores; 
- Ter participação em termos de volume financeiro maior ou igual a $0,1 \%$ (zero vírgula um por cento), no mercado a vista (lote-padrão), no período de vigência das 3 (três) carteiras anteriores;

- Não ser classificado como “Penny Stock” (ativos cuja cotação seja inferior a R $\$ 1,00$ ).

No Ibovespa, os ativos são ponderados pelo valor de mercado do "free float" (ativos que se encontram em circulação) da espécie pertencente à carteira, com limite de participação baseado na liquidez. A representatividade de um ativo no índice, quando das reavaliações periódicas, não poderá ser superior a duas vezes a participação que o ativo teria, caso a carteira fosse ponderada pela representatividade dos INs individuais no somatório de todos os INs dos ativos integrantes da carteira. Caso isso ocorra, serão efetuados ajustes para adequar o peso desse ativo a esse limite, redistribuindo-se o excedente proporcionalmente aos demais ativos integrantes da carteira.

\subsubsection{2 Índice Governança Corporativa - Novo Mercado (IGC-NM)}

O objetivo do IGC-NM é ser o indicador do desempenho médio das cotações dos ativos de emissão de empresas que apresentem bons níveis de governança corporativa, listadas no Novo Mercado da BM\&FBovespa. O IGC-NM é um índice de retorno total (É um indicador que procura refletir não apenas as variações nos preços dos ativos integrantes do índice no tempo, mas também o impacto que a distribuição de proventos por parte das companhias emissoras desses ativos teria no retorno do índice). Serão selecionados para compor o IGC-NM os ativos que atendam cumulativamente aos critérios abaixo:

Nas recomposições quadrimestrais:

- Ser listado no Novo Mercado da BM\&FBovespa;

- Ter presença em pregão de 50\% (cinquenta por cento) no período de vigência das 3 (três) carteiras anteriores ou em seu período de listagem, se inferior;

- Não ser classificado como “Penny Stock” (ativos cuja cotação seja inferior a R\$1,00).

Durante a vigência da carteira:

- Ser listado no Novo Mercado da BM\&FBovespa;

No IGC-NM, os ativos são ponderados pelo valor de mercado do "free float" (ativos que se encontram em circulação) da espécie pertencente à carteira. 


\subsubsection{3 Índice de Ações com Governança Corporativa Diferenciada (IGC-X)}

O IGC é o resultado de uma carteira teórica de ativos que tem como objetivo ser o indicador do desempenho médio das cotações dos ativos de empresas listadas no Novo Mercado ou nos Níveis 1 ou 2 da BM\&FBovespa. O IGC-X é um índice de retorno total que, conforme o Manual de Definições e Procedimentos dos Índices da BM\&FBovespa, procura refletir não apenas as variações nos preços dos ativos integrantes do índice no tempo, mas também o impacto que a distribuição de proventos por parte das companhias emissoras desses ativos teria no retorno do índice. Serão selecionados para compor o IGC-NM os ativos que atendam cumulativamente aos critérios abaixo:

Nas recomposições quadrimestrais:

- Ser listado no Novo Mercado ou nos Níveis 1 ou 2 da BM\&FBovespa;

- Ter presença em pregão de 50\% (cinquenta por cento) no período de vigência das 3 (três) carteiras anteriores ou em seu período de listagem, se inferior;

- Não ser classificado como "Penny Stock” (ativos cuja cotação seja inferior a R \$1,00).

Durante a vigência da carteira:

- Ser listado no Novo Mercado ou nos Níveis 1 ou 2 da BM\&FBovespa;

No IGC-X, os ativos são ponderados pelo valor de mercado do "free float" (ativos que se encontram em circulação) da espécie pertencente à carteira, multiplicados por um fator de governança. Esse fator será igual a 2 para os ativos do Novo Mercado, 1,5 para os ativos do Nível 2 e 1 para os ativos do Nível 1.

\subsubsection{Retornos e Volatilidade}

Considerando $P_{t}$ como sendo o preço de uma ativo no instante $t$. Assim, o retorno do ativo no instante $t$ é definido como sendo:

$$
r_{t}=\frac{P_{t}}{P_{t-1}}-1
$$

Uma característica comum em séries de retornos financeiros é a sua estacionaridade. $\mathrm{O}$ que torna, em geral, preferível analisar séries de retornos do que séries de preço de ativos.

Partindo de uma série de retornos $\left(r_{t}, t=1, \ldots, T\right)$ podemos escrever a distribuição conjunta dos retornos como o produto das distribuições de cada retorno condicionado aos retornos anteriores:

$$
p\left(r_{1}, \ldots, r_{T}\right)=p\left(r_{1}\right) p\left(r_{2} \mid I_{2}\right) p\left(r_{3} \mid I_{3}\right) \ldots p\left(r_{t} \mid I_{T}\right), \text { sendo } I_{t}=r_{t-1}, r_{t-2}, \ldots \text { a informação }
$$

anterior até o instante $t$. A variância dessas distribuições condicionais é convencionalmente chamada de volatilidade, que será objeto de estudo desta dissertação. 
Assumimos que a esperança de cada distribuição condicional é zero. Assim, a volatilidade será:

$\sigma_{t}^{2}=\operatorname{Var}\left(r_{t}, I_{t}\right)=E\left(r_{t}^{2}, I_{t}\right)$, sendo $I_{t}$ a informação prévia até $t$, ou seja, $I_{t}=$ $\left(r_{t_{1}}, r_{t_{2}}, \ldots, \sigma_{t-1}^{2}, \sigma_{t-2}^{2}, \ldots\right)$.

Assumimos, também, que a o risco de um ativo será analisado a partir de sua volatilidade. 



\section{Referencial Teórico}

\subsection{Aspectos da Governança Corporativa}

\subsubsection{Conflitos de Agência}

A Teoria de Agência envolve conceitos de Administração e Economia, com repercussões nos campos do Direito e Ciência Política. Em seu fundamental artigo sobre o tema Jensen e Meckling (1976) iniciam citando Adam Smith (A Riqueza das Nações, 1776), o que mostra como é antiga essa discussão. Segundo esses autores, a teoria da firma, como classicamente compreendida, foca a interação da empresa com o mercado. A firma é, dessa forma, uma "caixa preta". Diferentemente desse enfoque, os autores buscam entender a relação entre os diferentes atores dentro da firma.

O problema de agência aparece nas mais diversas situações. Uma agência, em termos gerais, é uma relação entre duas partes, onde uma é o principal e a outra é um agente, contratado pelo principal para a realização de alguma tarefa. Principais comumente delegam poder de decisão aos agentes. São exemplos de situações principal-agente: acionista/administrador, político/eleitor, vendedor/comprador, prestador de serviço/usuário. Nessa relação, os dois lados cooperam para alcançar um objetivo. No entanto, suas funções de utilidade são diferentes.

Os problemas que a teoria mira são: 1) os problemas que aparecem quando os desejos e objetivos do principal e do agente estão em conflito, e o principal é incapaz de verificar (porque é difícil e/ou caro) o que o agente está realmente fazendo. Envolve assimetria de informação (o agente conhece mais do negócio e de seus atos do que o principal) e moral hazard, já que pode haver falta de esforço por parte do agente; e 2) os problemas que aparecem quando o principal e o agente têm diferentes atitudes em relação ao risco: os agentes podem ser mais propensos a risco porque não arcarão com possíveis perdas (novamente moral hazard) ou, por outro lado, o agente, por não ter alternativa de emprego, pode ser mais avesso a risco do que o principal, que é capaz de diversificar seus investimentos.

Jensen e Meckling (1976) se detêm no estudo da relação de agência entre acionistas e executivos. O problema aparece mesmo quando o administrador é proprietário mas não detém o capital total da empresa. $\mathrm{O}$ administrador pode agir de acordo com parâmetros que não são os melhores do ponto de vista do proprietário. Esse agente está na posição de auferir, além dos ganhos pecuniários, ganhos não pecuniários (conforto na atividade) que podem não reverter integralmente para acionistas.

Os custos de agência são, então, a soma das despesas de incentivo ou monitoramento pelo principal, de garantias dadas pelos agentes e a perda residual. O principal pode limitar 
divergências de seus interesses estabelecendo incentivos apropriados para o agente e incorrendo em custos de monitoramento desenhados para limitar atividades aberrantes dos agentes. Além disso, em algumas situações o agente dispenderá recursos (bonding costs) para garantir que ele não tomará certas ações que feririam os interesses do principal ou para assegurar que o principal será compensado se ele incorrer em tais atos. Contudo, geralmente é impossível para o principal ou para o agente, a custo zero, assegurar que o agente tomará decisões ótimas do ponto de vista do principal (perda residual).

Dados os custos de agência, por que a economia moderna se organiza com essa separação? É a questão abordada por Fama (1980), onde explica como a separação entre propriedade e controle, típicas em grandes organizações, pode ser uma eficiente forma de organização econômica.

O problema da agência pode ser mitigado por contratos baseados em comportamentos ou em resultados. Em seu artigo Teoria de Agência: Verificação e Revisão, propõe que, quando o principal sabe exatamente o que o agente está fazendo, o contrato baseado em comportamento (pagamento de salários) é mais eficiente. Os contratos baseados em resultados são mais indicados quando há grande assimetria de informação e existência de moral hazard. Um bom exemplo de contrato por resultados é a distribuição de opções de compra de ações da empresa aos executivos, desde que essas ações atinjam determinado patamar. Ironicamente, o oportunismo dos agentes pode levá-los a tentar inflar artificialmente o preço dessas ações (JENSEN; MECKLING, 1976).

A Teoria de Agência, em contraponto à análise econômica tradicional, se mostra bastante profícua e tem despertado o interesse dos teóricos e o uso do seu instrumental de análise tem se disseminado. Ela tem o seu apelo mas não esgota a análise da organização (nem parece ter essa intenção) .

O papel da Governança Corporativa é, entre outras coisas, monitorar as relações existentes entre a administração e os acionistas (majoritários e minoritários) e tentar minimizar as discrepâncias existentes entre eles. Para Shleifer e Vishny (1997) a governança corporativa apresenta um conjunto de mecanismos pelos quais os investidores garantem que obterão o retorno de seus investimentos. De uma forma mais abrangente, Costa (2008) esclarece que a governança corporativa pode ser entendida como o conjunto de mecanismos de incentivo e controle, internos e externos, para minimização dos custos decorrentes do problema de agência dos gestores. Nesse contexto, a governança corporativa tem a função de prover aos acionistas e credores segurança, com o intuito de que estes não possam ser expropriados pelos agentes da mesma.

\subsubsection{A Governança Corporativa e seus Impactos no Desempenho das Empresas}

Governança Corporativa é o sistema pelo qual empresas são dirigidas e controladas e que especifica a distribuição de direitos e responsabilidades entre os diferentes participantes 
na empresa, tais como conselho, os gestores, acionistas e outras partes interessadas, que define regras e procedimentos para se tornarem decisões nos assuntos de empresa (OCDE, 1999).

De acordo com Roe (2005) os problemas centrais da Governança Corporativa podem ser divididos em três grupos distintos:

- Governança Corporativa Vertical - custos de agências gerenciais: envolve problemas relacionados 'aos conflitos de agência, ou seja, maximização do bem-estar de seus acionistas e/ou gestores;

- Governança Corporativa Horizontal - limitação da ação de acionista majoritário: o principal risco enfrentado pelos demais acionistas (minoritários) é a expropriação por parte doo acionista que detém o controle acionário da firma;

- Governança Corporativa Externa - legitimidade corporativa: trata da legitimidade da governança da firma para a sociedade e da possibilidade de incursões externas nas decisões da companhia. Roe (2005) apresenta duas abordagens possíveis para tal legitimidade: defensiva: agentes internos estruturam instituições para protegê-los de incursões externas; e, - legitimidade determinada por externos: políticas restringem a maneira como a firma pode ser governada, com o objetivo de permitir a implementacão de determinadas políticas públicas, como relações trabalhistas específicas.

Convém discorrer sobre as origens da governança corporativa e, por assim fazer, identificar os conceitos acadêmicos existentes sobre ela. Além das levantadas por Jensen e Meckling (1976) e Fama (1980), há razões fundamentais que levaram ao nascimento e fortalecimento da governança corporativa:

- as afinidades históricas entre a formação do sistema capitalista, a evolução do mundo corporativo e o desenvolvimento da ciência da administração;

- O agigantamento das corporações, a dispersão do controle acionário e a despersonalização da propriedade;

- A ascensão dos gestores não proprietários e da tecnoestrutura organizacional como novas figuras que se estabeleceram no topo do mundo corporativo, assumindo o seu controle efetivo e usufruindo de seu poder;

- Os interesses não perfeitamente simétricos entre proprietários passivos (distantes das corporações) e não proprietários usufrutuários (presentes e gestores dos resultados e de suas destinações); e

- Os conflitos de agência resultantes da assimetria de interesses entre proprietários e gestores e também entre acionistas majoritários e minoritários. 
De forma mais específica o Instituto Brasileiro de Governança Corporativa - IBGC (2015) define governança corporativa como "o sistema pelo qual as empresas e demais organizações são dirigidas, monitoradas e incentivadas, envolvendo os relacionamentos entre sócios, conselho de administração, diretoria, órgãos de fiscalização e controle e demais partes interessadas".

Muito embora na sua origem a governança tenha se concentrado em buscar solucionar os conflitos de agência entre acionistas e gestores e entre grupos majoritários e minoritários de controle das empresas, as relações entre sociedade e companhias têm ampliado o escopo da governança.

Conforme o IBGC, as boas práticas de governança corporativa convertem princípios básicos em recomendações objetivas, alinhando interesses com a finalidade de preservar e otimizar o valor econômico de longo prazo da organização, facilitando seu acesso a recursos e contribuindo para a qualidade da gestão da organização, sua longevidade e o bem comum. Baseados nessa ideia, estudos foram estimulados no sentido de observar se práticas de governança corporativa impactariam o desempenho de empresas.

A maioria da literatura sobre a relação entre governança corporativa e desempenho das empresas documenta que forte governança corporativa (GC) é associada com valorização da firma. Enquanto essa literatura lida com aspectos específicos da GC, parte dela agrega atributos individuais de GC para formar índices de GC. Poucos estudos investigam o impacto da valorização de práticas no nível da firma em um contexto internacional, algumas exceções usam dados compilados por Porta et al. (1998) em proteção de direitos de acionistas minoritários, medidas de CLSA (Credit Lyonnais Securities Asia), a qual a utilidade foi questionada por outros autores. Com a emergência de informações de GC no nível da firma mais detalhadas para grandes amostras de diversos países, uma nova linha de pesquisa surgiu. Percebeu-se, por meio dos estudos cross countries, que empresas com sede nos EUA e outros países apresentam diferenças em sua valorização dependendo do nível de GC, a valorização das empresas não americanas decrescem em relação a diminuição no seu índice de GC em comparação a suas empresas similares nos EUA. Portanto, a valorização da empresa é associada tanto em aspectos de proteção dos acionistas no país inserido quanto a atributos de governança corporativa, conforme ratificado por outros autores.

Klapper e Love (2004) exploraram as diferenças entre mecanismos de governança interna, seus relacionamentos com as medidas normativas do país inserido e a correlação entre governança e desempenho. Primeiramente, investigaram os determinantes da governança interna da empresa e observaram que existe variância na governança interna, embora o grau de variância não esteja relacionado ao sistema legal do país onde a empresa está inserida. Os autores encontraram que a governança interna reage positivamente às medidas do país de proteção ao investidor e que a governança média é maior em países com fortes sistemas normativos. Depois, encontraram evidências que suportaram a hipótese de que empresas crescentes, que possuem grande necessidade de financiamento, tem mais incentivos a adotar melhores práticas de GC para 
diminuir seu custo de capital.

Investigaram também a relação entre governança e desempenho e descobriram que melhor GC é associado com alto índice de desempenho operacional e alto índice de Q de Tobin. Após incluir os efeitos fixos para o país, encontraram que a correlação entre a medida de desempenho e a governança, torna-se duas vezes maior. Isso sugere que o aperfeiçoamento da governança relativamente a média das empresas presentes no país são mais importantes que o valor absoluto do índice.

Os principais resultados, portanto, são: (1) empresas em países com fraco sistema legal possuem em média menor índice de governança; (2) governança no nível da empresa está correlacionado com variáveis relacionadas com a extensão da assimetria de informações e imperfeições contratuais que a empresa enfrente; (3) empresas que tem ações negociadas nos EUA possuem maior nível de GC, especialmente as filiais alocadas em países com fraco sistema legal; (4) boa GC é positivamente correlacionada com valorização do mercado e desempenho operacional; e (5) essa relação é maior em países com sistema legal forte.

Existem evidências que amplas medidas de GC interna prediz alto valor do preço da ação em mercados emergentes (BLACK; LOVE; RACHINSKY, 2006).

Foi encontrado uma relação econômica e estatisticamente significativa entre governança e valor de mercado da firma para um índice de governança combinado e para os índices Brunswick, Troika, Standards e Poor's disclosure e ICLG. Eles encontraram diferenças no poder preditivo e nos componentes de diferentes índices. A força de índices em particular, como preditor do valor de mercado da empresa, tipicamente é fruto do subconjunto limitado de componentes incluídos no índice. Portanto, pode-se depreender disso que a forma como é medida a governança importa para os resultados.

Brown e Caylor (2006) estudaram a GC no nível interno da empresa, por isso eles se propuseram a investigar quais eram as medidas de governança interna que importavam para predizer o valor de mercado das empresas, baseado em uma amostra retirada de um novo provedor de dados de GC. Foi criado um índice de GC agregando as informações disponíveis na base Institutional Shareholder Services (ISS) para empresas americanas em $1^{\circ}$ de fevereiro de 2003 com 51 atributos e agrupados em 7 sub índices.

Eles identificaram sete medidas de governança que são chave para direcionar o link entre governança e desempenho da empresa: (1) membros do conselho são selecionados anualmente; (2) empresa não possui poison pill ou tem que ser aprovado pelos acionistas; (3) opção de recompra não aconteceu dentro dos últimos 3 anos; (4) opções médias oferecidas nos últimos 3 anos como percentual de ações ordinárias não excede 3\%; (5) todos os diretores atenderem a pelo menos $75 \%$ das reuniões do conselho ou possuírem uma desculpa válida para não atender; (6) diretrizes do conselho está presente em cada relatório; e (7) diretores são sujeitos a orientações de propriedade de ações. Conforme Brown e Caylor (2006), essas sete medidas agregadas são 
responsáveis por determinar totalmente a relação entre o Gov-Score e o valor de mercado da firma. Além disso, o Gov-Score apresenta um poder explanatório maior e melhor que não é possível observar pelos dados oferecidos somente pela base de dados Investor Responsibility Research Center (IRRC).

Brown e Caylor (2006) contribuem para a literatura do tema ao documentar que governança corporativa efetiva requer tanto medidas internas quanto externas. Em segundo lugar, identificaram cinco fatores de governança interna que são relacionados diretamente com o valor da firma, expandindo dramaticamente o conhecimento do número de fatores relacionados com medidas de governança de dentro da firma. Em terceiro lugar, usando uma base de dados, período de tempo e metodologia diferentes do que pesquisas anteriores, confirmaram os resultados anteriores de que conselhos de diretores intercalados e poison pill são positivamente relacionados com valor da firma. Também, revalidaram estudos anteriores que afirmam que uma pequena parte de fatores de governança são relevantes para predizer o valor da firma.

Apesar de existir extensa literatura investigando a relação entre GC e o valor da firma, ainda não existe consenso em como medir a GC. Literatura prévia, quase exclusivamente, usa índices aditivos dando pesos iguais para cada atributo de governança corporativa. Em adição em usar duas abordagens para construção do índice de governança, Ammann, Oesch e Schmid (2011) confiam na análise de componentes principais para condensar as informações de um grande número de variáveis em um pequeno e rastreável número de índices de governança.

Os autores encontraram forte e positiva correlação entre GC no nível da firma e valorização da empresa, também entre o comportamento social e o valor da firma. Esses resultados são robustos com as diferentes técnicas usadas para construir os índices de GC, a separação da amostra por anos e países, e o estimador de métodos de momentos generalizados em um painel dinâmico. Os resultados indicaram que melhores práticas de GC refletem maiores valores de mercado, com relações estatisticamente e economicamente significantes. Então, pelo menos para uma empresa média, na amostra deles, os custos de implementação de mecanismos de GC parece ser pequeno em relação aos benefícios, resultando em maiores fluxos de caixa para investidores e menor custo de capital das empresas. Consequentemente, na perspectiva da empresa, GC pode ser entendida como uma oportunidade ao invés de uma obrigação.

Ammann, Oesch e Schmid (2011) fornecem novas evidências no relacionamento entre governança corporativa no nível da empresa e a avaliação da empresa em um contexto internacional. Eles contribuem para a literatura utilizando uma nova e inexplorada base de dados da Governance Metrics International (GMI). De acordo com eles, usar uma nova base de dados é importante, pois a qualidade dos dados ofertados sobre GC foi questionada por outros autores. Assim, avaliar se os resultados anteriores se repetem em um nova base trata-se de uma forma de validação das descobertas.

Black, Carvalho e Gorga (2012) discutiram sobre duas questões principais. A primeira 
questão é: quais regras de GC provavelmente serão benéficas para mercados emergentes? Uma pode ser compilar uma lista de itens que refletem plausivelmente boa GC e testar, combinada em um índice, se eles preveem valor de mercado. Outro pode ser testar se alguns aspectos gerais de GC preveem valor de mercado médio de diversas firmas em diversos países. Essas abordagens são úteis, porém possuem limitações importantes. Principalmente, eles pouco indicam quais práticas adotadas nas empresas e em quais países. Outro problema relacionado é a correlação interna entre os aspectos de GC, assim se um mede o poder preditivo geral de uma lista de medidas de GC, ele pode não saber quais elementos direcionam o poder geral. Em resumo, para identificar o que importa em governança corporativa, em qual país, precisa de um amplo índice que é adaptado às nuances do país e possui aspectos comuns suficientes que permitam uma generalização.

A segunda questão é: qual aspecto de GC importa para as firmas? Geralmente não estudada, a segunda questão envolve quais firmas se beneficiam de quais aspectos de GC. Numerosas hipóteses foram sugeridas em trabalhos anteriores. Tamanho da firma, empresas grandes podem precisar de GC melhor (mais formal) para responder as suas operações mais complexas, enquanto que firmas menores, com menor concentração institucional, podem voar abaixo do radar. Lucratividade, empresas altamente lucrativas podem precisar de menos governança externa ou podem ter menor necessidade de financiamento externo e portanto menor motivação para aperfeiçoar governança com o objetivo de atrair investidores. Crescimento, empresas com alta taxa de crescimento precisam de capital externo para sustentar seu crescimento e assim podem escolher ter melhor governança para atrair investidores. Essa discussão, portanto, sugere que para determinar quais aspectos de governança são importantes para cada empresa, é necessário ter uma ampla amostra de empresas em cada país.

Primeiramente foi demonstrado uma importante relação econômica entre um amplo índice brasileiro de GC (BCGI) e o valor de mercado defasado. Uma mudança do pior para o melhor no índice prediz quase o dobro no Q de Tobin, de 1,16 para 2,13. Depois eles avaliaram quais aspectos da GC explica essa associação em geral, por meio da regressão do Q de Tobin contra cada um dos 6 subíndices, controlando para o restante do índice. O resultado indica que o índice geral é direcionado quase todo da propriedade, procedimento do conselho e direito dos acionistas minoritários. Um subíndice de divulgação é significante por si mesmo, mas perde significância quando ocorre o controle para o resto do BCGI, confirmando o seu real valor.

A estrutura do conselho, especialmente independência do conselho, é amplamente dado como um aspecto central de GC. Em contraste ao principal trabalho de independência do conselho em cross-country, os autores encontraram uma relação negativa entre a independência do conselho e valor de mercado da empresa. Assim, os resultados revelaram o prejuízo em generalizar diretamente o que importa em GC.

Os autores investigaram para que tipo de firmas o índice geral e os sub índices preveem maior valor de mercado. São estudadas as 4 características amplas da empresa: tamanho, lu- 
cratividade, taxa de crescimento e manufatura versus não manufatura. Nessa linha, os autores encontraram forte relação entre o BCGI e o valor de mercado de empresas não manufatureiras, pequenas empresas e com alta taxa de crescimento.

Por fim, os autores compararam os resultados encontrados no Brasil com a Rússia, Índia e Coreia. Os índices de governança utilizados em cada país são similares, mas refletem as particularidades de cada um. Os autores encontraram similaridades e diferenças entre os países. Em todos os países, governança prediz alto valor de mercado em pequenas empresas e de alta lucratividade. A menor lacuna entre direito de voto e direitos sobre o fluxo de caixa prediz alto valor de mercado no Brasil e Coreia, os dois países que possuem essa medida. No todo, os resultados encontrados fornecem alguns temas comuns, mas também destaca o quanto ainda não se sabe sobre GC em mercados emergentes.

Por meio da coleta de dados de sites de instituições de créditos romenos, Dedu e Chitan (2013) investigaram a influência da GC interna ao banco no desempenho do setor bancário, incluindo as características do corpo de gerenciamento, estrutura de propriedade e um índice interno de GC. O índice de GC interno influenciou negativamente o desempenho do banco, medido pelo ROA, ROE e Z-Score, determinando a necessidade de aumentar o número de membros independentes dentro do corpo de gerenciamento e a necessidade de mudar o comportamento de negócio dos acionistas com o objetivo de reduzir a exposição aos riscos. Em relação às características dos membros do conselho de administração, os resultados suportam a ideia de crescimento do número de membros de outras nacionalidades e aqueles independentes, que devem ter o direito de tomarem decisões independentes e objetivas.

Fuenzalida et al. (2013) estudaram a relação entre a adoção de boas práticas de GC e a geração de retornos positivos na bolsa de valores de Lima. Primeiramente, os autores queriam saber se o anúncio de que uma empresa possui um bom índice de GC aumenta o preço da ação e oferece um retorno anormal positivo. Em segundo lugar, do ponto de vista do investimento socialmente responsável um investimento em um portfólio de empresas peruanas com boas práticas de GC oferece melhor desempenho em empresas com GC ruim.

Esse estudo analisou o comportamento do preço da ação das oito firmas que compõem o índice de GC perto do anúncio da sua inclusão no índice pela bolsa de valores de Lima. Para responder a segunda pergunta de pesquisa o estudo agrupou todas as firmas listadas na bolsa em dois grupos: o primeiro mostrou um alto nível de adequação aos princípios de GC (portfólio democrático) e o segundo grupo é composto pelas firmas com menor nível de adequação aos princípios de GC. O estudo examinou o desempenho das empresas no período de 2004 a 2008. Os resultados demonstraram que o anúncio da inclusão de uma firma no índice de GC produz um retorno anormal que vai de $0,95 \%$ a $1,11 \%$ no dia do anúncio. Além disso, empresas com boas práticas de GC que estão em um portfólio democrático tem um desempenho superior àquelas com práticas ruins em um portfólio autocrático que possui um retorno mensal médio de $3 \%$ durante o período de janeiro de 2004 a dezembro de 2008. 
Garay et al. (2013) examinaram a relação entre índice de divulgação baseado na internet e o valor da firma nas sete maiores bolsas de valores da América Latina. Para a amostra de empresas listadas nas bolsas de valores, os autores construíram um índice de divulgação das informações baseado nas informações disponíveis na internet para investidores. Os anos escolhidos para a análise foram 2006, 2008 e 2010. Depois avaliaram se o Q de Tobin da empresa é relacionado com o índice produzido no contexto de um ajuste transversal entre países.

Os autores encontraram, em geral, uma relação positiva e forte entre o índice e o Q de Tobin para empresas na América Latina, mais especificamente o aumento de $1 \%$ na nota do índice gera o aumento de $0,159 \%$ no Q de Tobin e de $0,011 \%$ no ROA das empresas analisadas. Esses resultados são robustos depois de considerar o potencial de endogeneidade entre as variáveis da regressão. Em resumo, mesmo em um ambiente com fraca proteção ao investidor como na América Latina, empresas podem melhorar seu valor de mercado pela adoção própria de práticas de divulgação. As evidências contribuíram para a literatura sugerindo que empresas podem se diferenciar entre si adotando a internet como meio de divulgação corporativa e financeira.

Munisi e Randoy (2013) investigaram em que medida as práticas de GC advogadas por empresas em países desenvolvidos são aplicadas a empresas em países em desenvolvimento. Foram investigadas as empresas listadas nos países sub sarianos da África, em particular foi examinada a relação entre práticas de GC com o desempenho da empresa. São utilizados dados coletados manualmente dos relatórios anuais das empresas. Foi utilizado o método generalizado dos momentos dinâmicos para examinar a associação entre a GC e o desempenho. Eles mediram o desempenho por meio dos indicadores ROA e Q de Tobin.

Empresas na região sub sariana da África implementaram parcialmente as boas práticas de governança corporativa. Foi encontrada uma associação positiva entre o índice construído e o desempenho contábil das empresas, porém negativo entre o índice e a valoração do mercado. Indo além, os autores examinaram a associação entre os sub índices de GC e o desempenho contábil e de mercado. Dos cinco sub índices, o conselho de administração e o comitê de auditoria possuem relação positiva com o desempenho contábil. Em relação ao desempenho do mercado, o sub índice de comitê de auditoria possui relação negativa e forte. Isso sugere que algumas características do índice de GC são mais importantes em explicar a associação entre GC e o desempenho das empresas na região sub sariana da África. Os resultados do estudo possuem implicações para a implementação de práticas de GC na região estudada. Assumindo uma imutabilidade das condições de mercado de capitais e condições legais, os resultados indicam que as empresas com adequação maior as práticas de GC podem esperar atingir maior desempenho contábil.

Rani, Yadav e Jain (2013) investigaram se as diferenças na qualidade das práticas GC de empresas influenciam o desempenho de curto prazo para uma amostra de companhias, por meio da criação de índice de GC. O estudo é baseado em uma survey de 155 companhias tendo completado uma aquisição ou uma fusão anunciadas durante 2003 a 2008. Os autores 
utilizaram uma ampla medida de GC, que foi baseada em respostas objetivas de uma pesquisa, suplementada com entrevistas a gerentes sênior, diretores, diretores financeiros, membros dos conselhos, secretários da empresa, representantes de compliance e representantes da relação com investidores. O questionário foi baseado nos maiores padrões de qualidades relevantes para medir a GC. Os resultados apresentam uma relação positiva entre o índice de GC e os retornos anormais de curto prazo, por meio da construção de um amplo índice de GC para empresas indianas listadas na bolsa.

Kim et al. (2013) analisaram os efeitos da adequação de governança no desempenho corporativo das indústrias da Coreia. Baseado na visão do stakeholder, os autores argumentaram que o objetivo da firma deveria ser a maximização do valor do stakeholder ao invés da maximização da riqueza do acionista. Os autores encontraram um relação significativa entre adequação da governança e o desempenho corporativo da empresa. Além disso, os sub índices: riqueza dos acionistas, conselho de diretores, divulgação, comitê de auditoria e política de dividendos também são significativamente relacionados ao desempenho.

Black, Carvalho e Sampaio (2014) analisaram a evolução da GC no Brasil no período de 2004 a 2009 e associação entre governança e valor da firma. Os dados foram coletados por três extensas survey conduzidas em práticas de governança, nos anos de 2004, 2006 e 2009. As informações de governança foram então agregadas em seis índices cobrindo os principais aspectos de GC: estrutura do conselho, propriedade, procedimentos dos conselhos, negociações relacionadas com propriedade, direito dos acionistas e divulgação.

Os autores identificaram que as práticas de GC no Brasil se aperfeiçoaram significativamente nesse período. Essa evolução se deve a dois aspectos: crescimento da listagem Novo Mercado e Nível 2, principalmente pela abertura de capital de novas empresas; e melhoria de práticas de empresas não listadas nesses níveis, principalmente por meio da adaptação de elementos de governança requeridos pelo Novo Mercado (NM) e Nível 2 (L2). Adoção de elementos do índice de governança necessários para a listagem NM e L2 predizem um maior valor de mercado. Em contraste, a adoção das demais práticas do índice criados não predizem um valor maior. Assim, mudanças de governança parece responder as preferências dos investidores. Porém, os resultados possuem limitações. Primeiramente qualquer medida de governança corporativa, incluindo a dos autores, é um construto: eles começam com opiniões, muitas vezes baseadas em julgamentos com evidências limitadas, sobre o que é considerada boa governança corporativa. Em segundo lugar, empresas que respondem a pesquisa representam uma grande fração da capitalização da bolsa de valores, porém uma pequena fração das empresas pequenas.

Catapan e Colauto (2014) examinaram se existe relação entre a governança corporativa e o desempenho econômico-financeiro em empresas brasileiras listadas na BM\&FBovespa, considerando os anos de 2010-2012. Para tanto, os dados foram recolhidos junto ao DIVEXT, sistema de divulgação de informações da Comissão de Valores Mobiliários (CVM), e o software Empresas Net, também da CVM. Foi utilizada a regressão com dados em painéis para analisar as 
relações. O resultado obtido evidenciou uma relação direta percebida entre valor de mercado das empresas e nível de divulgação. Este resultado ilustrou que quanto maior a evidenciação de informações, maior o valor de mercado das empresas. Além da relação significativa entre o valor de mercado e das empresas, observou-se relação entre Índice de Governança Corporativa e duas variáveis: Q de Tobin e Retorno sobre o ativo.

\subsection{Spillover de Preços e de Volatilidades}

\subsubsection{Preços de Ações e Taxas de Câmbio}

A literatura existente relativa à associação entre os preços das ações e taxas de câmbio mostra perspectiva diversa. Há uma linha tradicional de pesquisa que defende que as taxas de câmbio exercem influência nos preços das ações. Por outro lado, mudanças no preço das ações podem influenciar o movimento nas taxas cambiais por meio de ajustes (entradas e saídas de capital estrangeiro). Uma diminuição nos preços das ações induziria uma redução na riqueza do investidor doméstico, levando a uma queda na demanda por dinheiro e reduziria as taxas de juros, fazendo com que as saídas de capital resultassem na desvalorização da moeda.

Vários modelos teóricos têm sugerido que a taxa de câmbio entre duas moedas é afetada por mudanças de preços de ações nos respectivos países. De acordo com a abordagem do ativo para determinação da taxa de câmbio (BRANSON, 1983) e (MEESE; ROGOFF, 1983). Taxas de câmbio se ajustam para igualar oferta e demanda de ativos financeiros, como ações e títulos.

Uma das primeiras tentativas de analisar a taxa de câmbio e a dinâmica de preço das ações foi de Franck e Young (1972), e encontraram nenhuma relação entre estas duas variáveis financeiras.

Dornbusch (1975) e Boyer (1977) apresentaram modelos que sugerem que as mudanças nos preços das ações e taxas de câmbio estão relacionados com fluxo de capitais. Diminuições nos preços das ações reduzem a riqueza nacional, diminuindo a demanda por moeda e taxas de juros, induzindo a saída de capitais e desvalorizando a moeda.

Smith (1992) utilizou um modelo Balance Portfolio para examinar os determinantes das trocas de taxas. O modelo considerou os valores de ações, os estoques de títulos e dinheiro, importante determinante da taxa de câmbio. Os resultados mostraram que os valores de capital tem uma influência significativa nas taxas de câmbio, mas o estoque de moeda e de títulos tem pouco impacto sobre taxas de câmbio. Estes resultados implicam não só que as ações são um importante fator adicional para incluir nos modelos de equilíbrio do portfólio da taxa de câmbio, mas também sugerem que o impacto das ações é mais importante do que o impacto de títulos do governo e dinheiro. Seguindo nas conclusões de relação positiva entre as variáveis, Solnik (1987) examinou o impacto de diversas variáveis (taxas de câmbio, taxas de juros e mudanças na expectativa inflacionária) sobre os preços das ações. Ele usou dados mensais de nove mercados 
ocidentais (Estados Unidos, Japão, Alemanha, Reino Unido, França, Canadá, Holanda, Suíça e Bélgica). Encontrou depreciação para ter uma influência positiva, mas insignificante no mercado de ações dos EUA em relação à mudança na expectativa de inflação e taxas de juros.

Desde o início dos anos noventa pesquisadores começaram a usar ferramentas econométricas sofisticadas para descobrir a relação entre as variáveis e apresentaram resultados variados. Bahmani-Oskooee e Sohrabian (1992) utilizaram valores mensais de S\&P 500 e taxa de câmbio efetiva do dólar dos EUA para o período de 1973-1988 e utilizaram co-integração e teste de causalidade de Granger para detectar a relação entre as variáveis. Eles descobriram causalidade bidirecional no curto prazo. Eles não encontraram nenhuma relação de longo prazo entre as variáveis. Nieh e Lee (2002) apoiaram as conclusões de Bahmani-Oskooee e Sohrabian (1992) e não encontraram nenhum relacionamento significativo entre os preços das ações de longo prazo e taxas de câmbio nos países do G-7.

Abdalla e Murinde (1997) utilizaram o teste de co-integração para examinar a relação entre os preços das ações e taxas de câmbio por quatro países asiáticos, Índia, Paquistão, Coreia do Sul e Filipinas, por um período de 1985 a 1994. No estudo não foi encontrada relação de longo prazo para o Paquistão e Coreia, mas fez encontrar uma relação de longo prazo para a Índia e Filipinas. Eles também analisaram a questão da causalidade entre os preços das ações e taxas de câmbio. Usando testes de causalidade de Granger encontraram uma causalidade unidirecional de taxas de câmbio para os preços das ações, para Paquistão e Coreia. Uma vez que uma associação de longo prazo foi encontrada para a Índia e Filipinas que utiliza uma abordagem de modelagem de correção de erros para examinar a causalidade para estes países. Os resultados mostram uma causalidade unidirecional de taxa de câmbio para os preços das ações para a Índia, mas para Filipinas a causalidade inversa de preços das ações a taxas de câmbio foi encontrada.

Ajayi, Friedman e Mehdian (1999) utilizaram dados diários e relataram que a causalidade vai do mercado de ações para o mercado de moeda na Indonésia e nas Filipinas, enquanto na Coreia corre na direção oposta. Nenhuma relação causal significativa é observada em Hong Kong, Singapura, Tailândia, ou Malásia. No entanto, em Taiwan, eles detectaram causalidade bi-direcional. Além disso, os ajustes contemporâneos são significativos em apenas três desses países. Nos países desenvolvidos, eles encontraram causalidade unidirecional dos preços das ações nos mercados cambiais.

Em um estudo abrangente Huang, Yang e Hu (2000) estudaram países do Leste Asiático. Eles concluíram que mudança nos preços das ações Filipinas levam a mudanças nas taxas de câmbio. Encontraram uma relação oposta, no caso da Coreia do Sul.

Em outro estudo, Muhammad, Rasheed e Husain (2002) examinaram a relação entre os preços das ações e taxas de câmbio de quatro países do sul da Ásia nomeados como Bangladesh, Índia, Paquistão e Sri-lanka e constataram que há relação não significante entre as variáveis no curto prazo ou no longo prazo, no Paquistão e na Índia. Mas eles encontraram uma relação 
bidirecional em caso de Bangladesh e Sri-lanka.

Mookerjee e Yu (1997) empregaram índices diários de preços de ações e de câmbios à vista obtido dos mercados financeiros de Hong Kong, Tóquio, Cingapura e durante o período de 3 de janeiro de 1983 a 15 de Junho de 1994 para examinar a possível interação entre estas variáveis financeiras. Os seus resultados, com base no teste de causalidade de Granger, mostram que as alterações nos preços são causadas por mudanças nas taxas de câmbio em Tóquio e Hong Kong mercados. No entanto, nenhuma causa foi encontrada para o mercado de Cingapura, ou seja, não foi identificada causalidade reversa de preços das ações a taxas de câmbio, os resultados mostram como a causalidade apenas para o mercado de Tóquio. Portanto, para o mercado de Tóquio há uma causalidade bi-direcional na relação entre retornos e mudanças nas taxas de câmbio. Eles também usaram o modelo de vetor auto-regressivo para analisar uma relação estável de longo prazo entre os preços das ações e taxas de câmbio nos mercados financeiros asiáticos. Seus resultados encontraram uma forte relação de longo prazo estável entre os preços das ações e taxas de câmbio sobre os níveis para os três mercados.

Granger, Huang e Yang (1998) examinaram a questão da causalidade por meio de testes de causalidade de Granger e função de impulso resposta para nove países asiáticos. Eles usaram dados diários para o período de 03 de janeiro de 1986 a 14 de novembro de 1997 . Os países incluídos no estudo são: Hong Kong, Indonésia, Japão, Coreia do Sul, Malásia, Filipinas, Cingapura, Tailândia e Taiwan. Para o Japão e Tailândia eles constataram que taxas de câmbio leva aos preços das ações com correlação positiva. Os dados a partir de Taiwan sugerem que os preços das ações levam a taxas de câmbio com correlação negativa. Nenhuma relação foi encontrada para Cingapura e causalidade bi-direcional foi descoberta para o restante dos países.

Amare e Mohsin (2000) examinaram a associação de longo prazo entre os preços das ações e taxas de câmbio para nove países asiáticos (Japão, Hong Kong, Taiwan, Singapura, Tailândia, Malásia, Coreia, Indonésia e Filipinas). Eles usaram dados mensais de Janeiro de 1980 a junho de 1998 e empregaram a técnica de co-integração. A longo prazo a relação entre os preços das ações e taxas de câmbio foi encontrada somente para Cingapura e Filipinas. Eles atribuíram a falta de integração entre as referidas variáveis para o viés da "omissão de variáveis importantes". Quando a variável taxa de juros foi incluída em sua equação, encontraram cointegração entre os preços das ações, taxas de câmbio e taxa de juros para seis dos nove países.

Tabak (2006) estudou a dinâmica da relação entre preços de ações e variações cambiais na economia brasileira. Ao utilizar o teste de causalidade de Engle-Granger, linear e não linear, e VAR o estudo identificou relação entre a variação nos preços das ações e mudanças na taxa de câmbio. Contudo, utilizando testes de cointegração, inclusive com quebras estruturais, não foi encontrada uma relação de longo prazo entre taxas de câmbio e preços das ações.

Grande parte da evidência empírica disponível tratando os mercados de ações e de câmbio tem se concentrado nos primeiros momentos. Yang e Doong (2004) observaram que há uma 
escassez de evidência empírica que se concentra em ligações entre os segundos momentos da distribuição das variáveis. Uma série de estudos têm examinado, no entanto, a medida em que a volatilidade de um mercado de ações se espalha para outros mercados de ações, ou entre diferentes ativos. Phylaktis e Ravazzolo (2005) mostraram, a partir da aplicação da metodologia de cointegração e teste multivariado de causalidade de Granger a um grupo de países da Bacia do Pacífico, que os mercados de ações e de câmbio estão positivamente relacionadas.

\subsubsection{Spillover entre Volatilidade dos Preços de Ações e das Taxas de Câm- bio}

Kanas (2000) foi um dos primeiros estudos que analisaram spillovers de volatilidade do retorno das ações à variação cambial nos EUA, Reino Unido, Japão, Alemanha, França e Canadá. Ele encontrou evidências de spillovers de retornos de ações à variação cambial para todos os países, exceto na Alemanha, o que sugere que a abordagem de ativos para a determinação da taxa de câmbio é válida quando formulada em termos do segundo momento da distribuição da taxa de câmbio para os países incluídos em sua análise. Spillovers Volatilidade de variações cambiais para os retornos das ações foram insignificantes para todos os países.

Yang e Doong (2004) exploraram a natureza do mecanismo de transmissão de média e volatilidade entre os mercados de ações e de divisas para os países do G-7. Eles expandiram a amostra Kanas ao G-7, incluindo a Itália. Os resultados apontaram para spillovers volatilidade significativa e um efeito assimétrico do mercado de ações para o mercado de câmbio para a França, Itália, Japão e os EUA, o que sugere a integração entre os mercados de ações e de câmbio nesses países. Sua evidência empírica mostrou que os movimentos de preços de ações terão um impacto sobre os movimentos futuros da taxa de câmbio, mas as mudanças nas taxas de câmbio têm menos efeito direto sobre futuros retornos de ações, que é similar aos achados de Kanas.

Em um estudo semelhante feito por Fedorova e Saleem (2009), entre quatro países do leste da Europa, incluíram em seu estudo, Polônia, Hungria e Rússia e mostraram evidências de efeitos colaterais unidirecionais de volatilidade de mercado de moeda para o mercado de ações na economia, e só a República Checa que mostraram os efeitos da volatilidade spillover bidirecionais entre os mercados.

Goldberg (1993) encontrou evidências para os EUA, de que mudanças na volatilidade da taxa de câmbio tem efeitos significativamente negativos a longo prazo sobre o investimento. Darby et al. (1999), usando uma estimativa com uma única equação em seu estudo, encontrou um efeito cambial negativo semelhante sobre o investimento agregado com base nos dados de cinco países da OCDE. Carruth, Dickerson e Henley (2000), adotando uma estrutura GARCH, encontrou um impacto altamente negativo significativo da incerteza da taxa de câmbio real sobre o investimento.

Amihud (1994) e Bartov e Bodnar (1994) constataram que as mudanças contemporâneas 
do dólar têm pouco poder para explicar retornos anormais. Eles também encontraram que uma mudança defasada do dólar está negativamente associada com retornos anormais. Os resultados da regressão mostraram que uma mudança defasada do dólar tem poder explicativo no que diz respeito a erros nas previsões de analistas de lucro trimestral.

Ajayi e Mougouè (1996) encontraram evidências de que variação cambial exerce uma influência significativa e dinâmica em retornos para oito países industrializados. Eles mostraram que um aumento no valor agregado doméstico das ações tem um efeito negativo de curto prazo no valor da moeda nacional, mas nos aumentos de longo prazo nos preços das ações têm um efeito positivo no valor da moeda doméstica. No entanto, a depreciação da moeda tem um efeito negativo de curto prazo no mercado de ações.

Zapatero (1995) mostra que, nos mercados financeiros totalmente integrados, há uma ligação explícita entre a volatilidade dos preços das ações e a volatilidade da taxa de câmbio. Jorion (1990) e Booth e Rotenberg (1990) não conseguiram encontrar uma ligação significativa entre a variação cambial e os retornos das ações de empresas dos EUA, e os EUA e empresas canadenses, respectivamente. Em um outro estudo semelhante Muradoglu, Taskin e Bigan (2000) tentaram descobrir a relação entre retornos e algumas variáveis macroeconômicas e concluíram que existe uma relação causal da forma de taxas de câmbio para o retorno das ações na Nigéria, México, Coreia, Grécia, Colômbia e Brasil.

Chen, Naylor e Lu (2004) apontaram que em um grande mercado com empresas bem diversificadas, fatores domésticos podem ser mais importantes do que os fatores internacionais. Em contrapartida, o mercado da Nova Zelândia é muito pequeno em relação ao mercado norteamericano e as empresas na Nova Zelândia são muito menos diversificadas. Usando um modelo de dois fatores, Chen, Naylor e Lu (2004) acharam que os retornos de empresas da Nova Zelândia (o primeiro momento) são significativamente explicados pela variação cambial. No entanto, não analisaram a volatilidade (segundo momento) spillover entre os retornos do mercado de ações e mudanças nas taxas de câmbio na economia da Nova Zelândia.

Black (1976) e Christie (1982) perceberam que uma queda do preço das ações é seguido por um aumento na volatilidade das ações subsequente. Esta observação é denominada como o efeito de alavanca, que é testado no modelo GJR-GARCH desenvolvido por (GLOSTEN; JAGANNATHAN; RUNKLE, 1993).

Um estudo de Alaganar e Bhar (2007) indica que os efeitos de primeira e de segunda ordem da taxa de câmbio têm um impacto significativo em carteiras diversificadas no mercado acionário norte-americano. Empregaram os modelos GJR-GARCH e GARCH-M para testar o impacto da volatilidade da taxa de câmbio sobre os retornos de carteiras de índices de país diversificados. Eles apontaram que a variância da taxa de câmbio é importante para diversificações no mercado de ações.

Morales (2008) estudou os spillovers Volatilidade entre retornos e de câmbio: evidências 
de quatro países do Leste Europeu. Para os efeitos de transbordamento assimétricos eles descobriram que este efeito é relevante para todos os países, a partir dos retornos das ações para as taxas de câmbio, tendo todos os coeficientes com sinais positivos, que é interpretada da seguinte forma: uma boa notícia tem um impacto maior na volatilidade do que inesperada má notícia.

Diamandis e Drakos (2011) examinaram a dinâmica de longo prazo e de curto prazo entre os mercados de ações e câmbio de quatro países latino-americanos (Argentina, Brasil, Chile e México), bem como suas interações com os mercados de ações dos EUA. Esses autores encontraram que os dois mercados nessas economias estão positivamente relacionados e o mercado de ações dos Estados Unidos representa um canal de transmissão para esses efeitos.

Chkili e Nguyen (2014) usaram uma abordagem de modelo de mudança de regime para investigar as relações dinâmicas entre as taxas de câmbio e os retornos do mercado de ações para os países BRICS (Brasil, Rússia, Índia, China e África do Sul). A análise univariada indica que os retornos das ações dos países do BRICS evoluem de acordo com dois regimes diferentes: um regime de baixa volatilidade e um regime de alta volatilidade. Por outro lado, os modelos VAR com mudança de regime markoviano sugerem que os mercados de ações têm mais influência nas taxas de câmbio durante os dois períodos calmos e turbulentos. Estas percepções empíricas têm implicações importantes para os investimentos em carteira e cobertura de risco cambial.

\subsubsection{Volatilidade entre Índices do Mercado Financeiro}

A interdependência de curto prazo dos preços e da volatilidade dos preços através de três principais mercados de ações internacionais foram estudadas por Hamao, Masulis e Ng (1990). Cotações diárias de abertura e fechamento dos principais índices de ações para os mercados de ações de Tóquio, Londres e Nova Iorque foram examinadas. A análise utiliza a família auto-regressivo condicionalmente heterocedásticos $(\mathrm{ARCH})$ para explorar essas relações de preços. Evidência de spillovers de volatilidade dos preços de Nova Iorque para Tóquio, Londres a Tóquio e Nova York a Londres foram observadas, mas sem efeitos colaterais as volatilidades dos preços em outras direções foram encontradas para o período de pré-outubro de 1987.

O resultado da pesquisa de Theodossiou e Lee (1993) resultou em artigo que trouxe esclarecimentos adicionais sobre a natureza e o grau de interdependência dos mercados de ações dos Estados Unidos, Japão, Reino Unido, Canadá e Alemanha, e relatou o grau em que a volatilidade nesses mercados influenciam retornos esperados. A análise utilizou o modelo GARCH-M multivariado. Apesar de serem considerados fracos, spillovers estatisticamente significativos irradiaram de mercados de ações dos EUA para o Reino Unido, Canadá e Alemanha, e depois dos mercados de ações do Japão para a Alemanha. Nenhuma relação foi encontrada entre a volatilidade do mercado condicional e retornos esperados. Forte volatilidade condicional, variável no tempo, foi encontrada na série de retorno de todos os mercados. Os spillovers de volatilidade nos próprios mercados do Reino Unido e do Canadá são insignificantes, suportando 
a ideia de que a volatilidade condicional dos retornos nesses mercados é "importado"do exterior, especialmente dos Estados Unidos onde spillovers de volatilidade irradiaram significativamente do mercado de ações dos EUA para os quatro mercados de ações, do mercado de ações do Reino Unido para o mercado de ações canadense, e do mercado de ações alemão para o mercado de ações japonês. Os resultados encontrados foram robustos e não ocorreram alterações na estrutura de correlação dos retornos ao longo do tempo.

O artigo de Susmel e Engle (1994) examinou os spillovers de volatilidade entre Nova Iorque e os mercados de ações de Londres. Usando um modelo ARCH verificaram que a evidência de spillovers de volatilidade entre estes mercados é mínima e têm uma duração de uma hora, ou menos. Os efeitos mais significativos envolvem o movimento dos preços das ações em torno da abertura de Nova Iorque, mas esses resultados não são fortes.

O artigo de Wei et al. (1995) testou a sabedoria convencional de que a volatilidade de preços e mudanças a curto prazo transbordam dos países desenvolvidos para os mercados emergentes, mas não vice e versa. Os autores também investigaram como o grau de abertura do mercado afeta os retornos e transbordamentos de volatilidade. Três mercados desenvolvidos, Nova Iorque, Tóquio e Londres, e dois mercados emergentes, Taiwan e Hong Kong, foram examinados. Dois achados mais interessantes foram: em primeiro lugar, o mercado de Tóquio tem menos influência do que o mercado de Nova Iorque sobre os mercados de Taiwan e Hong Kong; e segundo, o mercado de Taiwan é mais sensível do que o mercado de Hong Kong para o comportamento dos preços e volatilidade dos mercados avançados, apesar de Taiwan não ser tão aberto como Hong Kong e o dólar de Taiwan não estar ligado ao dólar americano, enquanto o dólar de Hong Kong está.

Veiga e McAleer (2003) testaram a existência de spillovers de preços e de volatilidade entre os três principais índices do mercado de ações, ou seja, S\&P 500, FTSE 100 e Nikkei 225. O VARMA-AGARCH modelo de Hoti et al. (2002) foi usado para modelar as volatilidades condicionais multivariadas e para testar a existência de spillovers de volatilidade. Este modelo geral não foi aplicado anteriormente para testar transbordamentos de volatilidade.O modelo VARMA-AGARCH e a estimativa sequencial permitem obter uma inferência estatística válida porque as propriedades estruturais e estatísticas do modelo foram estabelecidas em Hoti et al. (2002).

Em Veiga e McAleer (2003) evidência significativa de spillovers de retornos foram encontrados em todos os pares de índices de ações, bem como spillovers de volatilidade a partir FTSE 100 a ambos S\&P 500 e Nikkei 225, e de S\&P 500 e FTSE 100. Estes resultados diferem dos da literatura, em que a volatilidade originária da S\&P 500 tem sido geralmente encontrados para ter transbordamento a todos os outros índices, e foi encontrado resultado da volatilidade de Nikkei 225 tendo efeitos (spillovers) para FTSE 100.

Miyakoshi (2003) em seu artigo examinou a magnitude do retorno e volatilidade spillovers 
do Japão e dos EUA a sete mercados de ações asiáticos. Foi construído um modelo spillover de volatilidade para lidar com o choque dos EUA como uma variável exógena em um EGARCH bivariado para o Japão e para os mercados asiáticos. Em primeiro lugar, apenas a influência dos EUA foi considerada importante para os retornos do mercado da Ásia; não foi identificada influência do Japão. Em segundo lugar, a volatilidade do mercado asiático foi mais influenciada pelo mercado japonês que pelos EUA. Em terceiro lugar, foi observada uma influência negativa da volatilidade do mercado asiático para o mercado japonês.

Baele (2005)investigaram em que medida a globalização afetou a crescente interdependência do mercado de ações. Concentraram-se na Europa Ocidental, já que esta região passou por um período único de integração econômica, financeira e monetária. Mais especificamente, os autores quantificam a magnitude e os efeitos de contágio de volatilidade do mercado agregado europeu e do mercado dos EUA para 13 mercados de ações europeus locais. Para ter em conta a integração variável no tempo, foi utilizado um modelo de mudança de regime para permitir que as sensibilidades à mudança de choque ao longo do tempo fossem identificadas. Tanto a intensidade do choque spillover do agregado europeu quanto dos EUA aumentaram substancialmente ao longo dos anos 1980 e 1990, embora o aumento tenha sido mais pronunciado para spillovers do agregado europeu.

Em uma análise de 19 mercados globais de capital a partir do início de 1990 até 2009, Diebold e Yilmaz (2009) encontraram evidência notável de comportamento divergente na dinâmica de spillovers de retorno versus spillovers de volatilidade: spillovers de retorno exibem uma tendência ligeiramente crescente, enquanto spillovers de volatilidade não exibem tendência, mas saltos claros. Diebold e Yilmaz (2009) forneceram uma medida simples e intuitiva de interdependência dos retornos de ativos e/ou de volatilidades. Em particular, formularam e analisaram as medidas precisas e separadas de spillovers de retorno e de volatilidade. A estrutura utilizada facilitou o estudo de ambos, não de crise e episódios de crise, incluindo tendências e quebras em spillovers; ambos acabam por ser empiricamente importantes.

Foram estudadas por Bae e Karolyi (1994) a dinâmica conjunta de volatilidade de retorno durante a noite e durante o dia para o Nikkei Stock Average em Tóquio e a Standard and Poor Stock Index 500 em Nova Iorque no período 1988-1992. Os autores estenderam a estrutura GARCH de Engle (1982) e Bollerslev (1986) para permitir efeitos negativos assimétricos ("más notícias") e positivos ("boas notícias"). A evidência mostrou que a magnitude e persistência dos choques originários de Nova Iorque ou de Tóquio que transmitem a outro mercado sejam compreendidos significantemente, se esse efeito assimétrico for ignorado.

O artigo de Kanas (1998) examinou a questão dos spillovers de volatilidade nos três maiores mercados de ações europeus, nomeadamente Londres, Frankfurt e Paris. O modelo auto-regressivo condicionalmente heterocedásticos $(\mathrm{ARCH})$ foi usado para capturar potenciais efeitos assimétricos de inovações sobre a volatilidade. Durante o período de 01/01/84 a 07/12/93, spillovers recíprocas são encontrados para existir entre Londres e Paris, e entre Paris e Frankfurt, 
e spillovers unidirecionais de Londres para Frankfurt. Em quase todos os casos, as repercussões são assimétricas no sentido de que más notícias em um mercado tem um efeito maior sobre a volatilidade de um outro mercado do que uma boa notícia.

\subsection{Spillovers, Governança Corporativa e os Efeitos Lead-Lag}

$\mathrm{Na}$ Teoria Financeira, a informação tem um papel fundamental nas mais diferentes correntes de pensamento. A forma pela qual a informação é incorporada aos preços e como os indivíduos a utilizam para tomada de ações efetivas é ponto de debate na literatura. Essa questão tornou-se tão relevante que originou toda uma linha de pesquisa em Finanças conhecida como microestrutruras de Mercado, conforme Madhavan (2000). A análise das microestruturas de mercado estuda a estrutura institucional na qual as transações envolvendo ativos financeiros são efetivamente concluídas. Entre as principais linhas de pesquisa nessa área destacam-se a adoção de incrementos fixos para as cotações dos ativos (Ticks), intervalos irregulares de tempo observado (ou não observado) entre as diferentes transações ocorridas ao longo de um período, a existência de spreads entre os preços de compra e venda dos formadores de mercado, a variação do volume (número de contratos) referente a cada operação realizada ao longo de um período. Em comum a todas essas linhas de pesquisa temos o papel da incorporação de informação nos preços dos ativos.

Uma linha de pensamento mais clássica, como Fama (1991) e Jr (1978), defendem que equilíbrio é alcançado com a utilização de toda informação disponível. Outros autores Byrne e Brooks (2008) defendem erros momentâneos de incorporação de informações que geram pequenos desequilíbrios e oportunidades de arbitragem. Nesse contexto a velocidade de incorporação de informação, o custo de capital e o valor de mercado de empresas passaram a ter uma relação inicialmente estuda por Jensen (1978), para o qual uma informação somente é utilizada quando seu benefício marginal supera seu custo marginal de processamento. Estudos como o de Easley e O'hara (2004), Botosan, Plumlee e Xie (2004), Bushman, Piotroski e Smith (2004) e Plumlee (2003) encontram evidências de que quanto maior a assimetria de informação entre os agentes econômicos, maior o custo de capital das empresas. A complexidade da informação tem um maior tempo de processamento conforme apresentado por Plumlee (2003), além de que empresas acompanhadas por um número maior de analistas, incorporam as informações mais rapidamente, segundo Brennan, Jegadeesh e Swaminathan (1993).

O efeito Lead-Lag, segundo Nakamura (2010) é observado, quando existe uma relação (ou ainda uma correlação) entre os movimentos de preços de dois mercados distintos, onde um mercado segue o movimento do outro mercado considerado "Líder"com alguma defasagem. Para Jiang, Fung e Cheng (2001), o efeito Lead-Lag é definido como dois ou mais preços se movem em sequência. Esse efeito quando verificado, rompe com a hipótese de eficiência de mercado desenvolvida por Malkiel e Fama (1970), que afirma que os preços das ações se comportam 
como um passeio aleatório, não sendo sujeitos a previsão e arbitragem. Contudo, a mesmo na presença confirmada de efeitos Lead-Lag, os custos de transação podem inviabilizar a arbitragem, fazendo válida novamente a hipótese de eficiência de mercado.

Miller (1980) utilizaram o efeito Lead-Lag para verificar que o preço de atacado (Líder) é seguido pelo preço do produtor de carne de porco nos Estados Unidos. Com relação a mercados de ações, o efeito Lead-Lag foi utilizado de diferentes maneiras, como na análise da relação entre mercado à vista e mercados futuros por Herbst, McCormack e West (1987) para o índice S\&P 500, Tse (1995) examina essa mesma relação para os contratos do índice Nikkei, com evidências de que os preços futuros lideram os preços à vista no curto prazo. Outros estudos dos efeitos Lead-Lag foram realizados para o índice FTSE100 de Londres por Brooks, Rew e Ritson (2001), assim como o estudo de Suarez (2008) para o índice IBEX35 da espanha. Daigler (1990) estudo os efeitos Lead-Lag para os índices S\&P500, MMI e contratos NYSE analisando a relação entre retornos e volumes de transações. Um estudo para America Latina foi realizado por Saatcioglu e Starks (1998).

Para o caso brasileiro GAIO e ROLIM (2007), mediram o impacto de mudanças nos principais índices de bolsas de valores no mundo no Ibovespa, apresentando evidências de que o comportamento das bolsas de valores internacionais influenciam os preços no mercado acionário brasileiro. Medeiros e Oliveira (2008) estudaram co-movimentos do índice Dow Jones e o índice Ibovespa e identificou a existência de efeitos Lead-Lag entre o mercado brasileiro e o norte americano no período de julho de 2006 a setembro de 2007, utilizando dados de alta frequência, concluindo que não espaço para arbitragem por conta dos custos de transação. Por outro lado, Nakamura (2010) mostra a existência de efeitos Lead-Lag entre mercado acionário brasileiro e seus ADRs. Pena, Guelman e Rabello (2010) analisaram a relação entre o índice Dow Jones e Nikkei com o índice Ibovespa, de janeiro de 2006 a maio de 2008, os autores identificaram uma relação contemporânea entre os índices e efeitos defasados que seriam oriundos da diferença de fusos horários.

O estudo de Neto, Medeiros e Queiroz (2012) identificou a existência de efeitos LaedLag entre o índice IGC-X e o índice Ibovespa, ou seja, um maior grau de governança estaria associado uma mais rápida incorporação de informação nos preços, fazendo o índice com qualidade de governança causar no sentido de granger o Ibovespa. Nesse sentido o presente estudo trabalha com semelhante hipótese a ser testada: Os efeitos spillovers de mercados cambiais e de mercados financeiros internacionais são menores para os índices que traduzem alta qualidade de governança?

Essa hipótese, sintetiza outras relevantes questões do estudo, como a estimação dos efeitos de transbordamentos via modelos MGARCH, o teste de causalidade de Granger de segunda ordem para identificar sua direção, o que também significa testar a existência de efeitos Lead-Lag para as volatilidades condicionais dos índices Bovespa e dos mercados cambiais e financeiros internacionais. 


\section{Modelos GARCH Multivariados}

Os modelos de séries de tempo univariados foram pioneiros nos estudos da volatilidade do retorno de ativos financeiros, em especial quando essa volatilidade tem um comportamento variando ao longo do tempo. Esses estudo evoluíram para os casos multivariados. Neste capítulo vamos apresentar alguns modelos apropriados para séries financeiras que apresentam a variância condicional evoluindo no tempo. Existe uma variedade grande de modelos não-lineares disponíveis na literatura, aqui iremos nos concentrar em algumas extensões da classe de modelos ARCH (auto-regressivos com heteroscedasticidade condicional), introduzida por Engle (1982).

Uma generalização dos modelos ARCH foi sugerida por Bollerslev (1986), o chamado modelo GARCH ('generalized ARCH'). Um modelo GARCH pode ser usado para descrever a volatilidade com menos parâmetros do que um modelo ARCH.

Contudo em muitas situações de pesquisa existe a necessidade de considerarmos mais de um ativo, e consequentemente suas correlações. Dessa forma, assim como a volatilidade variando no tempo ganhou repercussão em pesquisas, a correlação variando começou a ganhar destaques com os modelos GARCH multivariados (MGARCH).

A questão fundamental está em diferenciar a correlação com toda a série temporal dos ativos envolvidos e a correlação temporal a cada período conforme descrito abaixo:

$$
\begin{gathered}
\rho_{i j}=\frac{\sigma_{i j}}{\sqrt{\sigma_{i}^{2} \sigma_{j}^{2}}} \\
\rho_{i j t}=\frac{E_{t-1}\left(r_{i t} r_{j t}\right)}{\sqrt{E_{t-1}\left(r_{i t}^{2}\right) E_{t-1}\left(r_{j t}^{2}\right)}}
\end{gathered}
$$

Medida de dependência linear com $\rho_{i j}$ e $\rho_{i j t} \in(-1,1)$.

\subsection{O Modelo GARCH Multivariado}

O modelo GARCH multivariado tem a seguinte forma geral:

$$
\begin{gathered}
\operatorname{vech}\left(\Sigma_{t \mid t-1}\right)=A_{0}+\sum_{j=1}^{q} A_{j} \operatorname{vech}\left(u_{t-j} u_{t-j}^{\prime}\right)+\sum_{j=1}^{m} B_{j} \operatorname{vech}\left(\Sigma_{t-j \mid t-j-1}\right) \\
u_{t}=\Sigma_{t}^{1 / 2} \mathbf{z}_{t}, \mathbf{z}_{t} \sim i i d\left(\mathbf{0}, \mathbf{I}_{K}\right)
\end{gathered}
$$




$$
\Sigma_{t}=\Sigma_{t}^{1 / 2}\left(\Sigma_{t}^{1 / 2}\right) \quad(\text { Cholesky })
$$

A matriz $B_{j}$ é fixada com $\left(\frac{1}{2} K(K+1) \times \frac{1}{2} K(K+1)\right)$ matrizes de coeficientes. Um exemplo bivariado, MGARCH( $(1,1)$ com $\mathrm{K}=2$;

$$
\begin{gathered}
\text { vech }\left[\begin{array}{ll}
\sigma_{11, t \mid t-1} & \sigma_{12, t \mid t-1} \\
\sigma_{12, t \mid t-1} & \sigma_{22, t \mid t-1}
\end{array}\right]=\left[\begin{array}{c}
\sigma_{11, t \mid t-1} \\
\sigma_{12, t \mid t-1} \\
\sigma_{22, t \mid t-1}
\end{array}\right] \\
{\left[\begin{array}{c}
\sigma_{11, t \mid t-1} \\
\sigma_{12, t \mid t-1} \\
\sigma_{22, t \mid t-1}
\end{array}\right]=\left[\begin{array}{l}
\alpha_{10} \\
\alpha_{20} \\
\alpha_{30}
\end{array}\right]+\left[\begin{array}{lll}
\alpha_{11} & \alpha_{12} & \alpha_{13} \\
\alpha_{21} & \alpha_{22} & \alpha_{23} \\
\alpha_{31} & \alpha_{32} & \alpha_{33}
\end{array}\right]\left[\begin{array}{c}
u_{1, t-1}^{2} \\
u_{1, t-1} u_{2, t-1} \\
u_{2, t-1}^{2}
\end{array}\right]+\left[\begin{array}{lll}
\beta_{11} & \beta_{12} & \beta_{13} \\
\beta_{21} & \beta_{22} & \beta_{23} \\
\beta_{31} & \beta_{32} & \beta_{33}
\end{array}\right]\left[\begin{array}{c}
\sigma_{11, t-1 \mid t-2} \\
\sigma_{12, t-1 \mid t-2} \\
\sigma_{22, t-1 \mid t-2}
\end{array}\right] .}
\end{gathered}
$$

O espaço de parâmetros de um modelo MGARCH tem uma dimensão grande e, em geral, precisa ser restringido para garantir a unicidade da representação e obter propriedades adequadas de covariâncias condicionais. Para reduzir o espaço de parâmetros, Bollerslev, Engle e Wooldridge (1988) discutiram modelos MGARCH diagonais, onde o $A_{j}{ }^{\prime} s$ e $B_{i}{ }^{\prime} s$ são matrizes diagonais. Em alternativa, um modelo BEKK GARCH é usualmente representado da seguinte forma:

$$
\Sigma_{t \mid t-1}=A_{0}^{* \prime} A_{0}^{*}+\sum_{n=1}^{N} \sum_{j=1}^{q} A_{j n}^{*^{\prime}} u_{t-j} u_{t-j}^{\prime} A_{j n}^{*}+\sum_{n=1}^{N} \sum_{j=1}^{m} B_{j n}^{*^{\prime}} \Sigma_{t-j \mid t-j-1} B_{j n}^{*}
$$

Onde $A_{0}^{*}$ é uma matriz triangular $K \times K$ e os coeficientes matriciais $A_{j n}^{*^{\prime}}$ e $B_{j n}^{*^{\prime}}$ são também $K \times K$.

Os modelos MGARCH devem ser fáceis de estimação e entendimento, e permitir flexibilidade na dinâmica das variâncias e correlações condicionais. Os modelos MGARCH devem ter um número limitado de parâmetros. $\Sigma_{t}$ deve ser positiva semi-definida. Os elementos da diagonal de $\Sigma_{t}^{1 / 2}$ devem ser maiores ou iguais a zero.

Com essas condições elencadas, temos então que a estimação dos modelos MGARCH necessita de restrições no espaço de parâmetros para garantir uma representação única e obter boas propriedades das covariâncias condicionais. Os diferentes modelos MGARCH serão diferenciados pelo diferentes métodos de tratamento dessas restrições ao espaço de parâmetros, ou seja ao tratamento dado a $\Sigma_{t}$. 


\subsection{Modelos MGARCH Baseados em GARCH Univariados}

Nos modelos BEKK e DVEC a matriz de covariância condicional é modelada diretamente. O que resulta em um grande número de parâmetros. Outra abordagem na modelagem GARCH multivariado é primeiro modelar individualmente as séries, usando GARCH univariado, e depois modelar as correlações condicionais entre as séries.

\subsubsection{Modelo CCC}

Dado que $\sigma_{i j}=\rho_{i j} \sigma_{i} \sigma_{j}$ é uma matriz $K \times K$ de covariância $\sum$, é possível decompô-la em:

$$
\sum=\mathrm{DRD}
$$

onde $\mathbf{R}$ é a matriz de correlação, $\mathbf{D}$ é uma matriz diagonal com o vetor $\left(\sigma_{1}, \ldots, \sigma_{k}\right)$ na diagonal e $\sigma_{i}$ é o desvio-padrão da $i$-ésima série.

$$
\begin{aligned}
& \mathbf{R}=\left[\begin{array}{cccc}
1 & \rho_{12} & \cdots & \rho_{1 k} \\
\rho_{12} & 1 & \cdots & \rho_{2 k} \\
\vdots & \vdots & \ddots & \vdots \\
\rho_{1 k} & \rho_{2 k} & \cdots & 1
\end{array}\right] \\
& \mathbf{D}=\left[\begin{array}{cccc}
\sigma_{1} & 0 & \cdots & 0 \\
0 & \sigma_{2} & \cdots & 0 \\
\vdots & \vdots & \ddots & \vdots \\
0 & 0 & \cdots & \sigma_{k}
\end{array}\right]
\end{aligned}
$$

Bollerslev (1990) sugere modelar a matriz de covariância tempo-variante como:

$$
\sum_{t}=\mathbf{D}_{t} \mathbf{R} \mathbf{D}_{t}
$$

onde $\mathbf{R}$ é uma matriz de correlação constante e $\mathbf{D}$ é uma matriz diagonal:

$$
\mathbf{D}=\left[\begin{array}{cccc}
\sigma_{1 t} & & & \\
& \sigma_{2 t} & & \\
& & \ddots & \\
& & & \sigma_{k t}
\end{array}\right]
$$

$\operatorname{com} \sigma_{i t}$ seguindo um processo GARCH univariado, para $i=1,2, \ldots, k$. 
As correlações $\rho_{i j}$ são constantes porém, as covariâncias condicionais $\rho_{i j, t}=\rho_{i j} \sigma_{i t} \sigma_{j t}$ são tempo-variantes.

R pode ser a matriz de correlação amostral ou uma matriz com valores especificados.

\subsubsection{Modelo DCC}

Engle (2002) estendeu o modelo CCC de Bollerslev (1990) permitindo que as correlações condicionais variem no tempo, isto é:

$$
\begin{gathered}
\mathbf{r}_{t}=\mu+\mathbf{u}_{\mathbf{t}}, u_{t} \sim i i d \sim N\left(\mathbf{0}, \mathbf{\Sigma}_{t}\right) \\
\operatorname{var}\left(u_{t} \mid I_{t-1}\right)=\mathbf{\Sigma}_{t}=\mathbf{D}_{t} \mathbf{R}_{t} \mathbf{D}_{t} \\
\mathbf{R}=\left[\begin{array}{cccc}
1 & \rho_{12, t} & \cdots & \rho_{1 k, t} \\
\rho_{12, t} & 1 & \cdots & \rho_{2 k, t} \\
\vdots & \vdots & \ddots & \vdots \\
\rho_{1 k, t} & \rho_{2 k, t} & \cdots & 1
\end{array}\right] \\
\mathbf{D}=\left[\begin{array}{cccc}
\sigma_{1, t} & 0 & \cdots & 0 \\
0 & \sigma_{2, t} & \cdots & 0 \\
\vdots & \vdots & \ddots & \vdots \\
0 & 0 & \cdots & \sigma_{k, t}
\end{array}\right]
\end{gathered}
$$

Para cada série univarda $(i=1,2, \ldots, k)$, temos:

$$
\begin{gathered}
u_{i t}=\sigma_{i t} z_{i t}, z_{i t} \sim N(0,1) \\
\operatorname{var}\left(u_{i t} \mid I_{t-1}\right)=\sigma_{i t}^{2}
\end{gathered}
$$

Seja o vetor de erros padronizados (retornos) $\mathbf{z}_{t}=\left(z_{1 t}, \ldots, z_{k t}\right)^{\prime}$, então:

$$
E\left[\mathbf{z}_{t} \mathbf{z}_{t}^{\prime} \mid I_{t-1}\right]=\mathbf{R}_{t} \neq \mathbf{I}_{k}
$$

Considere:

$$
\begin{gathered}
\operatorname{corr}\left(u_{i t}, u_{j t} \mid I_{t-1}\right)=\frac{\operatorname{cov}\left(u_{i t}, u_{j t} \mid I_{t-1}\right)}{\sigma_{i t} \sigma_{j t}}=\frac{\operatorname{cov}\left(\sigma_{i t} z_{i t}, \sigma_{j t} z_{j t} \mid I_{t-1}\right)}{\sigma_{i t} \sigma_{j t}}=\frac{\sigma_{i t} \sigma_{j t} \operatorname{cov}\left(z_{i t}, z_{j t} \mid I_{t-1}\right)}{\sigma_{i t} \sigma_{j t}} \\
=\operatorname{cov}\left(z_{i t}, z_{j t} \mid I_{t-1}\right)=E\left[z_{i t}, z_{j t}\right]
\end{gathered}
$$


A ideia do modelo DCC é estimar modelos GARCH(p,q) para cada $\mathbf{r}_{i t}(i=1, \ldots, K)$ e armazena-se os resíduos padronizados. Modela-se então aos pares de covariâncias condicionais entre os resíduos padronizados e com isso estima-se a matriz de covariância condicional a partir das volatilidades univariadas e das correlações bivariadas estimadas.

\subsection{Modelos GARCH Multivariados Estruturais}

\subsubsection{Modelo Diagonal VEC}

Bollerslev, Engle e Woodridge (1988) estenderam o modelo GARCH univariado para a forma multivariada: o modelo diagonal VEC. Os Modelos DVEC restringem as variâncias e covariâncias condicionais a dependerem apenas de seus próprios valores defasados e do produto cruzado dos termos de erro.

$$
\boldsymbol{\Sigma}_{t}=\mathbf{A}_{0}+\sum_{i=1}^{p} \mathbf{A}_{i} \odot\left(u_{t-1} u_{t-1}^{\prime}\right)+\sum_{j=1}^{q} \mathbf{B}_{j} \odot \boldsymbol{\Sigma}_{t-j}
$$

$\odot=$ Produto de Hadamard (elemento por elemento), onde $\mathbf{A}_{0}, \mathbf{A}_{i}$ e $\mathbf{B}_{j}$ são matrizes simétricas.

Basicamente, o modelo DVEC implica em modelos $\operatorname{GARCH}(1,1)$ para as variâncias e covariâncias, contudo sem efeitos cruzados entre variância e covariâncias para um mesmo ativo (ou para uma mesma variância), ou seja, no exemplo bivariado apresentado anteriormente, $\sigma_{11, t}$ não depende de $\sigma_{12, t}, \epsilon_{t-1}^{2}$ ou $\sigma_{22, t}$. Esse modelo apresenta um grande número de parâmetros $\frac{(p+q+1) K(K+1)}{2}$ além de não apresentar garantia de que $\Sigma_{t}$ seja definida positiva, o que pode ocasionar variâncias negativas e correlações com valores em módulo maior que 1.

Neste caso, a covariância condicional entre $u_{j, i}$ e $u_{i, t}, \sigma_{i, j, t}$ dependerá apenas dos produtos cruzados dos choques e das covariâncias defasadas:

$$
\begin{gathered}
\sigma_{11, t}=\alpha_{10}+\alpha_{11} u_{1, t-1}^{2}+\beta_{11} \sigma_{11, t-1} \\
\sigma_{12, t}=\alpha_{20}+\alpha_{22} u_{1, t-1} u_{2, t-1}+\beta_{22} \sigma_{12, t-1} \\
\sigma_{22, t}=\alpha_{30}+\alpha_{33} u_{2, t-1}^{2}+\beta_{33} \sigma_{22, t-1}
\end{gathered}
$$

A grande vantagem do modelo é a facilidade em garantir que a matriz de covariância seja positiva semi-definida, sendo que para que isso ocorra basta que as matrizes $\alpha_{i 0}, \alpha_{i i}$ e $\beta_{i i}$ sejam positivas semi-definidas. Para casos onde o número de covariâncias condicionais não seja grande (até 4 ativos) este modelo não sofre saturação na estimação dos parâmetros. 
A grande fragilidade do modelo é ele ser muito restritivo, não permitir que a variância condicional seja dependente do histórico das outras variáveis do sistema (Ver Franses e Dijk (2000).).

Uma simplificação para esse modelo chamado de Scalar DVEC, que restringe $A_{i}$ para ter elementos comuns $a_{i}$ e $B_{j}$ elementos comuns $b_{j}$ e com isso o total de parâmetros passa a ser $K(K+1)+(p+q)$.

\subsubsection{Modelo BEKK}

O modelo BEKK (Baba, Engle, Kraft e Kroner) dá uma dinâmica mais rica do que o modelo Scala DVEC. O modelo BEKK, então, é dado por:

$$
\boldsymbol{\Sigma}_{t}=\mathbf{A}_{0} \mathbf{A}_{0}^{\prime}+\sum_{i=1}^{p} \mathbf{A}_{i}\left(u_{t-i} u_{t-i}^{\prime}\right) \mathbf{A}_{i}^{\prime}+\sum_{j=1}^{q} \mathbf{B}_{j} \boldsymbol{\Sigma}_{t-j} \mathbf{B}_{j}^{\prime}
$$

Onde $\mathbf{A}_{0}$ é uma matriz triangular inferior, porém $\mathbf{A}_{i}$ e $\mathbf{B}_{j}$ são matrizes quadradas irrestritas.

Observação: Tem-se $k(k+1)(p+q) / 2$ parâmetros a mais em relação ao DVEC(p,q).

Se consideramos o caso bivariado, podemos observar que $\sigma_{11, t-1}$ tem impacto direto sobre $\sigma_{22, t}$, contudo isso aumenta em dois parâmetros em relação ao modelo DVEC.

Embora o modelo de BEKK de baixa ordem seja uma representação relativamente parcimoniosa da estrutura de covariâncias condicionais, o número de parâmetros ainda cresce rapidamente com a dimensão do sistema subjacente. Portanto, na prática, é apenas factível se sistemas com apenas algumas variáveis estão sendo considerados e outras medidas de simplificação foram propostas para aliviar a modelagem de processos de dimensões mais elevadas. Alguns deles podem ser vistos como modelos especiais BEKK.

Nos mercados financeiros, tem sido observado com frequência que os choques negativos e positivos, ou notícias, têm efeitos muito diferentes Black (1976). Esse efeito de alavanca pode ser introduzido de forma diferente em modelos MGARCH. Por exemplo, Hafner e Herwartz (1998) e Herwartz e Lütkepohl (2000) generalizaram uma proposta univariada de Glosten, Jagannathan e Runkle (1993) e substituíram $A_{11}^{*^{\prime}} u_{t-1} u_{t-1}^{\prime} A_{11}^{*}$ por

$$
A_{11}^{*^{\prime}} u_{t-1} u_{t-1}^{\prime} A_{11}^{*}+A_{-}^{*^{\prime}} u_{t-1} u_{t-1}^{\prime} A_{-}^{*} I\left(\sum_{k=1}^{K} u_{k t}<0\right)
$$

em um modelo BEKK com $\mathrm{N}=1$.

Aqui I(.) denota uma função indicadora que assume o valor 1 se o argumento é válido e 0 se não e $A_{-}^{*}$ é um coeficiente adicional da matriz $(K \times K)$.

Um exemplo com MGARCH(1,1)-BEKK, N=2 com: 
$A_{1}=\operatorname{diag}\left(\alpha_{11}, \alpha_{22}\right)$ e $B_{1}=\operatorname{diag}\left(\beta_{11}, \beta_{22}\right)$ o modelo se reduz para:

$$
\begin{aligned}
& \Sigma_{t}=A_{0} A_{0}^{\prime}+\left[\begin{array}{cc}
\alpha_{11} & 0 \\
0 & \alpha_{22}
\end{array}\right]\left[\begin{array}{cc}
u_{1 t-1}^{2} & u_{1 t-1} u_{2 t-1} \\
u_{2 t-1} u_{1 t-1} & u_{2 t-1}^{2}
\end{array}\right]\left[\begin{array}{cc}
\alpha_{11} & 0 \\
0 & \alpha_{22}
\end{array}\right]^{\prime} \\
& +\left[\begin{array}{cc}
\beta_{11} & 0 \\
0 & \beta_{22}
\end{array}\right]\left[\begin{array}{ll}
\sigma_{11 t-1} & \sigma_{12 t-1} \\
\sigma_{21 t-1} & \sigma_{22 t-1}
\end{array}\right]\left[\begin{array}{cc}
\beta_{11} & 0 \\
0 & \beta_{22}
\end{array}\right]^{\prime} \\
& \sigma_{11, t}=\alpha_{10}+\alpha_{11}^{2} u_{1, t-1}^{2}+\beta_{11}^{2} \sigma_{11, t-1} \\
& \sigma_{12, t}=\alpha_{20}+\alpha_{11} \alpha_{22} u_{1, t-1} u_{2, t-1}+\beta_{11} \beta_{22} \sigma_{12, t-1} \\
& \sigma_{22, t}=\alpha_{30}+\alpha_{22}^{2} u_{1, t-1}^{2}+\beta_{22}^{2} \sigma_{11, t-1}
\end{aligned}
$$

\subsection{Identificação das Ordens dos Modelos GARCH}

A seleção das ordens em modelos GARCH é mais desenvolvida para o caso univariado, não havendo extensa literatura para o caso multivariado conforme Lütkepohl (2005). Contudo, para este estudo utilizamos a abordagem de identificação do caso univariado como indicação para o caso multivariado haja vista que para o MGARCH estrutural (BEKK) a saturação de parâmetros pode rapidamente comprometer sua estimação. Dessa forma, utilizaremos a sequencia sugerida por Franses e Dijk (2000):

1. Calcular estatísticas de séries temporais (ACF e PACF, ou seja a função de autocorrelação e a função de autocorrelação parcial, respectivamente.);

2. Comparar os valores ou tamanhos dessas estatísticas com valores teóricos que digam se o modelo é adequado. (Identificação);

3. Estimar os parâmetros do modelo sugerido no passo 2. (Estimação);

4. Teste de autocorrelação dos resíduos padronizados e do quadrado dos resíduos padronizados;

5. Avaliar modelos utilizando métricas de adequação (critérios AIC e BIC). (Validação);

6. Reespecificar o modelo se necessário;

7. Use o modelo com propósitos descritivos ou preditivos. (Previsão). 
A preocupação deste estudo está na fase de identificação da estrutura de defasagem apropriada para a equação de variância condicional em um processo GARCH. As funções de autocorrelação e de autocorrelação parcial das séries de inovações são normalmente usadas para identificar e validar o comportamento temporal das séries dos modelos ARMA Box e Jenkins (1976). Bollerslev, Engle e Wooldridge (1988) mostrou que essas mesmas funções, quando aplicadas à série dos quadrados dos resíduos podem ser úteis para identificar e validar o comportamento temporal da equação da variância condicional na forma de GARCH. A seguir apresentamos as indicações de ordem quando consideramos comportamento das funções ACF e PACF:

\begin{tabular}{|c|c|c|c|c|c|}
\hline & ARCH(1) & $\operatorname{ARCH}(2)$ & $\operatorname{GARCH}(\mathbf{1}, \mathbf{1})$ & $\operatorname{GARCH}(\mathbf{1 , 2})$ & $\operatorname{GARCH}(2,1)$ \\
\hline $\mathrm{ARCH}(1)$ & - & & & & \\
\hline $\mathrm{ARCH}(2)$ & PACF2 & - & & & \\
\hline $\operatorname{GARCH}(1,1)$ & $\begin{array}{c}\text { ACF1; } \\
\text { Decaimento } \\
\text { exponencial } \\
\text { (PACF2 em } \\
\text { diante) }\end{array}$ & $\begin{array}{l}\text { ACF1; PACF2; } \\
\text { Decaimento } \\
\text { exponencial } \\
\text { (PACF3 em } \\
\text { diante) }\end{array}$ & - & & \\
\hline $\operatorname{GARCH}(1,2)$ & $\begin{array}{l}\text { ACF1; PACF2; } \\
\text { Decaimento } \\
\text { exponencial } \\
\text { (PACF3 em } \\
\text { diante) }\end{array}$ & $\begin{array}{c}\text { ACF1; } \\
\text { Decaimento } \\
\text { exponencial } \\
\text { (PACF3 em } \\
\text { diante) }\end{array}$ & PACF2 & - & \\
\hline $\operatorname{GARCH}(2,1)$ & $\begin{array}{l}\text { ACF1; ACF2; } \\
\text { Decaimento } \\
\text { exponencial } \\
\text { (PACF2 em } \\
\text { diante) }\end{array}$ & $\begin{array}{c}\text { ACF1; ACF2; } \\
\text { PACF2; } \\
\text { (PACF3 em } \\
\text { diante) }\end{array}$ & $\mathrm{ACF} 2$ & ACF2; PACF2 & - \\
\hline
\end{tabular}

Tabela 1 - Resumo das diferenças de comportamento das ACFs e PACF dos modelos. 


\section{Método e Técnica de Pesquisa}

Até o momento já foi apresentada a introdução do trabalho, no qual foi discutido o problema de pesquisa, apresentado o objetivo da pesquisa e sua justificação teórica e prática. Após essa introdução foram expostos os conceitos e pesquisas pioneiras e recentes sobre o tema. Em resumo o presente trabalho se dispõem a analisar o transbordamento de volatilidade cambial e de mercados financeiros internacionais sobre a volatilidade das ações de empresas com alta qualidade de Governança Corporativa. Nesse capítulo será dada atenção a classificação metodológica da pesquisa, apresentação do modelo estatístico utilizado e a descrição dos dados a serem estudados.

A fim de realizar a busca bibliográfica para este trabalho, foram utilizadas as seguintes palavras-chaves: spillovers de volatilidade, volatility spillovers, volatilidade dos retornos das ações. Após a busca dos artigos que se encaixavam nesses critérios foram feitas as análises necessárias a fim de determinar sua relevância para o trabalho, foram observados também outros artigos dos autores citados nos artigos analisados.

A presente pesquisa enquadra-se como do tipo documental tendo em vista o uso de dados secundários e a manipulação estatística dos dados para determinar a relação entre as variáveis estudadas. O trabalho tem a finalidade de ser do tipo explicativo. Segundo a teoria de Gil (1999), a pesquisa explicativa identifica os fatores que determinam ou contribuem para a ocorrência dos fenômenos. Em razão do uso de dados secundários e sua manipulação por meio de técnicas estatísticas, entende-se que essa pesquisa tem uma abordagem quantitativa, que diferentemente da pesquisa qualitativa, se preocupa com o comportamento geral dos acontecimentos.

A base de dados analisada nesta pesquisa se refere à série histórica das taxas de câmbio de 48 países, dos índices de bolsas de 17 mercados financeiros (17 países), do índice Bovespa (Ibovespa) e dos índices de Governança Corporativa da BM\&FBovespa (IGC-NM e IGC-X). Dessa população, foi analisado o período de tempo compreendido entre 02.01.2007 e 31.03.2016 (dados diários), perfazendo 2.284 observações por variável. A coleta dos dados foi feita a partir da base de dados disponibilizada pela plataforma "Bloomberg".

As séries históricas foram estatisticamente analisadas a fim de avaliar a existência de assimetria e/ou excesso de curtose que pudessem indicar se tratar de distribuição normal ou outras características. Em seguida foram calculados os retornos das séries. As estatísticas descritivas e testes de hipóteses clássicos foram realizados. Utilizando-se Análise de Componentes Principais foram construídos índices de volatilidades cambiais e de mercados financeiros internacionais. Posteriormente, utilizamos os modelos GARCH multivariados para a estimação da volatilidade/correlação condicional entre os índices a fim de examinar a existência do spillover de volatilidade cambial e de mercados financeiros internacionais sobre a volatilidade das ações de 
empresas com alta qualidade de Governança Corporativa. Por fim, foram feitos testes de causalidade de Granger de segundos momentos para volatilidade a fim de indicar a direção/precedência dos transbordamentos da volatilidade. Testamos, ainda, se as correlações condicionais observadas para o Ibovespa são estatisticamente maiores do que a dos índices com qualidade de governança tanto quanto testamos se as correlações condicionais do índice IGC-X são maiores do que a do índice IGC-NM, haja vista o IGC-NM está associado a maior qualidade de governança.

Na sequência da parte metodológica deste trabalho estão descritos um conjunto de testes estatísticos e critérios de informação que foram aplicados previamente a cada série. Em seguida descrevemos a técnica de representação dos dados - Análise de Componentes Principais. Na sequência apresentamos uma descrição do modelo geral GARCH multivariado seguindo para seus detalhamentos e particularidades.

\subsection{Teste de Causalidade de Engle-Granger}

O teste de causalidade proposto por Granger visa superar as limitações do uso de simples correlações entre variáveis. Esse teste procura a existência de relação de causa defasada entre duas ou mais variáveis. Uma variável $Z$ causa, no sentido de Granger, uma variável $Y$, se a previsão obtida no valor corrente de $Y$ puder ser melhorada levando em consideração as informações defasadas de $Z$.

Para testar a causalidade de Granger é necessário que as séries sejam estacionárias, ou seja, as séries $Y_{t}$ e $Z_{t}$ devem ser integradas de ordem zero - $I(0)$. Conforme Enders (2004), o seguinte modelo VAR (Vetor Auto-Regressivo) pode ser estimado para testar a causalidade entre duas variáveis:

$$
\begin{aligned}
& Z_{t}=\alpha_{1}+b_{11} Z_{t-1}+b_{12} Z_{t-2}+\ldots+b_{1 p} Z_{t-p}+a_{11}+Y_{t-1}+a_{12} Y_{t-2}+\ldots+a_{1 p} Y_{t-p}+\varepsilon_{t} \\
& Y_{t}=\alpha_{2}+b_{21} Z_{t-1}+b_{22} Z_{t-2}+\ldots+b_{2 p} Z_{t-p}+a_{21}+Y_{t-1}+a_{22} Y_{t-2}+\ldots+a_{2 p} Y_{t-p}+\varepsilon_{t}
\end{aligned}
$$

Se, por exemplo, o objetivo for testar se $Z_{t}$ causa $Y_{t}$, no sentido de Granger, busca-se rejeitar ou aceitar as seguintes hipóteses por meio de um teste de Wald com distribuição $F$ (de Fisher) da seguinte forma:

$$
H_{0}: b_{21}=b_{22}=\ldots=b_{2 p}=0
$$

$H_{1}: b_{2 p} \neq 0$ para pelo menos um $p$, onde $p$ é o número de defasagens.

Assim, a hipótese nula $\left(H_{0}\right)$ na qual $Z_{t}$ não causa $Y_{t}$ no sentido de Granger é testada contra a hipótese alternativa $\left(H_{1}\right)$ de que ao menos uma defasagem da variável $Z_{t}$ causa no sentido de Granger $Y_{t}$. 
Enders (2004) destaca o fato da causalidade de Granger ser completamente diferente de um teste de exogeneidade. Uma variável $Z_{t}$ é exógena (forte) em relação a $Y_{t}$ se os valores passados e correntes de $Y_{t}$ não afetam $Z_{t}$. Como a causalidade de Granger refere-se apenas aos efeitos dos valores defasados de $Y_{t}$ sobre os valores correntes de $Z_{t}$, não se pode afirmar se $Z_{t}$ é exógena com base em um teste de causalidade de Granger.

A exogeneidade fraca, porém, por ser definida para apenas os valores defasados de $Y_{t}$ não afetarem $Z_{t}$, pode ser testada por meio da causalidade de Granger. Se $Y_{t}$ não causa no sentido de Granger $Z_{t}, Z_{t}$ é exógena fraca em relação a $Y_{t}$.

\subsection{Teste de Causalidade de Granger de Segunda Ordem}

Como visto, a definição de causalidade de Granger se baseia em previsões. Sob condições adequadas, as previsões ótimas são obtidas como esperanças condicionais. Portanto, a causalidade de Granger pode ser definida em termos ótimos como esperanças condicionais. Em outras palavras, podemos definir uma variável de séries de tempo $X_{t}$ para ser causal de $Z_{t}$, se

$$
E\left(z_{t+1} \mid z_{t}, z_{t-1, \ldots}\right) \neq E\left(z_{t+1} \mid z_{t}, z_{t-1}, \ldots, x_{t}, x_{t-1}, \ldots\right)
$$

Esta definição sugere uma extensão direta de ordem superior de momentos condicionais. Nós definimos $x_{t}$ ser causal para $z_{t}$ no r-ésimo momento se

$$
E\left(z_{t+1}^{r} \mid z_{t}, z_{t-1, \ldots}\right) \neq E\left(z_{t+1}^{r} \mid z_{t}, z_{t-1}, \ldots, x_{t}, x_{t-1}, \ldots\right)
$$

Assim, a primeira desigualdade define a causalidade em média e considerando os segundos momentos centrais a segunda desigualdade dá uma definição de causalidade na variância que é análoga à definição prévia de causalidade de Granger em média. Em outras palavras, se $X_{t}$ é causal na variância para $Z_{t}$, a volatilidade condicional de $Z_{t}$ pode ser prevista de forma mais precisa, tendo em conta a informação presente e passada em $X_{t}$ sem levar em conta esta informação.

A estrutura de covariância condicional pode ser descrita por modelos ARCH ou GARCH multivariados, as restrições implícitas por estas definições também são semelhantes aos de causalidade de Granger em VAR e modelos VARMA (COMTE; LIEBERMAN, 2000). Em outras palavras, pode ser descrito em termos de zero restrições nos parâmetros ARCH e MGARCH. Dependendo da não-linearidade na presente situação. Os testes de causalidade na variância foram propostos e investigados por Cheung, Hong, e Pantelis.

Também é possível generalizar a definição da causalidade e especificar, por exemplo, as condições para ambas as ordens, primeiros e segundos momentos condicionais (Granger engle). 
Em termos mais gerais, pode-se considerar as distribuições condicionais completas ao invés de apenas momentos específicos. Em outras palavras, pode-se definir $X_{t}$ ser causal para $Z_{t}$ se

$$
F_{z_{t+1} \mid z_{t}, z_{t-1}, \ldots}(.) \neq F_{z_{t+1} \mid z_{t}, z_{t-1}, \ldots, x_{t}, x_{t-1}, \ldots}(.)
$$

em que $F_{z \mid x}($.$) representa a função de distribuição condicional de z$ dado $x$. Generalizando estes conceitos ao caso em que $X_{t}$ e $Z_{t}$ são vetores é teoricamente simples, como no caso de causalidade de Granger para esperanças condicionais.

Um vetor de variáveis não causa a outro vetor de variáveis, conforme a causalidade de Granger de segunda ordem, se as informações do passado sobre a variabilidade do primeiro não pode melhorar a previsão de variâncias condicionais dos últimos. A definição da não causalidade de segunda ordem assume que as relações causais de Granger podem existir no processo de média condicional, no entanto, elas devem ser modeladas a partir de filtros. Caso contrário, essas relações podem ter impacto sobre os parâmetros responsáveis pelas relações causais em variâncias condicionais.

A fim de definir os conceitos de causalidade para a variância de um vetor $\varepsilon_{t}$, duas hipóteses simplificam a apresentação e nos permitem concentrar no problema da inferência de causalidade. O primeiro pressuposto é que a média condicional é zero, isto é , $E\left[\varepsilon_{t} \mid \mathcal{F}_{t-1}\right]=0$. Sem esta suposição, haveria uma diferença entre um conceito que corrige para a média usando toda a informação disponível e um que corrige para a média usando apenas a informação da variável que está a ser causada pelas outras. A primeira noção foi introduzida por Granger, Robins e Engle (1986), e a segunda por Comte e Lieberman (2000). Sob a hipótese de $E\left[\varepsilon_{t} \mid \mathcal{F}_{t-1}\right]=0$, no entanto, ambas as noções são equivalentes.

A segunda hipótese de simplificar diz respeito ao número de sub-grupos do vector $\varepsilon_{t}$. Nós assumimos que há apenas dois sub-grupos e investigamos os conceitos de causalidade entre estes dois grupos. Como é bem conhecido, de Dufour e Renault (1998), em tais configurações é suficiente para investigar o horizonte causalidade um período. Se houver não causalidade no horizonte de um, então não há não causalidade em cada horizonte. Se houvesse mais sub-grupos do vetor $\varepsilon_{t}$, e formos investigar a relação de causalidade entre os primeiros dois sub-grupos, digamos, então poderia haver causalidade em horizontes maiores, embora não pode não ser a causalidade no horizonte de um. A razão é intuitiva que pode haver uma relação de causalidade cadeia que vai do sub-grupo causando a um terceiro sub-grupo e, em seguida, em um período posterior a partir deste terceiro sub-grupo para o sub-grupo para ser causado. Assim, a restrição de apenas dois sub-grupos significa que podemos restringir a nossa atenção para um horizonte de um período, que notadamente é conveniente.

Primeiro, defina os conjuntos de índices $\tau=\left(i_{1}, \ldots, i_{k}\right)$ e $v=\left(j_{1}, \ldots, j_{K-k}\right)$ onde $\tau \cup v=\left(i_{1}, \ldots, i_{K}\right)$ e $\tau \cap v=\emptyset$. Vamos investigar a questão de saber se as variáveis indexadas por $v$ causam as variáveis indexadas por $\tau$. Foram definidos os sub-vetores de $\varepsilon_{t}$ por 
$\varepsilon_{t}^{\tau}=\left(\varepsilon_{t, i_{1}}, \ldots, \varepsilon_{t, i_{k}}\right)^{\prime} \mathrm{e} \varepsilon_{t}^{v}=\left(\varepsilon_{t, j_{1}}, \ldots, \varepsilon_{t, j_{K-k}}\right)^{\prime}$,e temos $\eta_{t}^{\tau}=v e c h\left(\varepsilon_{t}^{\tau} \varepsilon_{t}^{\tau^{\prime}}\right)$, que é um vetor de comprimento $k^{*}=k(k+1) / 2$. As $\sigma$-álgebras geradas por $\varepsilon_{s}^{\tau}$ e $\varepsilon_{s}^{v}, s \leq t$, são indicados por $\mathcal{F}_{t}^{\tau}$ e $\mathcal{F}_{t}^{v}$, respectivamente.

Agora, semelhante a Comte e Lieberman (2000), definimos causalidade na variância e causalidade linear da variância. Dizemos que:

- $\varepsilon_{s}^{v}$ não causa $\varepsilon_{s}^{\tau}$ na variância, denotado por $\varepsilon_{s}^{v} \stackrel{V}{\not \rightarrow} \varepsilon_{s}^{\tau}$ se $\operatorname{Var}\left(\varepsilon_{t}^{\tau} \mid \mathcal{F}_{t-1}\right)=\operatorname{Var}\left(\varepsilon_{t}^{\tau} \mid \mathcal{F}_{t-1}^{\tau}\right)$

- $\varepsilon_{s}^{v}$ não causa $\varepsilon_{s}^{\tau}$ linearmente a variância, denotado por $\varepsilon_{s}^{v} \stackrel{L V}{\not \rightarrow} \varepsilon_{s}^{\tau}$ se $P\left(\eta_{t}^{\tau} \mid \mathcal{H}_{t-1}\right)=$ $P\left(\eta_{t}^{\tau} \mid \mathcal{H}_{t-1}^{\tau}\right)$

\subsubsection{Teste CCF}

Com base nos quadrados dos resíduos $\hat{\xi}_{i, t}^{2}=u_{i, t}^{2} / \hat{\sigma}_{i, t}^{2}$ onde $\hat{\sigma}_{i, t}^{2}$ é a variância condicional estimada de $u_{i, t}$ usando GARCH univariado, Cheung e Ng (1996) introduziram uma estatística manual para testar a hipótese nula de não causalidade na variância,

$$
H_{0}: \varepsilon_{j, t} \stackrel{V}{\not \rightarrow} \varepsilon_{i, t}, \forall i \in \tau, \forall j \in v
$$

A estatística de teste baseia-se na relação cruzada da amostra e é lida como

$$
P_{m}=T \sum_{l=1}^{m} r_{i j, l}^{2}, i \in \tau, j \in v
$$

Onde

$$
r_{i j, l}=\frac{c_{i j, l}}{\sqrt{c_{i i, 0} c_{j j, 0}}}, c_{i j, l}=\frac{1}{T} \sum_{t=1}^{T}\left(\xi_{i, t}^{2}-\bar{\xi}_{i}^{2}\right)\left(\xi_{j, t-1}^{2} \bar{\xi}_{j}^{2}\right)
$$

E onde, $\bar{\xi}_{i}^{2}=T^{-1} \sum_{t=1}^{T} \xi_{i, t}^{2}$

Na prática, a escolha de $m$ deve permitir cobrir o maior potencial de defasagem da casualidade na variância. Cheung e Ng (1996) provaram que sob estimativa consistente de parâmetros GARCH univariadas $P_{m}$ segue assintoticamente a distribuição $\chi_{m}^{2}$ sob a hipótese nula. Estatísticas análogas podem ser definidos para testar a hipótese de causalidade bidireccional.

O teste CCF tem a característica atraente para ser facilmente calculável. Uma desvantagem, no entanto, é que a ordem $m$ tem de ser determinada. Se $m$ escolhido é muito pequeno, pode-se perder causalidades em desfasamentos mais elevadas, se for escolhido demasiado grande, os graus de aumento de liberdade e, portanto, o poder do teste diminui. O teste CCF tem é considerado de pouco poder, se a alternativa é GARCH multivariada, independentemente da escolha de $m$. 


\subsubsection{Teste $\mathrm{HH}$}

A não causalidade em variância está associada a um certo conjunto de restrições que zeram alguns valores das matrizes $A_{j}$ e $B_{j}$ em

$$
\operatorname{vech}\left(\Sigma_{t \mid t-1}\right)=A_{0}+\sum_{j=1}^{q} A_{j} \operatorname{vech}\left(u_{t-j} u_{t-j}^{\prime}\right)+\sum_{j=1}^{m} B_{j} \operatorname{vech}\left(\Sigma_{t-j \mid t-j-1}\right)
$$

Para encontrar essas restrições, primeiramente definimos o índice

$$
k_{i j}^{K}=i+(j-1)\left(K-\frac{j}{2}\right)
$$

para $i j \in \tau \cup v$ e $i \geq j$ que é a posição do $(i, j)$-th elemento da matriz $\mathrm{M}$ simétrica $(K \times K)$ no vetor vech $(M)$. Lembrando que vech $(M)$ contém $K^{*}=\frac{K(K+1)}{2}$ elementos. Além disso, definimos os conjuntos de índices

$$
\tau^{*}=\left\{k_{i j}^{K} \mid i, j \in \tau\right\}
$$

$\mathrm{e}$

$$
v^{*}=\left\{1, \ldots, K^{*}\right\} \mid \tau^{*}
$$

A partir dessas notações, podemos agora definir as condições para a não causalidade na variância. Consideremos as duas condições a seguir

$$
\left[\Phi_{n}\right]_{i j}=0, \forall n \geq 1, \forall i \in \tau^{*}, \forall j \in v^{*}
$$

$\mathrm{e}$

$$
\left[A_{a}\right]_{i j}=0, a=1, \ldots, q,\left[B_{b}\right]_{i j}=0, b=1, \ldots, p, \forall i \in \tau^{*}, \forall j \in v^{*}
$$

Supomos agora que $\tilde{Q}$ é uma matriz de dimensão $k(K-k) \times(K)^{2}$, de posto $k(K-k)$. Os $(r, \varpi)$ elementos de $\tilde{Q}$ são definidos por

$$
\tilde{Q}_{r, \varpi}=\left\{\begin{array}{l}
1, \varpi=s_{m n} \\
0, \varpi \neq s_{m n}
\end{array}\right.
$$

Onde $r=m+(n-1), s_{m n}=i_{m}+\left(j_{n}-1\right) K, i_{m} \in \tau, j_{n} \in v$, e $m=1, \ldots, k$, $n=1, \ldots, K-k$. 
A hipótese nula de ausência de causalidade no modelo BEKK agora pode ser escrita como

$$
H_{0}: Q v=0
$$

$\operatorname{Com} v=\left[\operatorname{vech}\left(A_{0}^{*}\right), \operatorname{vech}\left(A_{j n}^{*}\right)^{\prime}, \operatorname{vech}\left(B_{j n}^{*}\right)\right]^{\prime}$ e $Q=\left[0_{k(K-k) \times(K)}, \tilde{Q}, \tilde{Q}\right]$.

Suponha agora que temos $\mathrm{T}$ observações $u_{1}, \ldots, u_{T}$. Nós assumimos a seguir que o verdadeiro processo é conhecido como pertencendo à classe BEKK, conforme Comte e Lieberman (2003). Denotamos um estimador consistente do verdadeiro vetor de parâmetros $\vartheta_{0}$ por $\hat{\vartheta}$ e assumimos que a sua distribuição assintótica é dada por

$$
\sqrt{T}\left(\hat{\vartheta}-\vartheta_{0}\right) \stackrel{\text { ass }}{\longrightarrow} N\left(0, \Omega_{\vartheta}\right)
$$

Com alguma matriz definida e simétrica positiva $\Omega_{\vartheta}$. Consideremos também que uma estimador consistente de $\Omega_{\vartheta}$ é dado por $\hat{\Omega_{\vartheta}}$. Então $\sqrt{T}\left(\hat{\vartheta}-\vartheta_{0}\right) \stackrel{\ell}{\longrightarrow} N\left(0, \Omega_{\vartheta}\right)$ mantém em condições de regularidade listados por Comte e Lieberman (2003), e $\Omega_{\vartheta}$ é dado por

$$
\Omega_{\vartheta}=S^{-1} D S^{-1}
$$

Onde

$$
D=E\left[\left.\frac{\partial l_{t}(\vartheta)}{\partial \vartheta} \frac{\partial l_{t}(\vartheta)}{\partial \vartheta^{\prime}}\right|_{\vartheta_{0}}\right], S=-E\left[\left.\frac{\partial^{2} l_{t}(\vartheta)}{\partial \vartheta \partial \vartheta^{\prime}}\right|_{\vartheta_{0}}\right]
$$

Com

$$
l_{t}(\vartheta)=-\frac{K}{2} \ln (2 \pi)-\frac{1}{2} \ln \left|\Sigma_{t \mid t-1}(\vartheta)\right|-\frac{1}{2} v_{t}^{\prime} \Sigma_{t \mid t-1}^{-1}(\vartheta) v_{t}
$$

Hafner e Herwartz (2008) forneceram expressões para $D$ e $S$ e de suas estimativas. Para os testes de significância Hafner e Herwartz (2008) mostram que a utilização de técnicas analíticas expressões para $\Omega_{\vartheta}$ é de longe superior ao uso de derivados numéricos em termos de tamanho empírico e poder de estimativas.

Propomos a seguinte estatística Wald padrão para testar as hipóteses $H_{0}: Q v=0$,

$$
W_{T}=T(Q \hat{\vartheta})^{\prime}\left(Q \hat{H}_{\vartheta} Q^{\prime}\right)^{-1}(Q \hat{\vartheta})
$$

Usando $\sqrt{T}\left(\hat{\vartheta}-\vartheta_{0}\right) \stackrel{a s s}{\longrightarrow} N\left(0, \Omega_{\vartheta}\right)$ e a proposição de Lütkepohl (1993), a distribuição assintótica da estatística Wald é dada por

$$
W_{T} \stackrel{a s s}{\longrightarrow} \chi_{k(K-k)}^{2}
$$


Uma estatística análoga pode ser definida para o modelo Diagonal VEC com base na hipótese nula $H_{0}: Q v=0$, desde que as condições de normalidade assintótica dos estimadores forem atendidas. Note-se que os graus de liberdade da estatística de Wald para o modelo Diagonal VEC seria $k^{*}\left(K^{*}-k^{*}\right)$.

\subsection{Análise de Componentes Principais e Estudo de Outliers Multivariados}

$\mathrm{Na}$ análise multidimensional há uma área que estuda a identificação de observações discordantes. Pela impossibilidade de uma ordenação única dos dados multivariados, a seleção e a detecção de outliers numa perspectiva multidimensional tem grande limitação. Porém, algumas subordens podem ser usadas no sentido de permitir a seleção de observações discordantes. Os principais resultados desse estudo aparece em Barnett (1976).

Existem particularidades na identificação de outliers que são verificadas apenas em dados multivariados. A primeira corresponde à necessidade de 'reformular' a noção de 'afastamento em relação aos restantes' para uma perspectiva multivariada. Mas essa ordenação é uma característica univariada e que se perde desde a dimensão dois.

Outra dificuldade surge em censos, em estudos de opinião ou em tabelas de contingência. Estas são as três áreas onde se desenvolvem os estudos mais recentes do estudo de outliers em dados estatísticos.

Com grandes volumes de dados multivariados é importante encontrar representações simples que permitam construir uma 'sensibilidade' sobre o comportamento de cada observação em relação às restantes. Os resíduos - entendidos na generalidade como afastamentos que tanto podem ser construídos numa análise em componentes principais como num modelo de regressão multivariada - podem ser usados para esse fim.

A escolha do número de 'fatores a reter', no contexto duma simplificação da complexidade dimensional através de uma Análise de Componentes Principais (ACP), tem sido objeto de numerosos critérios, em que geralmente são necessárias opções de natureza subjetiva por parte do utilizador. Esta subjetividade também pode influenciar o estudo de outliers multivariados.

A ACP consiste na procura da maior parte de explicação para a variabilidade global dos dados, entendida como a soma das variâncias de todas as variáveis. No processo as variáveis originais são transformadas em novas variáveis denominadas componentes principais, através de um transformação e com o objetivo estratégico destas terem variâncias decrescentes. As características mais relevantes dos componentes principais, e que as tornam mais importantes que as variáveis originais, são: a não correlação e a quantidade de informação retida. Por construção, as componentes principais são ortogonais entre si. Assim, cada componente traz uma informação estatística diferente das restantes. Além disso, cada componente maximiza aquela 
informação.

Recomenda-se que se faça uma ACP preliminar aos dados em estudo e que se analisem as projeções das observações nas componentes principais de diferentes ordens. Como a última componente principal tem a menor variância é sobre ela que deve recair a maior importância para detecção de observações que se afastem e discordem das restantes.

Uma questão fundamental para uma análise de dados multivariados é a de quantos componentes devemos reter em uma ACP. Para o estudo de outliers multivariados as primeiras componentes principais são 'sensíveis' à presença de observações discordantes que se liguem a dados com variâncias ou covariâncias inflacionadas. Por sua vez, as últimas permitem identificar perturbações nos resíduos.

Nesse contexto, comecemos analisando como as componentes condicionam e são decisivas para encontrar outliers multivariados. Uma ACP pode ser interpretada como o ajustamento aos dados de um conjunto de hiperplanos ortogonais minimizando a soma dos quadrados dos desvios ortogonais das observações a cada um daqueles planos. Consideremos o vetor aleatório $\mathbf{x}=\left(X_{1}, \ldots, X_{p}\right)$ das observações num espaço de dimensão $p$. Admitamos $\mathbf{x}$, em geral, com valor médio e matriz de covariâncias.

O novo grupo de variáveis, as componentes principais $C_{1}, \ldots, C_{p}$ têm variâncias decrescentes e são não correlacionadas com $X_{1}, \ldots, X_{p}$. Supõe-se ainda que cada componente $C_{i}$ é uma combinação linear das variáveis $X_{i}$ pelo que $C_{i}=\mathbf{c}_{i}^{t} \mathbf{x}_{i} i=1, \ldots, p$ onde $\mathbf{c}_{i}$ é um vetor de constantes. Uma vez que, no cálculo, cada vetor é arbitrário pode impor-se a condição de normalização $\mathbf{c}_{i}^{t} \mathbf{c}_{i}=1$. Esta condição garante que a transformação das componentes principais é ortogonal e que, portanto, são mantidas as distâncias no espaço de dimensão $p$.

Sendo assim, infere-se que os resíduos podem ser importantes. Os componentes principais devem ser determinados pelo valor decrescente das respectivas variâncias. Devemos portanto calcular $\mathbf{c}_{1}$ de modo que $C_{1}$ tenha variância máxima e sujeita à condição de normalização acima referida. Assim, podemos fazer uso dos resíduos para posterior estudo de eventuais observações discordantes.

Na metodologia de multiplicadores de Lagrange e pela sua relação com a variância das componentes, principalmente as selecionadas para representar a maior variabilidade dos dados, os valores próprios $\lambda_{i}(i=1,2, \ldots, p)$, da matriz fatorizada, são bastante importantes no estudo da discordância nas observações. Para a avaliação da importância, vários testes podem ser efetuados sobre os valores próprios. Os cálculos efetuados garantem ainda que as constantes determinadas para a primeira componente principal são as coordenadas do vetor próprio $\mathbf{c}_{1}$ correspondente ao maior valor próprio. Para a segunda componente principal um estudo análogo conduz a relevar o segundo maior valor próprio, etc. A metodologia assim definida vai permitir construir todas as $p$ componentes principais.

Note, quer os valores próprios, quer os vetores próprios da matriz fatorizada (de covari- 
âncias $S$ ou de correlações $R$ ) devem ser utilizadas para análise de valores discordantes numa amostra. Se representarmos por $C$ a matriz $(p \times p)$ dos vetores próprios e porque os valores próprios são iguais às variâncias das componentes temos, para os traços das diferentes matrizes envolvidas nos cálculos:

$$
\operatorname{tr}(S)(\text { ou } \operatorname{tr}(R))=\operatorname{tr}(C)=\sum_{i=1}^{p} \lambda_{i}=\sum_{i=1}^{p} \operatorname{var}\left(X_{i}\right)
$$

Verificamos assim que, a transformação envolvendo as componentes principais, mantém a soma das variâncias das variáveis originais e das transformadas. Este é um resultado importante que também fundamenta a aplicação da ACP na pesquisa de observações discordantes pois a transformação que lhe está associada mantém a variabilidade dos dados. Podemos portanto 'medir' a importância de cada componente através da percentagem da variação total nos dados que, por ela, é explicada. De pretendermos que cada componente tenha valor médio nulo devemos usar uma constante adequada que obviamente vai envolver a média amostral $\bar{x}$. Através de $\mathbf{c}=C^{t}(x-\bar{x})$ obtém-se as componentes.

Para um dado indivíduo $x_{i}$ tem-se agora o correspondente vetor observado $\mathbf{z}_{i}=C^{t}\left(x_{i}-\bar{x}\right)$ cujas coordenadas são vulgarmente chamadas 'scores'. Estes valores podem ser usados para a pesquisa e seleção de eventuais outliers multivariados na amostra.

Se for $X$ a matriz dos dados enta $Z=C^{t} X$ é chamada transformação das componentes principais e cada uma das colunas da matriz $C$ permite a determinação dos 'scores' enquanto cada linha de $Z$ mostra os desvios das projeções da amostra original no centroide, em relação a uma determinada componente principal.

Como sabemos, uma questão importante na detecção de um outliers multivariado é o fato de essa observação poder não ser extrema em nenhuma das variáveis mas 'tornar-se' discordante pela conjugação dessas variáveis na estrutura de dependência interna dos dados. Assim, perante aquela realidade estatística, o estudo de cada variável constituinte de uma observação, torna-se um instrumento exploratório com vista à identificação de outliers multivariados.

Quando usamos o ACP com o objetivo de ajustamento a uma dimensão menor e a consequente detecção de outliers a nossa atenção deve, principalmente, deter-se nas projeções dos dados sobre as componentes que correspondem aos menores valores próprios (isto é, as últimas linhas da matriz $Z$ ).

Para os componentes principais utiliza-se o método que minimiza as distâncias horizontais entre cada ponto coordenado e reta estabelecida pelo eixo latente. A definição dos componentes principais é baseada na maximização de sua variância. No entanto, o máximo da variância do componente principal não existe, pois na medida em que os componentes do vetor de coeficientes $\mathbf{e}_{i}$ crescem, a variância crescerá para o infinito. Assim, devemos impor a restrição de que a soma ao quadrado dos coeficientes do vetor, que estabelece a combinação linear dos componentes principais, seja igual à unidade. Assim, devemos maximizar a variância $\operatorname{Var}\left(Y_{i}\right)=\mathbf{e}_{i}^{\top} \Sigma \mathbf{e}_{i}$ com relação ao vetor $\mathbf{e}_{i}$, sujeito à restrição de $\mathbf{e}_{i}^{\top} \mathbf{e}_{i}=1$. Para isso, podemos utilizar a técnica de 
multiplicadores de Lagrange, na qual devemos maximizar:

$$
\max _{\mathbf{e}_{i}}\left[\mathbf{e}_{i}^{\top} \Sigma \mathbf{e}_{i}-\lambda_{i}\left(\mathbf{e}_{i}^{\top} \mathbf{e}_{i}-1\right)\right]
$$

com relação a $\mathbf{e}_{i}$, sendo $\lambda_{i}$ o multiplicador de Lagrange.

Uma abordagem mais tradicional impõe a restrição de outra forma dividindo a função original por $\mathbf{e}_{i}^{\top} \mathbf{e}_{i}$ resultando em uma função que devemos maximizar da seguinte forma:

$$
\lambda_{i}=\max _{\mathbf{e}_{i}} \frac{\mathbf{e}_{i}^{\top} \Sigma \mathbf{e}_{i}}{\mathbf{e}_{i}^{\top} \mathbf{e}_{i}}
$$

Para obtermos o máximo, em ambos os casos, derivamos a função resultante em relação a $\mathbf{e}_{i}$ e igualamos o sistema a zero, que após sofrer algumas simplificações resulta em:

$$
\left(\Sigma-\lambda_{i} \mathbf{I}\right) \mathbf{e}_{i}=\mathbf{0}
$$

em que I é uma matriz identidade $p \times p$. Desse de equações anterior verificamos a seguinte relação

$$
\Sigma \mathbf{e}_{i}=\lambda_{i} \mathbf{e}_{i}
$$

de onde podemos mostrar que

$$
\operatorname{Var}\left(Y_{i}\right)=\mathbf{e}_{i}^{\top} \Sigma \mathbf{e}_{i}=\mathbf{e}_{i}^{\top} \lambda_{i} \mathbf{e}_{i}=\lambda_{i} \mathbf{e}_{i}^{\top} \mathbf{e}_{i}=\lambda_{i}
$$

e também que

$$
\operatorname{Cov}\left(Y_{i}, Y_{k}\right)=\mathbf{e}_{i}^{\top} \Sigma \mathbf{e}_{k}=\mathbf{e}_{i}^{\top} \lambda_{k} \mathbf{e}_{k}=\lambda_{k} \mathbf{e}_{i}^{\top} \mathbf{e}_{k}=0, i \neq k
$$

uma vez que $\mathbf{e}_{i}$ e $\mathbf{e}_{k}$ são ortogonais.

Da observação do sistema $\Sigma \mathbf{e}_{i}=\lambda_{i} \mathbf{e}_{i}$ podemos concluir que a definição dos componentes principais, é na verdade, a obtenção dos autovalores e autovetores da matriz $\Sigma$. Os autovetores $\mathbf{e}_{i}(i=1,2,3, \ldots, p)$ representam o sentido da rotação dos eixos coordenados definidos pelas variáveis desses novos eixos coordenados. Como as covariâncias são nulas entre os diferentes pares de eixos, os novos eixos, que são os componentes principais, são ortogonais e, portanto, representam uma rotação rígida dos eixos originais. Em geral, escolhemos o componentes o componente principal de maior importância como sendo aquele de maior variância $\left(\max _{i} \lambda i\right)$, o segundo componente de maior importância, o que apresentar a segunda maior variância e assim 
sucessivamente, até o componente principal de menor importância. Se fizermos $\lambda_{1} \geq \lambda_{2} \geq$ $\lambda_{3} \ldots \geq \lambda_{p}$, teremos definido os componentes principais $Y_{1}=\mathbf{e}_{1}^{\top} \mathbf{X}, Y_{2}=\mathbf{e}_{2}^{\top} \mathbf{X}, \ldots, Y_{p}=\mathbf{e}_{p}^{\top} \mathbf{X}$, respectivamente. Dessa forma, temos tantos componentes principais quanto variáveis originais.

Se utilizarmos a decomposição espectral da matriz $\Sigma$, dada por $\Sigma=P \Lambda P^{\top}$, em que $\mathbf{P}$ é a matriz composta pelos autovetores de $\Sigma$ em suas colunas e $\Lambda$, a matriz diagonal de autovalores de $\Sigma$, então podemos observar que

$$
\operatorname{tr}(\Sigma)=\operatorname{tr}\left(P \Lambda P^{\top}\right)=\operatorname{tr}\left(\Lambda P^{\top} P\right)=\operatorname{tr}(\Lambda I)=\operatorname{tr}(\Lambda)=\sum_{i=1}^{p} \lambda_{i} .
$$

Mas, $\operatorname{tr}(\Sigma)$ é obviamente dada pela soma dos elementos da diagonal, ou seja,

$$
\operatorname{tr}(\Sigma)=\sum_{i=1}^{p} \sigma_{i i}
$$

de onde concluímos que

$$
\sum_{i=1}^{p} \sigma_{i i}=\sum_{i=1}^{p} \lambda_{i}
$$

que significa que a variabilidade total contida nas variáveis originais é igual à variabilidade total contida nos componentes principais.

Se tivermos $k<p$ componentes principais na tentativa de gerarmos um modelo mais parcimonioso para a matriz de covariância populacional, devemos nos basear em algum critério que nos informe quanto da variabilidade total foi explicada por ele. Para apresentarmos um critério como esse, vamos considerar inicialmente que o vetor de componentes principais $\mathbf{Y}=$ $\left[Y_{1}, Y_{2}, \ldots, Y_{p}\right]^{\top}$ pode ser obtido de forma vetorial por

$$
\mathbf{Y}=\mathbf{P}^{\top} \mathbf{X}
$$

Como a matriz $\mathbf{P}$ é ortogonal, sua inversa é igual à sua transposta, portanto o vetor $\mathbf{X}$ pode ser recuperado pela transformação não singular

$$
\mathbf{X}=\mathbf{P Y}
$$

Assim, de reduzirmos o número de variáveis transformadas, componentes principais, para $k<p$, teremos o vetor $\mathbf{Y}=\left[Y_{1}, Y_{2}, \ldots, Y_{k}\right]^{\top}(k \times 1)$ e se assumirmos que os $k$ primeiros autovetores da matriz $\mathbf{P}$ sejam utilizados para compor a matriz $\mathbf{P}_{k}(p \times k)$, teremos

$$
\mathbf{Y}=\mathbf{P}_{k}^{\top} \mathbf{X}
$$

Podemos obter a matriz inversa generalizada de $\mathbf{P}_{k}^{\top}$, utilizando a decomposição no valor singular. É fácil percebermos que a inversa generalizada de $\mathbf{P}_{k}^{\top}$ é a própria matriz $\mathbf{P}_{k}$, devido 
à ortonormalidade por coluna de $\mathbf{P}_{k}$. Assim, podemos recuperar as observações originais com determinado grau de precisão, o que depende de quão adequado o modelo parcimonioso tenha ajustado a matriz de covariâncias populacional. Assim, as observações das variáveis originais podem ser preditas pelo modelo escolhido da seguinte forma:

$$
\tilde{X}=\mathbf{P}_{k} \mathbf{Y}
$$

Podemos, ainda, observar que a covariância do vetor

$$
\mathbf{Y}(p \times 1)
$$

de componentes principais é dada por

$$
\operatorname{Cov}(\mathbf{Y})=\operatorname{Cov}\left(\mathbf{P}^{\top} \mathbf{X}\right)=\mathbf{P}^{\top} \operatorname{Cov}(\mathbf{X}) \mathbf{P}=\mathbf{P}^{\top} \Sigma \mathbf{P}=\mathbf{P}^{\top} \mathbf{P} \Lambda \mathbf{P}^{\top} \mathbf{P}=\Lambda
$$

Assim, como a variância total é igual ao traço da matriz de covariâncias, então a variância total contida nas variáveis originais é igual ao traço de $\Sigma$ que é $\operatorname{tr}(\Sigma)=\sum_{i=1}^{p} \sigma_{i i}$. Da mesma forma, a variância total de $\mathbf{Y}$ é igual a $\operatorname{tr}(\Lambda)=\sum_{i=1}^{p} \lambda_{i i}$. Verificamos, da relação estabelecida na equação $\sum_{i=1}^{p} \sigma_{i i}=\sum_{i=1}^{p} \lambda_{i}$, que a variabilidade total contida nas variáveis originais é preservada nas variáveis transformadas, componentes principais. Quando adotamos o modelo parcimonioso, com $k<p$ componentes principais, temos que a covariância do vetor $\mathbf{Y}(k \times 1)$ é

$$
\operatorname{Cov}(\mathbf{Y})=\operatorname{Cov}\left(\mathbf{P}_{k}^{\top} \mathbf{X}\right)=\mathbf{P}_{k}^{\top} \operatorname{Cov}(\mathbf{X}) \mathbf{P}_{k}=\mathbf{P}_{k}^{\top} \Sigma \mathbf{P}_{k}=\mathbf{P}_{k}^{\top} \mathbf{P} \Lambda \mathbf{P}^{\top} \mathbf{P}_{k}=\Lambda_{k}
$$

em que

$$
\Lambda_{k}=\left[\begin{array}{cccc}
\lambda_{1} & 0 & \cdots & 0 \\
0 & \lambda_{2} & \cdots & 0 \\
\vdots & \vdots & \ddots & \vdots \\
0 & 0 & \cdots & \lambda_{k}
\end{array}\right]
$$

Portanto, a variância total do vetor $\mathbf{Y}(k \times 1)$ é $\operatorname{tr}\left(\Lambda_{k}\right)=\sum_{i=1}^{k} \lambda_{i}$. Podemos estabelecer que explicação do modelo reduzido em relação ao modelo completo pode ser obtida pela relação das variâncias dos dois modelos, ou seja, quanto da variação total das variáveis originais é explicada pelo modelo de $k$ componentes principais. Essa proporção acumulada da explicação da variação total, expressa em porcentagem, é formalmente dada por

$$
\rho_{k}^{2}=\frac{\sum_{i=1}^{k} \lambda_{i}}{\sum_{i=1}^{p} \sigma_{i i}} \times 100
$$


A explicação individual de cada componente pode também ser considerada. Podemos obter a proporção da explicação do K-ésimo componente principal por

$$
P_{k}^{2}=\frac{\lambda_{k}}{\sum_{i=1}^{p} \sigma_{i i}} \times 100
$$

Como base na proporção de explicação da variância total, que o modelo de K componentes principais é responsável, podemos determinar o número de componentes devemos reter. Em muitos casos, as evidências empíricas e científicas nos conduzem a utilizar o critério de reter um número $k<p$ de componentes principais que contemplem pelo menos $70 \%$ da variação total. Algumas vezes, impomos um pouco mais de rigor e adotamos modelos que expliquem pelo menos $80 \%$ da variação total. Se o número mínimo de componentes $k$ para explicar a proporção mínima da variação total for muito grande, em muitas aplicações práticas não haverá vantagem em utilizar o método dos componentes principais. Segundo Timm (1980) quando maximizamos a forma quadrática que representa a variância do componente principal, também maximizamos a média geométrica das variâncias dos componentes principais, que equivale a maximizar a média geométrica dos autovalores de $\Sigma$ dada por

$$
\bar{\lambda}_{g}=\sqrt[p]{|\Sigma|}=\sqrt[p]{\prod_{i=1}^{p} \lambda_{i}}
$$

Uma outra propriedade interessante é a da ortogonalidade dos componentes principais, pois como podemos verificar $\mathbf{P}^{\top} \mathbf{P}=\mathbf{I}$. Assim, os componentes principais são mutuamente ortogonais. Da mesma forma, podemos mostrar que os componentes principais são não-ortogonais mutuamente, pois $\operatorname{Cov}(\mathbf{Y}=\Lambda$, que é uma matriz diagonal. A primeira propriedade confere aos componentes principais a capacidade de preservar as distâncias dos pontos coordenados originais para a origem invariante e maximiza suas variâncias. Muitas vezes, optamos poe expressar os componentes principais em escalas padronizadas e centrados em $\mathbf{0}$ da seguinte forma

$$
\mathbf{Y}^{*}=\Lambda^{-1 / 2} \mathbf{P}^{\top}(\mathbf{X}-\mu)=\left[\begin{array}{c}
\frac{\sum_{i=1}^{p} e_{1 i}\left(X_{i}-\mu_{i}\right)}{\sqrt{\lambda_{1}}} \\
\frac{\sum_{i=1}^{p} e_{2 i}\left(X_{i}-\mu_{i}\right)}{\sqrt{\lambda_{2}}} \\
\vdots \\
\frac{\sum_{i=1}^{p} e_{p i}\left(X_{i}-\mu_{i}\right)}{\sqrt{\lambda_{p}}}
\end{array}\right]
$$

Esses componentes principais são os componentes principais padronizados, ou seja, possuem média nula $E\left(\mathbf{Y}^{*}\right)=0$ e covariância igual à identidade $\operatorname{Cov}\left(\mathbf{Y}^{*}\right)=\mathbf{I}$.

Após obtermos os componentes principais, desejamos avaliar o grau de associação existente entre eles e as varáveis originais. Para isso podemos inicialmente obter a covariância entre o vetor de variáveis originais e os componentes principais por 


$$
\operatorname{Cov}(\mathbf{Y}, \mathbf{X})=\operatorname{Cov}\left(\mathbf{P}^{\top} \mathbf{X}, \mathbf{X}\right)=\mathbf{P}^{\top} \operatorname{Cov}(\mathbf{X})=\mathbf{P}^{\top} \Sigma=\Lambda \mathbf{P}^{\top}
$$

De acordo com essa expressão, verificamos que a covariância entre a k-ésima variável original e o i-ésimo componente principal é dada pelo produto entre i-ésimo autovetor de $\Sigma$ e o k-ésimo autovetor, ou seja, por $\operatorname{Cov}\left(Y_{i}, X_{i}\right)=\lambda_{i} e_{i K}$. Então, podemos nesse instante, determinar a matriz de correlação entre o vetor de componentes principais e o vetor de variáveis originais por

$$
\rho_{Y, X}=\Lambda^{-1 / 2} \Lambda \mathbf{P}^{\top} \mathbf{V}^{-1 / 2}=\Lambda^{1 / 2} \mathbf{P}^{\top} \mathbf{V}^{-1 / 2}
$$

em que $\mathbf{V}=\operatorname{diag}(\sigma i i)$. A i-ésima linha e a k-ésima coluna dessa matriz de correlações contêm o coeficiente de correlação $\left(\rho_{Y_{i}, X_{k}}\right)$ entre $Y_{i}$ e $X_{k}$, dado de forma escalar por

$$
\rho_{Y_{i}, X_{k}}=\frac{\sqrt{\lambda_{i}} e_{i k}}{\sqrt{\sigma_{k k}}}
$$

A extração de componentes principais da matriz de covariâncias $\Sigma$ representa a essência e o objetivo natural do método dos componentes principais, especialmente se eles devem ser utilizados posteriormente em outras análises. No entanto, em algumas situações o efeito da escala das variáveis pode fazer com que haja predominância na representação dos componentes principais por parte de algumas variáveis com grande variâncias. As demais variáveis irão contribuir muito pouco. os componentes principais podem, nessas situações, ser definidos em uma modelagem da matriz de correlação populacional $\rho$ ao invés da matriz de covariâncias $\Sigma$. Vamos utilizar o mesmo tipo de notação para representar os autovalores e autovetores dos dois parâmetros, $\rho$ ou $\Sigma$. O contexto particular é que irá definir o significado dessas representações.

A mudança de escala, de apenas uma parte das variáveis contidas no vetor de variáveis originais $\mathbf{X}$, provoca mudanças nas componentes principais de $\Sigma$. Assim, dizemos que os componentes principais de $\Sigma$ são invariantes às mudanças de escalas. Se utilizarmos uma transformação do tipo $\mathbf{X}^{*}=\Delta \mathbf{X}$, em que $\Delta$ representa uma matriz diagonal $p \times p$, veremos que os componentes principais de $\Sigma$ e os da matriz de covariâncias do vetor $\mathrm{X}^{*}$, dada por $\Delta \Sigma \Delta$, não são os mesmos, pois as equações características $\left|\Sigma-\lambda_{i} \mathbf{I}\right|=0$ e $\left|\Delta \Sigma \Delta-\lambda_{i} \mathbf{I}\right|=0$ não possuem a mesma solução. Se escolhermos a matriz $\Delta$ por $\mathbf{V}^{-1 / 2}$ e ainda realizarmos uma padronização de posição da seguinte forma

$$
\mathbf{Z}=\mathbf{V}^{-1 / 2}(\mathbf{X}-\mu)
$$

teremos a seguinte matriz de covariâncias do vetor aleatório padronizado $\mathbf{Z}$

$$
\operatorname{Cov}(\mathbf{Z})=\mid \mathbf{V}^{-1 / 2} \operatorname{Cov}(\mathbf{X}-\mu) \mathbf{V}^{-1 / 2}=\mathbf{V}^{-1 / 2} \Sigma \mathbf{V}^{-1 / 2}=\rho,
$$


em que $\mathbf{V}^{-1 / 2}=\operatorname{diag}\left(1 / \sqrt{\sigma_{i i}}\right)$.

Se sempre utilizarmos essa padronização, independentemente da escala original das variáveis, teremos que a matriz de covariâncias do vetor aleatório $\mathbf{Z}$ padronizado em posição e em escala, será igual à matriz de correlações populacional $\rho$. Assim, se modelarmos as variáveis aleatórias do vetor $\mathbf{Z}$ pelo modelo de componentes principais

$$
Y_{i}=\mathbf{e}_{i}^{\top} \mathbf{Z}=e_{i 1} Z_{1}+e_{i 2} Z_{2}+\ldots+e_{i p} Z_{p}
$$

estaremos modelando a matriz de correlação populacional $\rho$ da seguinte forma

$$
\rho=\mathbf{P} \Lambda \mathbf{P}^{\top}
$$

em que $\mathbf{P}$ e $\Lambda$, representam as matrizes de autovetores $(p \times p)$ e diagonal de autovalores respectivamente, da matriz $\rho$.

Os componentes principais de $\rho$ são invariantes às mudanças de escalas das variáveis que compõem o vetor aleatório $\mathbf{X}$, em que consequência da matriz $\rho$, por si só, ser invariante às mudanças de escalas nas variáveis originais. A derivação dos componentes principais das variáveis padronizadas $\mathbf{Z}$ segue as mesmas ideias apresentadas anteriormente para os componentes principais de $\Sigma$. Assim, seja a variância

$$
\operatorname{Var}\left(Y_{i}\right)=\operatorname{Var}\left(\mathbf{e}_{i}^{\top} \mathbf{Z}\right)=\mathbf{e}_{i}^{\top} \operatorname{Var}(\mathbf{Z}) \mathbf{e}_{i}=\mathbf{e}_{i}^{\top} \rho \mathbf{e}_{i}
$$

Da mesma forma, devemos maximizar a variância $\operatorname{Var}\left(Y_{i}\right)=\mathbf{e}_{i}^{\top} \rho \mathbf{e}_{i}$ com relação a $\mathbf{e}_{i}$, sujeito à restrição de $\mathbf{e}_{i}^{\top} \mathbf{e}_{i}=1$. Para isso utilizamos a técnica de multiplicadores de Lagrange, sendo que devemos maximizar a função restrita

$$
\max _{e_{i}}\left[\mathbf{e}_{i}^{\top} \rho \mathbf{e}_{i}-\lambda_{i}\left(\mathbf{e}_{i}^{\top} \mathbf{e}_{i}-1\right)\right]
$$

com relação a $\mathbf{e}_{i}$, sendo $\lambda_{i}$ o multiplicador de Lagrange.

Obtivemos o máximo derivando essa função em relação a $\mathbf{e}_{i}$ e igualando o sistema de equações resultante a zero, que após sofrer algumas simplificações gerou a seguinte solução

$$
\left(\rho-\lambda_{i} \mathbf{I}\right) \mathbf{e}_{i}=0
$$

Assim, concluímos que os componentes principais das variáveis padronizadas são totalmente definidos pelos autovalores e autovetores de $\rho$, conforme já havíamos comentado anteriormente. Assim, os componentes principais representam rotações rígidas dos eixos coordenados padronizados definidos pelas variáveis do vetor $\mathbf{Z}$. O primeiro eixo é definido no 
sentido de maior variabilidade, ou seja, maximizando as distâncias entre os pontos coordenados. O segundo eixo é o perpendicular ao primeiro, mas definido no sentido de maior variabilidade remanescente no sistema coordenado. Os demais eixos são definidos de forma similar. O sentido de cada eixo é determinado pelos autovetores da matriz $\rho$ e a variabilidade, pelos autovalores. Como as demais demonstrações seguem os mesmos princípios e propriedades vistas para a matriz $\Sigma$, apresentamos apenas os principais resultados na sequência.

A partir da decomposição espectral da matriz $\rho$, dada na equação $\rho=\mathbf{P} \Lambda \mathbf{P}^{\top}$, podemos obter a seguinte relação

$$
\operatorname{tr}(\rho)=\operatorname{tr}\left(P \Lambda P^{\top}\right)=\operatorname{tr}\left(\Lambda P^{\top} P\right)=\operatorname{tr}(\Lambda I)=\operatorname{tr}(\Lambda)=\sum_{i=1}^{p} \lambda_{i} .
$$

Como $\operatorname{tr}(\rho)$ é obviamente dada pela soma dos elementos da diagonal, ou seja, é dado

$$
\operatorname{tr}(\rho)=\sum_{i=1}^{p} 1=p
$$

concluímos que

$$
\sum_{i=1}^{p} \lambda_{i}=p
$$

que significa que a variabilidade total contida nas variáveis padronizadas $(p)$ é igual à variabilidade total contida nos componentes principais.

$\mathrm{O}$ vetor de componentes principais $\mathbf{Y}=\left[Y_{1}, Y_{2}, \ldots, Y_{p}\right]$ é dado por

$$
\mathbf{Y}=\mathbf{P}^{\top} \mathbf{Z}
$$

Em função de a matriz $\mathbf{P}$ ser ortonormal, o vetor aleatório $\mathbf{Z}$ pode ser recuperado pela transformação não-singular

$$
\mathbf{Z}=\mathbf{P Y}
$$

Podemos reter $k<p$ componentes principais para gerarmos um modelo mais parcimonioso da matriz de correlações populacional. Assim, reduzindo o número de variáveis latentes, componentes principais, para $(k<p)$, teremos o vetor $\mathbf{Y}=\left[Y_{1}, Y_{2}, \ldots, Y_{k}\right](k \times 1)$, e assumindo que os $k$ primeiros autovetores da matriz $\mathbf{P}$ sejam utilizados para compor a matriz $\mathbf{P}_{k}(p \times k)$, obtermos

$$
\mathbf{Y}=\mathbf{P}_{k}^{\top} \mathbf{Z}
$$


A partir da matriz inversa generalizada de $\mathbf{P}_{k}^{\top}$, a matriz $\mathbf{P}_{k}$, recuperamos as observações originais padronizadas com determinado grau de precisão, que depende de quão adequado o modelo reduzido ajustado a matriz de correlações populacional. Assim, as observações das variáveis originais padronizadas podem ser preditas pelo modelo escolhido da seguinte forma

$$
\tilde{\mathbf{Z}}=\mathbf{P}_{k} \mathbf{Y}
$$

Podemos, ainda, observar que a covariância do vetor $\mathbf{Y}(p \times 1)$ de todos os $p$ componentes principais é dada por

$$
\operatorname{Cov}(\mathbf{Y})=\Lambda
$$

Quando adotamos o modelo reduzido, com $(k, p)$ componentes principais, temos que a covariância do vetor $\mathbf{Y}(k \times 1)$ é

$$
\operatorname{Cov}(\mathbf{Y})=\operatorname{Cov}\left(\mathbf{P}_{k}^{\top} \mathbf{Z}\right)=\mathbf{P}_{k}^{\top} \operatorname{Cov}(\mathbf{Z}) \mathbf{P}_{k}=\mathbf{P}_{k}^{\top} \rho \mathbf{P}_{k}=\mathbf{P}_{k}^{\top} \mathbf{P} \Lambda \mathbf{P}^{\top} \mathbf{P}_{k}=\Lambda_{k}
$$

Portanto, a variância total do vetor $\mathbf{Y}(k \times 1)$ é $\operatorname{tr}\left(\Lambda_{k}\right)=\sum_{i=1}^{k} \lambda_{i}$. Assim, a explicação do modelo reduzido em relação ao modelo completo pode ser obtida pela relação das variâncias totais dos dois modelos, ou seja, quanto da variação total das variáveis originais é explicada pelo modelo de $k$ componentes principais. Essa proporção acumulada da explicação da variação total, expressa em porcentagem, é formalmente dada por

$$
\rho_{k}^{2}=\frac{\sum_{i=1}^{k} \lambda_{i}}{p} \times 100
$$

A explicação individual da k-ésimo componente principal pode também ser considerada por

$$
P_{k}^{2}=\frac{\lambda_{k}}{p} \times 100
$$

Após obtermos os componentes principais, desejamos avaliar o grau de associação existente entre eles e as variáveis originais padronizadas. Vamos inicialmente obter a covariância entre o vetor de variáveis originais padronizadas e os componentes principais por

$$
\operatorname{Cov}(\mathbf{Y}, \mathbf{Z})=\operatorname{Cov}\left(\mathbf{P}^{\top} \mathbf{Z}, \mathbf{Z}\right)=\mathbf{P}^{\top} \operatorname{Cov}(\mathbf{Z})=\mathbf{P}^{\top} \rho=\Lambda \mathbf{P}^{\top}
$$

De acordo com essa expressão, verificamos que covariância entre a k-ésima variável original padronizada e o i-ésimo autovalor de $\rho$ e o k-ésimo componente do i-ésimo autovetor, 


\begin{tabular}{cc}
\hline Valor & Grau da Adequação da Amostra \\
\hline$>0,90$ & Ótima \\
de 0,80 a 0,90 & Boa \\
de 0,70 a 0,80 & Razoável \\
de 0,60 a 0,70 & Baixa \\
$<0,60$ & Inadequada \\
\hline
\end{tabular}

Tabela 2 - Referências para Estatística KMO

ou seja, por $\operatorname{Cov}\left(Y_{i}, Z k\right)=\lambda_{i} e_{i k}$. Podemos determinar a matriz de correlação entre o vetor de componentes principais e o vetor de variáveis originais padronizadas por

$$
\rho_{Y, Z}=\Lambda^{-1 / 2} \Lambda P^{\top}=\Lambda^{1 / 2} P^{\top}
$$

em que a i-ésima linha e k-ésima coluna contêm o coeficiente de correlação $\left(\rho Y_{i}, Z_{k}\right)$ entre $Y_{i}$ e $Z_{k}$ dado de forma escalar por

$$
\rho_{Y_{i}, Z_{i}}=\sqrt{\lambda_{i} e_{i k}}
$$

em função do fato de a variável padronizada $Z_{k}$ possuir variância unitária.

\subsubsection{Estatística KMO}

O critério de Kaiser-Meyer-Olkin - KMO é uma estatística para identificar se o modelo de análise fatorial que está sendo utilizado está adequadamente ajustado aos dados, isto se dá testando a consistência geral dos dados. O método verifica se a matriz de correlação inversa é próxima da matriz diagonal, consiste em comparar os valores dos coeficientes de correlação linear observados com os valores dos coeficientes de correlação parcial. A medida de adequacidade que fundamenta esse princípio é dada pela seguinte expressão:

$$
K M O=\frac{\sum_{i=1}^{p} \sum_{j=1}^{p} r_{i j}^{2}}{\sum_{i=1}^{p} \sum_{j=1}^{p} r_{i j}^{2}+\sum_{i=1}^{p} \sum_{j=1}^{p} a_{i j}^{2}}
$$

em que $r_{i j}$ é o quadrado dos elementos da matriz de correlação original fora da diagonal e $a_{i j}$ é o quadrado das correlação parcial entre as variáveis.

Para interpretação da estatística KMO, os valores vão variar de 0 a 1 , pois, pequenos valores de KMO indicam que o uso da análise fatorial não é adequado, e quanto mais próximo de 1, mais adequada é a aplicação da análise fatorial nos dados. Assim podemos utilizar a referência de Mingoti (2005), conforme a tabela abaixo. 


\subsubsection{Teste Bartlett}

O teste de esfericidade de Bartlett é um dos meios de se verificar a adequação da aplicação da análise fatorial ou análise de componentes principais. O teste identifica a presença de correlações não nulas entre variáveis. Ele testa a hipótese nula de que a matriz de correlação é uma matriz identidade. Se essa hipótese for rejeitada, então a análise fatorial pode ser aplicada. O teste examina a matriz de correlação interna, e fornece a probabilidade estatística de que a matriz de correlações possui correlações estatisticamente significativas entre pelo menos um par de variáveis, sendo que o teste torna-se mais eficiente em detectar as correlações na medida em que se aumenta o tamanho da amostra.

$H_{0}$ : Não é adequado o uso de Análise de Componentes Principais ou Análise Fatorial.

A estatística do teste é dada por

$$
X^{2}=-\left[(n-1)-\frac{2 p+5}{6}\right] \ln |R|
$$

Que tem uma distribuição qui-quadrado com graus de liberdade $v=\frac{p(p-1)}{2}$,

onde $n$ é o tamanho da amostra, $p$ é o número de variáveis e $|R|$ o determinante da matriz de correlação.

\subsection{Descrição dos Modelos, Construção de Índices e Testes Utilizados}

O estudo inicialmente considera os seguintes conjunto de informação:

- Conjunto 1 - volatilidades de 48 câmbios: foram utilizados 48 câmbios com o intuito de capturar um efeito generalizado de choques cambiais.

- Conjunto 2 - volatilidades de 47 câmbios (excluindo-se o Dólar/Real): nesse conjunto de dados, com a exclusão do dólar, buscamos estimar um efeito contrafactual de todas as demais taxas de câmbio.

- Conjunto 3 - volatilidades de 17 bolsas de valores: foram utilizados 17 índices de bolsas de valores com o intuito de capturar um efeito generalizado de choques de mercados financeiros internacionais.

- Conjunto 4 - volatilidade do Dólar: objetivando capturar os efeitos únicos do dólar dado sua importância como principal moeda que compõe as reservas nacionais.

Os retornos foram calculados para cada série de dados de cada um dos conjuntos de informação. A partir dos retornos calculados foi utilizada a metodologia do ACP, para cada con- 
junto, a fim de obter um índice de retorno que fosse representativo da variabilidade. Claramente, a exceção desse tratamento com ACP é o conjunto de dados 4, o qual foi calculado apenas o retornos do Dólar/Real. dos retornos dos dados em questão. Os índices representativos foram denominados IND1, IND2 e IND3, conforme ilustra o esquema a seguir:

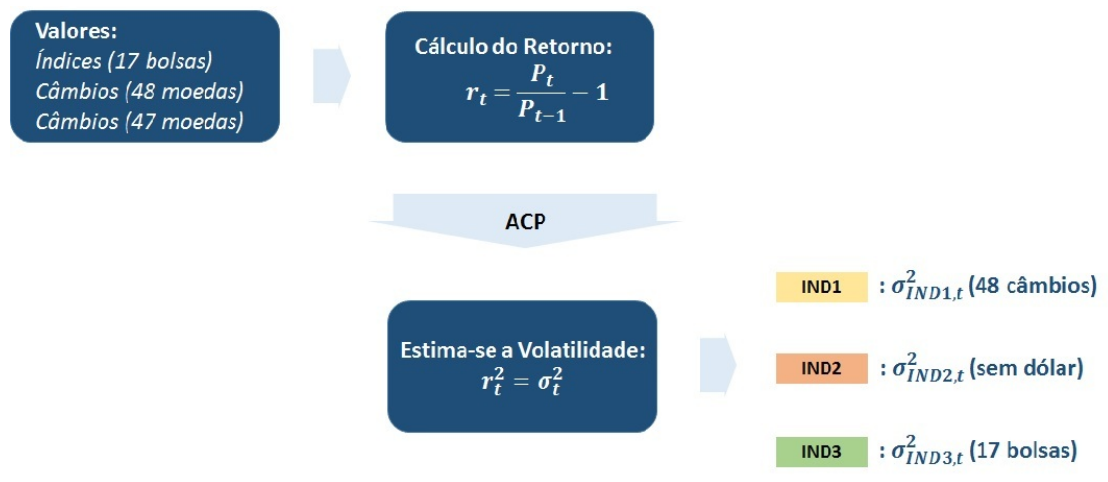

Figura 1 - Construção de Índices

Os 9 (nove) modelos estimados seguiram a lógica de combinar uma variável resposta (Ibovespa, IGC-NM ou IGC-X) com um índice que espelhe choque cambial (IND1, IND2 ou Retorno do Dólar) e o que representa choque de mercado financeiro internacional (IND3).

\begin{tabular}{|c|c|c|c|c|c|c|}
\hline Modelos & iBovespa IGC-NM & IGC-X & INDI & IND2 & IND3 & Retorno do Dólar \\
\hline I & $x$ & & $x$ & & $x$ & \\
\hline 2 & $x$ & & & $x$ & $x$ & \\
\hline 3 & $x$ & & & & $x$ & $x$ \\
\hline 4 & $x$ & & $x$ & & $x$ & \\
\hline 5 & $x$ & & & $x$ & $x$ & \\
\hline 6 & $x$ & & & & $x$ & $x$ \\
\hline 7 & & $x$ & $x$ & & $x$ & \\
\hline 8 & & $x$ & & $x$ & $x$ & \\
\hline 9 & & $x$ & & & $x$ & $x$ \\
\hline
\end{tabular}

Figura 2 - Modelos Estimados

Para cada modelo (de 1 a 9) foram estimadas as correlações condicionais com o modelo MGARCH BEKK, essa escolha se deve ao fato de que o teste HH está implementado para a utilização dos resultados desses modelos. Utilizamos testes de auto-correlação para os resíduos obtidos desses modelos para verificar sua adequação. . Esses testes foram aplicados para os resíduos padronizados e para o quadrado dos resíduos padronizados. Foram feitos os testes de causalidade de Granger de segunda ordem (Teste HH) para identificar a direção da causalidade, no sentido de Granger, das correlações condicionais estimadas.

Assim, para o modelo 1 estimamos a correlação condicional entre o índice Ibovespa e choque cambial (IND1) e a correlação condicional entre o Ibovespa e o choque de mercado 
financeiro internacional (IND3). Analogamente, no modelo 2 foi estimada a correlação condicional entre o Ibovespa e o choque cambial sem o dólar (IND2) e entre o Ibovespa e o choque de mercado financeiro internacional (IND3). Sucessivamente foram estimados as correlações condicionais seguindo as combinações representadas na figura 2 até que, finalmente, estimamos o modelo 9 que verificou a correlação condicional entre o IGC-X e o choque cambial (retorno do dólar) e o choque de mercado financeiro internacional (IND3). Ou seja, para cada modelo foram estimadas duas correlações condicionais, uma entre um índice da BM\&FBovespa (Ibovespa, IGC-NM ou IGC-X) e uma proxy de choque cambial (IND1, IND2 ou Retorno do Dólar) e outra correlação entre esse mesmo índice e a proxy de choque de mercado financeiro internacional (IND3).

A partir dos modelos 1, 4 e 7 foram estimadas as correlações condicionais que envolvem as três variáveis resposta (Ibovespa, IGC-NM e IGC-X), o IND1 (choque cambial, 48 câmbios) e o IND3 (choque de mercado financeiros internacional, 17 bolsas), fizemos testes comparativos entre as correlações a fim de identificar, estatisticamente, qual teria a maior correlação condicional. Procedimento análogo foi aplicado aos modelos 2, 5 e 8, já que envolvem as variáveis resposta, o IND2 e IND3. Mesmo tratamento dado aos modelos 3, 6 e 9 que dizem respeito às variáveis resposta, o retorno do Dólar e o IND3. Posteriormente foram feitas as análises e conclusões acerca dos resultados encontrados. 


\section{Resultados}

O capítulo de resultados está estruturado de maneira a reproduzir toda a sequência apresentada na parte metodológica, além de seguir os passos necessários para a obtenção das respostas às perguntas inicialmente propostas neste estudo. A primeira seção do capítulo trata da descrição das séries e das estatísticas exploratórias das variáveis respostas (Ibovespa, IGC-NM e IGC-X). Os resultados obtidos foram gerados utilizando o aplicativo MATLAB, a exceção dos Testes de Causalidade de Granger de Segunda Ordem feitos no “ R”. A seção subsequente apresenta os resultados obtidos na construção das proxies para choques cambiais e choques de mercados financeiros internacionais. Nessa mesma seção apresentamos os resultados iniciais do estudo da dinâmica temporal. Ou seja, a identificação das ordens dos modelos GARCH univariados conforme apresentado no capítulo 3. As três seções seguintes apresentam os resultados dos modelos e correlações condicionais estimados e seus respectivos testes de causalidade de Granger de segunda ordem. O capítulo é finalizado apresentando comparações das correlações condicionais estimadas e seus equivalentes testes estatísticos para respostas às questões relevantes apresentadas no capítulo de introdução.

\subsection{Descrição das Séries e Estatísticas Exploratórias}

Iniciamos esta seção apresentando os gráficos típicos para os retornos, e quadrados dos retornos, para as variáveis resposta em questão. Os resultados exploratórios e os gráficos corroboram para confirmar os fatos estilizados geralmente associados a retornos e quadrado dos retornos (aqui chamados de volatilidade). Esses fatos estilizados são elencados por Caldeira, Souza e Machado (2010):

- Fato Estilizado 1: Estacionariedade - as propriedades estatísticas da série são invariantes ao longo do tempo. Os resultados do teste ADF estão no Apêndice C

- Fato Estilizado 2: Fraca/Nenhuma dependência linear e dependência não linear (efeito GARCH) - a série normalmente é pouco ou não autocorrelacionada, mas a série do quadrado das observações é autocorrelacionada.

- Fato Estilizado 3: Não-normalidade - As distribuições das séries financeiras geralmente apresentam caudas pesadas e presença de assimetria, fugindo da curva Gaussiana.

- Fato Estilizado 4: Existência de conglomerados de Volatilidade - A série financeira costuma alternar entre períodos de alta volatilidade e períodos com baixa volatilidade, ou seja, a variância condicional da série varia ao longo do tempo. 


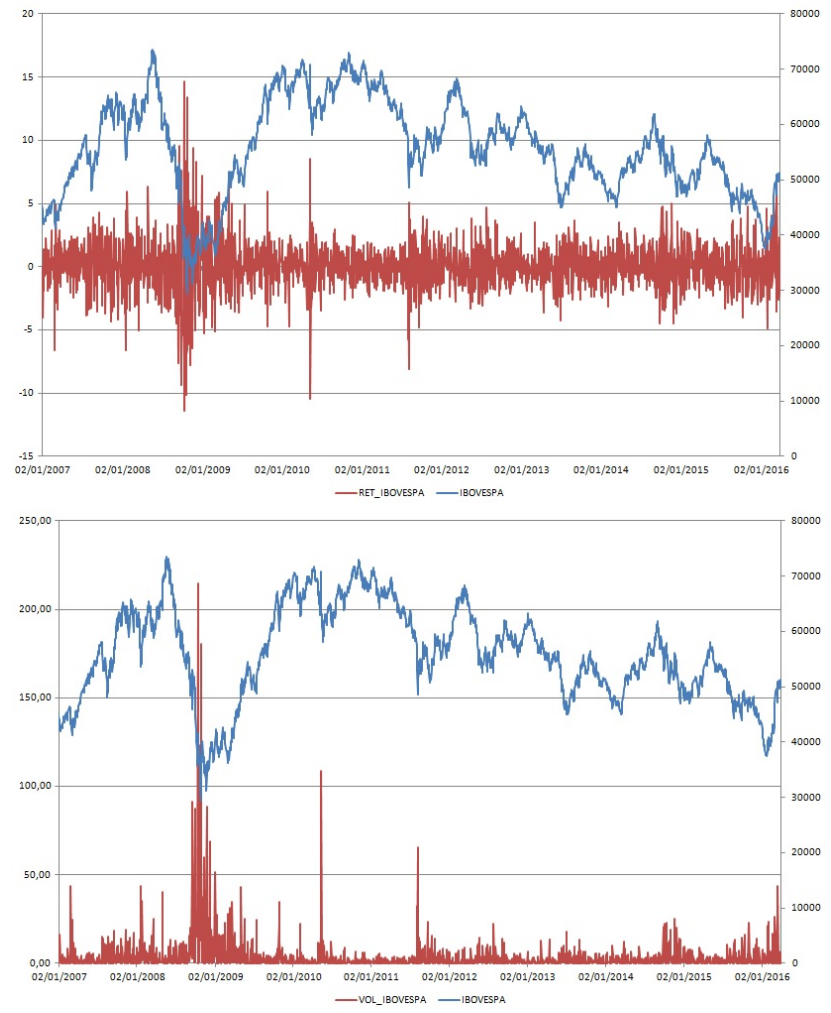

Figura 3 - Gráfico de Retorno e Volatilidade do Ibovespa

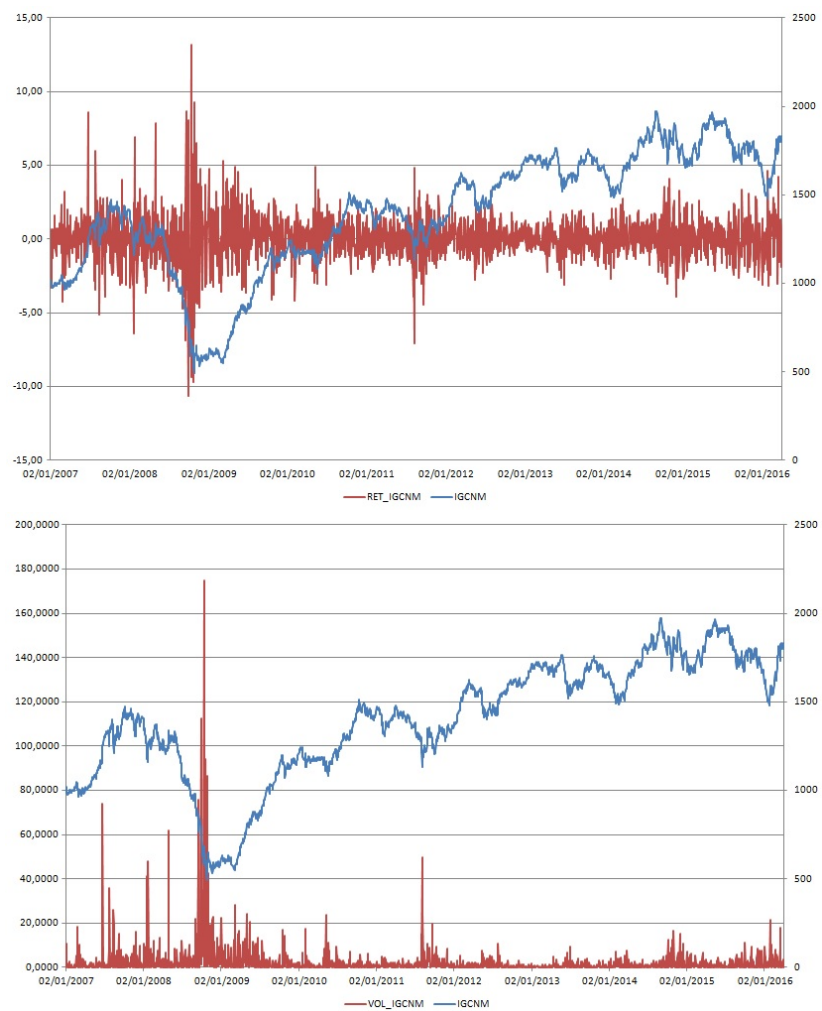

Figura 4 - Retorno e Volatilidade do IGC-NM 


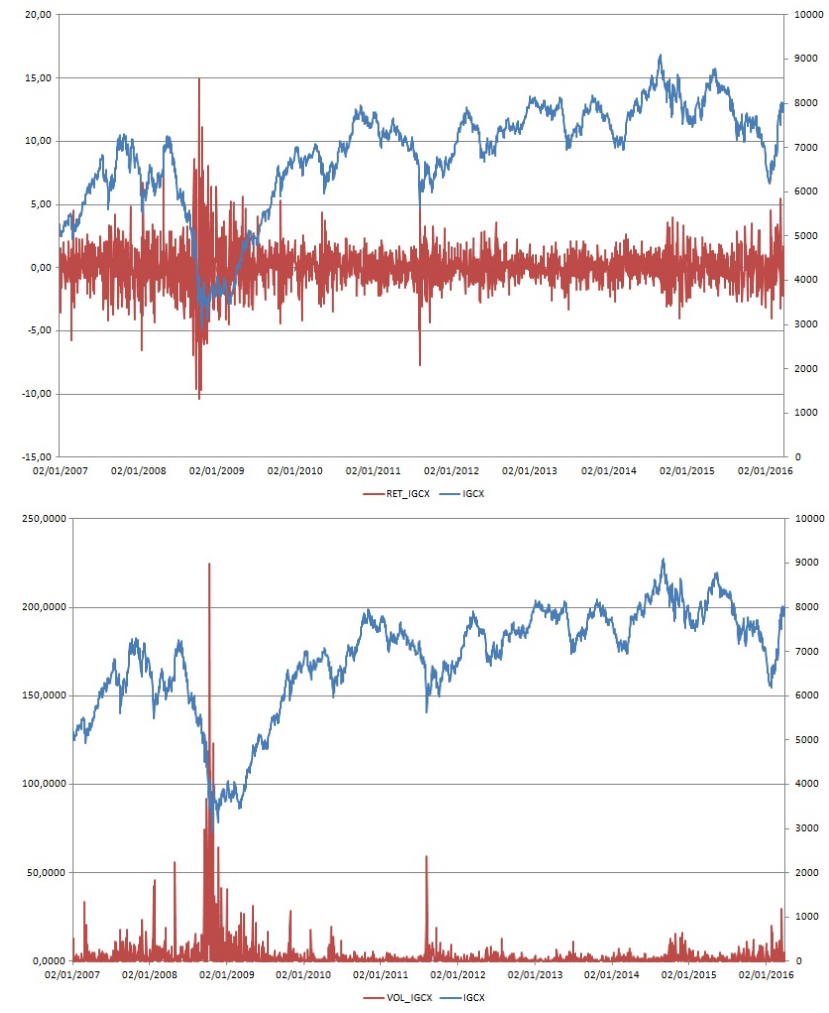

Figura 5 - Retorno e Volatilidade do IGC-X

Observamos nos gráficos acima típico comportamento de retornos oscilando em torno de uma média (próxima a zero). O quadrado dos retornos apresentam características típicas de clusters de volatilidade. Para todas as séries verificamos um aumento de volatilidade acentuado concomitante com queda dos índices nos períodos da crise econômica de 2008/2009.

A primeira confirmação do que sugeriram os gráficos apresentados está resumida nos resultados exploratórios a seguir:

\begin{tabular}{|c|c|c|c|}
\hline \multicolumn{4}{|c|}{ RETORNOS } \\
\hline TESTES/ESTATISTICAS & IBOVESPA & ICG NM & IGCX \\
\hline $\mathrm{n}$ & 2284 & 2284 & 2284 \\
\hline Média & 0,02 & 0,04 & 0,03 \\
\hline Mediana & 0,03 & 0,05 & 0,04 \\
\hline Máximo & 14,66 & 13,22 & 15,00 \\
\hline Minimo & 11,39 & $-10,61$ & $-10,36$ \\
\hline Variância & 3,47 & 2,30 & 2,65 \\
\hline Desvio Padrão & 1,86 & 1,52 & 1,63 \\
\hline Assimetria & 0,21 & 0,14 & 0,26 \\
\hline Curtose & 9,34 & I 1,32 & I1,15 \\
\hline Coef. Variação & 86,18 & 41,77 & 53,28 \\
\hline
\end{tabular}

\begin{tabular}{crcr}
\hline \multicolumn{4}{c}{ VOLATILIDADES } \\
TESTES/ESTATISTICAS & IBOVESPA & ICG NM & IGCX \\
\hline $\mathrm{n}$ & 2284 & 2284 & 2284 \\
Média & 2,65 & 2,30 & 3,47 \\
Mediana & 0,64 & 0,57 & 0,92 \\
Máximo & 224,91 & 174,67 & 214,85 \\
Minimo & 0,00 & 0,00 & 0,00 \\
Variância & 71,60 & 54,76 & 100,70 \\
Desvio Padrão & 8,46 & 7,40 & 10,04 \\
Assimetria & 12,86 & 11,52 & 10,50 \\
Curtose & 258,52 & 193,24 & 163,00 \\
Coef. Variação & 3,19 & 3,21 & 2,89 \\
\hline
\end{tabular}

Figura 6 - Análise Exploratória dos Dados - Índices Bovespa

Novamente observamos os valores de média e mediana dos retornos próximos a zero com a presença de valores altos de curtose, o que caracteriza distribuições de caudas pesadas e assimetria de retornos positivos e negativos. As características de curtose e assimetria se 
reproduzem também para os quadrados dos retornos. Podemos verificar parte desses fatos estilizados a partir dos histogramas e testes de normalidade. Foi utilizado o Teste de Jarque Bera de normalidade (Ver Lütkepohl (2005).).
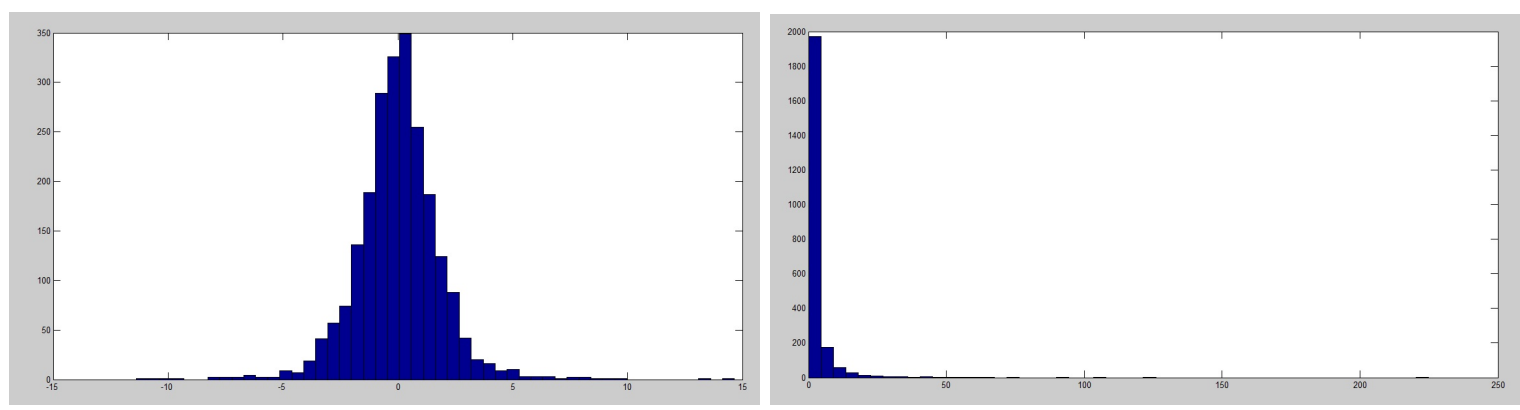

Figura 7 - Histograma de Retorno e Volatilidade do Ibovespa
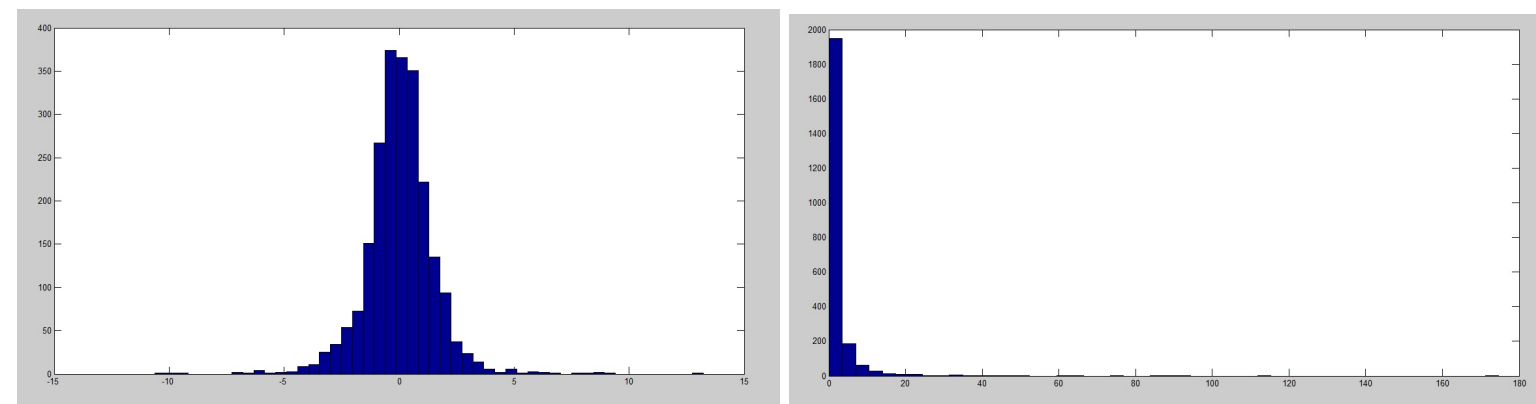

Figura 8 - Histograma de Retorno e Volatilidade do IGC-NM
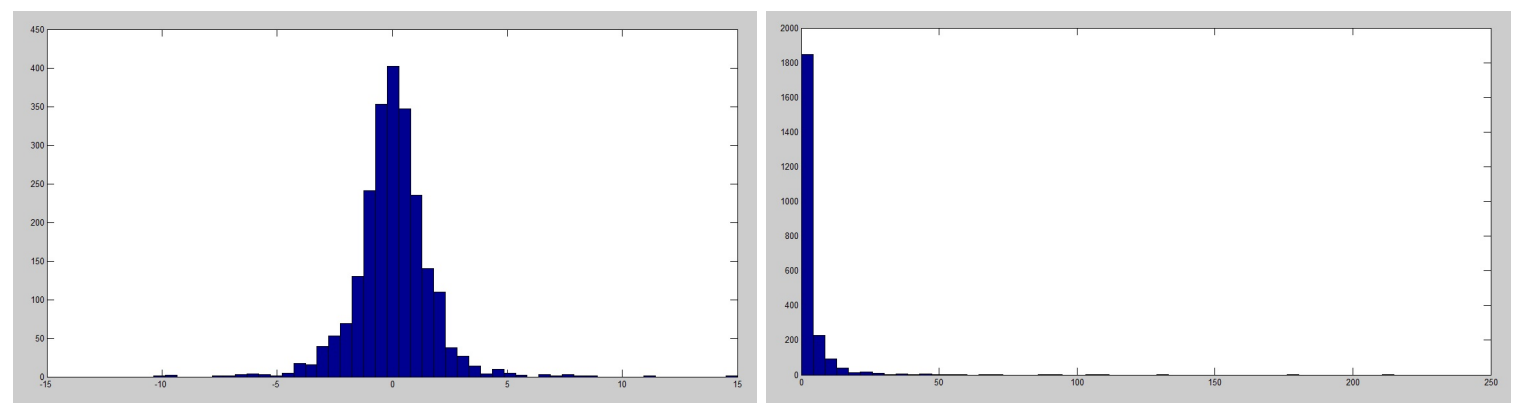

Figura 9 - Histograma de Retorno e Volatilidade do IGC-X

\begin{tabular}{l|c}
\hline \multicolumn{2}{c}{ Teste Jarque Bera } \\
Dados & P-valor \\
\hline Ibovespa Retornos & 0,00 \\
Ibovespa Volatilidade & 0,00 \\
IGC-NM Retornos & 0,00 \\
IGC-NM Volatilidade & 0,00 \\
IGC-X Retornos & 0,00 \\
IGC-X Volatilidade & 0,00 \\
\hline H: Os dados possuem distribuição normal.
\end{tabular}

Figura 10 - Resultados do Teste Jarque Bera 


\subsection{Análise de Componentes Principais e Construção de Ín- dices}

Apresentamos nesta seção os resultados da análise de componentes principais que foram utilizados para a construção das proxies de choques cambiais e de choques de mercados financeiros internacionais.

Inicialmente observamos se os conjuntos de dados poderiam ser tratados por meio de ACP. Para tanto, em termos exploratórios, observamos como adequado o uso de ACP por meio da estatística KMO com valores acima de 0,9. Em termos inferenciais o teste de Bartlet indicou adequada utilização do ACP, com a rejeição da hipótese nula. Os resultados do teste de Bartlet e da estatística KMO estão demonstrados na figura a seguir, já os autovalores encontrados a partir na análise de componentes principais podem ser observados nos apêndices.

\begin{tabular}{|c|c|c|c|c|}
\hline Indices & Descrição & BARTS P-Valor & KMO & $\begin{array}{c}\text { Variância Explicada pelo } 1^{\circ} \\
\text { Componente Principal }\end{array}$ \\
\hline INDI & CAMBIO RETORNOS & 0,00 & 0,97 & 0,884 \\
\hline IND2 & CAMBIO RETORNOS SEM DOLAR & 0,00 & 0,97 & 0,885 \\
\hline IND3 & BOLSAS DE VALOR RETORNOS & 0,00 & 0,90 & 0,886 \\
\hline
\end{tabular}

Figura 11 - Resultados do Teste de Bartlet e Estatística KMO

Conforme observamos a primeira componente, em todos os casos, tem alta representatividade em termos da variância total. Dessa forma, como todos os autovalores são não negativos (Apêndice D) temos que os índices criados são válidos.

Na sequencia apresentamos os resultados das estatísticas exploratórias dos índices criados.

\begin{tabular}{|c|c|c|c|c|}
\hline \multicolumn{5}{|c|}{ RETORNOS } \\
\hline TESTES/ESTATÍSTICAS & IND1 & IND2 & IND3 & DOLAR \\
\hline $\mathrm{n}$ & 2284 & 2284 & 2284 & 2284 \\
\hline Média & - $\quad 0,01$ & 0,03 & 0,02 & 0,03 \\
\hline Mediana & - $\quad 0,01$ & 0,01 & 0,07 & 0,01 \\
\hline Máximo & 3,31 & 8,32 & $8,7 \mathrm{I}$ & 6,60 \\
\hline Minimo & $-9,72$ & 4,48 & $-13,76$ & 7,31 \\
\hline Variância & 0,34 & 0,48 & 2,18 & 1,26 \\
\hline Desvio Padrão & 0,59 & 0,69 & 1,48 & 1,12 \\
\hline Assimetria & - $\quad 2,47$ & 1,56 & 0,76 & 0,31 \\
\hline Curtose & 42,99 & 24,37 & 11,59 & 7,88 \\
\hline Coef. Variação & 40,52 & 24,90 & 60,56 & 38,52 \\
\hline
\end{tabular}

\begin{tabular}{crcrr}
\hline \multicolumn{5}{c}{ VOLATILIDADES } \\
TESTES/ESTATISTICAS & \multicolumn{1}{c}{ IND1 } & \multicolumn{1}{c}{ IND2 } & \multicolumn{1}{c}{ IND3 } & DOLAR \\
n & 2284 & 2284 & 2284 & 2284 \\
Média & 0,31 & 0,48 & 2,18 & 1,26 \\
Mediana & 0,08 & 0,10 & 0,55 & 0,31 \\
Máximo & 35,38 & 69,25 & 189,31 & 53,39 \\
Minimo & 0,00 & 0,00 & 0,00 & 0,00 \\
Variância & 1,11 & 5,37 & 50,24 & 10,99 \\
Desvio Padrão & 1,05 & 2,32 & 7,09 & 3,31 \\
Assimetria & 19,70 & 19,28 & 13,17 & 7,84 \\
Curtose & 578,03 & 484,63 & 266,21 & 86,52 \\
Coef. Variação & 3,45 & 4,85 & 3,25 & 2,63 \\
\hline
\end{tabular}

Figura 12 - Análise Exploratória dos Dados - IND1, IND2, IND3 e Dólar

Os resultados são semelhantes aos observados para as variáveis Ibovespa, IGC-NM e IGC-X. Ou seja, média próxima de zero com presença de assimetria e curtose. Alguns dos fatos estilizados listados podem ser observados a partir dos histogramas e a rejeição da normalidade tanto dos retornos quanto das volatilidades, conforme teste Jarque Bera. 


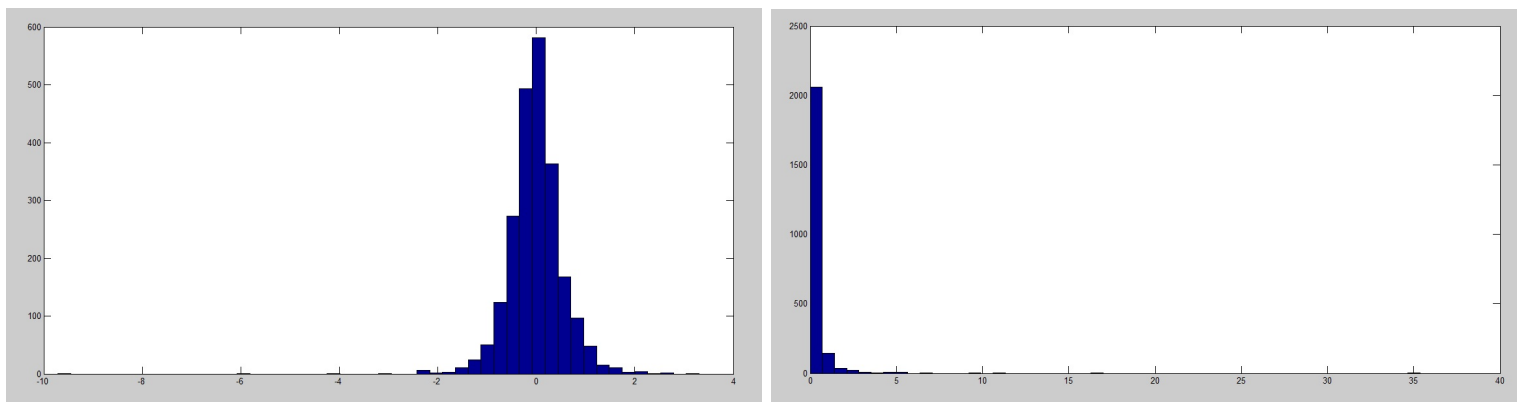

Figura 13 - Histograma de Retorno e Volatilidade do IND1

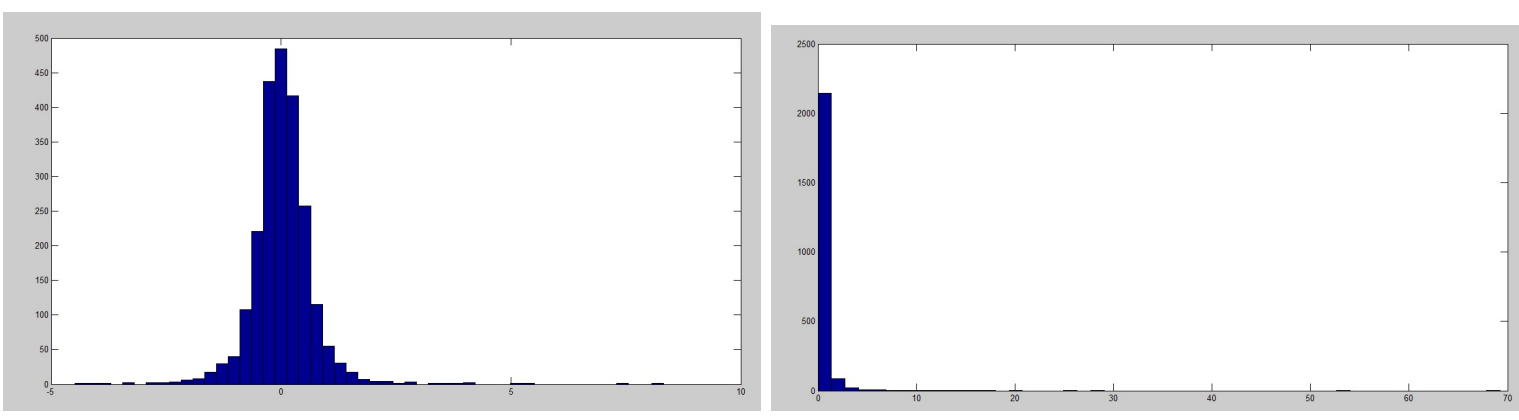

Figura 14 - Histograma de Retorno e Volatilidade do IND2
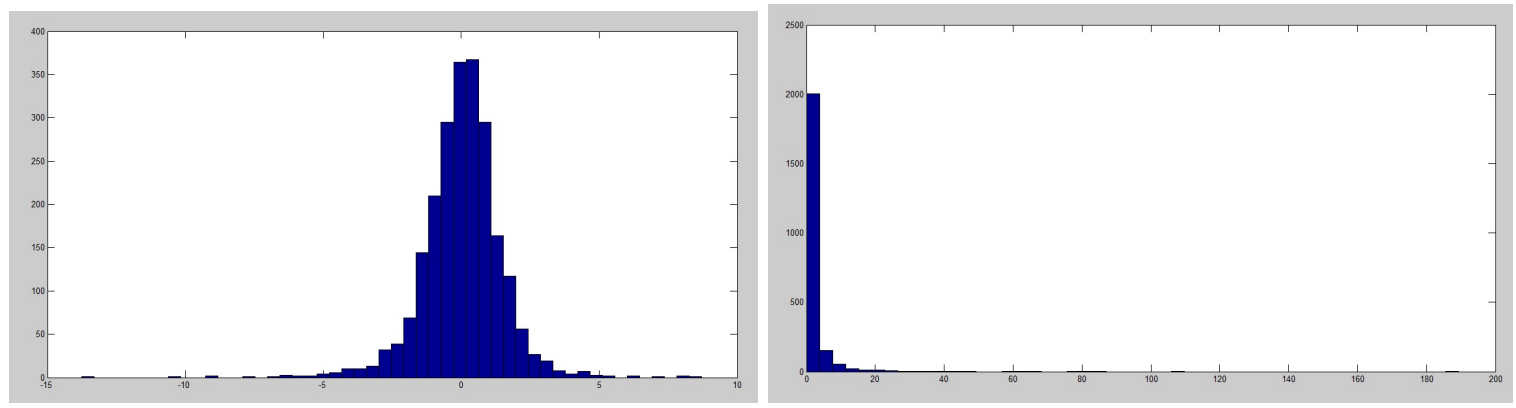

Figura 15 - Histograma de Retorno e Volatilidade do IND3
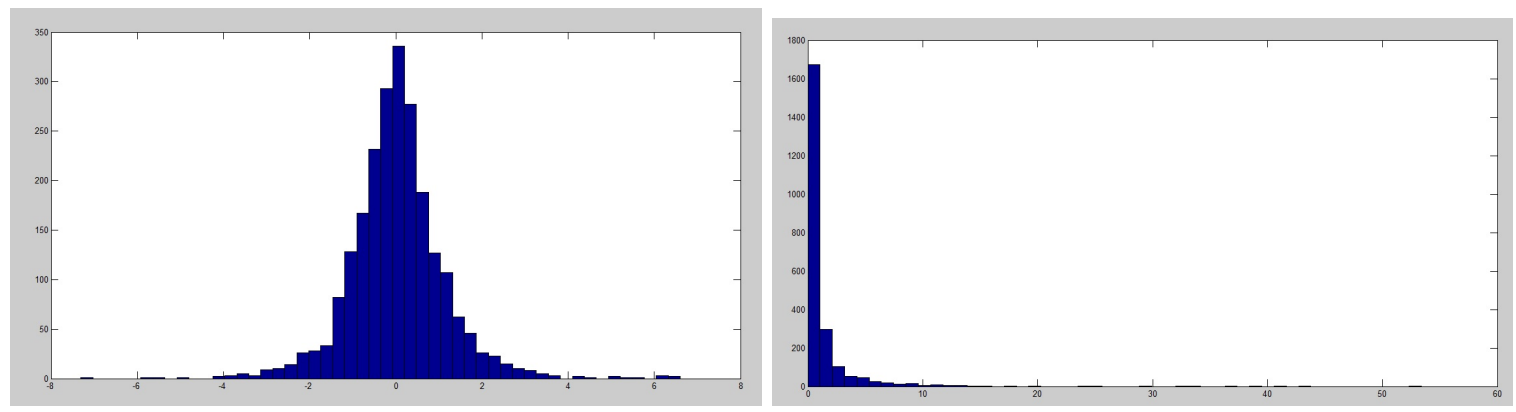

Figura 16 - Histograma de Retorno e Volatilidade do Dólar

\begin{tabular}{lc}
\multicolumn{2}{c}{ Teste Jarque Bera } \\
Dados & P-Valor \\
\hline INDI Retornos & 0,00 \\
INDI Volatilidade & 0,00 \\
IND2 Retornos & 0,00 \\
IND2 Volatilidade & 0,00 \\
IND3 Retornos & 0,00 \\
IND3 Volatilidade & 0,00 \\
Dólar Retornos & 0,00 \\
Dólar Volatilidade & 0,00 \\
\hline Ho: Os dados possuem distribuição normal.
\end{tabular}

Figura 17 - Resultados do Teste Jarque Bera para IND1, IND2, IND3 e Dólar 
A seguir apresentamos as matrizes de correlação contemporânea como um primeiro indicativo exploratório do comportamento da correlação entre as variáveis Ibovespa, IGC-NM, IGC-X e Dólar e os índices criados. As células destacadas indicam valores estatisticamente não significantes.

\begin{tabular}{crrr|rrrr}
\multicolumn{2}{c}{ RETORNOS IBOVESPA IGC NM } & \multicolumn{1}{c}{ IGCX } & \multicolumn{1}{l}{ INDI } & IND2 & IND3 & DOLAR \\
IBOVESPA & 1,00 & 0,89 & 0,96 & $-0,23$ & $-0,21$ & 0,50 & $-0,55$ \\
IGC NM & 0,89 & 1,00 & 0,93 & $-0,22$ & $-0,17$ & 0,46 & $-0,54$ \\
IGCX & 0,96 & 0,93 & 1,00 & $-0,23$ & $-0,20$ & 0,49 & $-0,55$ \\
INDI & $-0,23$ & $-0,22$ & $-0,23$ & 1,00 & $-0,18$ & 0,02 & 0,28 \\
IND2 & $-0,21$ & $-0,17$ & $-0,20$ & $-0,18$ & 1,00 & $-0,16$ & 0,20 \\
IND3 & 0,50 & 0,46 & 0,49 & 0,02 & $-0,16$ & 1,00 & $-0,30$ \\
DOLAR & $-0,55$ & $-0,54$ & $-0,55$ & 0,28 & 0,20 & $-0,30$ & 1,00 \\
\hline
\end{tabular}

Figura 18 - Matriz de Correlação Contemporânea dos Retornos

\begin{tabular}{c|crr|rrrrr}
\multicolumn{2}{c}{ VOLATILIDADE IBOVESPA IGC NM } & \multicolumn{1}{c}{ IGCX } & \multicolumn{1}{l}{ INDI } & IND2 & IND3 & DOLAR \\
IBOVESPA & I,00 & 0,93 & 0,94 & 0,25 & 0,08 & 0,33 & 0,63 \\
IGC NM & 0,93 & 1,00 & 0,84 & 0,21 & 0,06 & 0,35 & 0,61 \\
IGCX & 0,94 & 0,84 & 1,00 & 0,26 & 0,08 & 0,33 & 0,59 \\
IND1 & 0,25 & 0,21 & 0,26 & 1,00 & 0,11 & 0,47 & 0,23 \\
IND2 & 0,08 & 0,06 & 0,08 & 0,11 & 1,00 & 0,05 & 0,09 \\
IND3 & 0,33 & 0,35 & 0,33 & 0,47 & 0,05 & 1,00 & 0,30 \\
DOLAR & 0,63 & 0,61 & 0,59 & 0,23 & 0,09 & 0,30 & 1,00 \\
\hline
\end{tabular}

Figura 19 - Matriz de Correlação Contemporânea das Volatilidades

Primeira constatação é a alta correlação entre os três índices Bovespa haja vista a existência de empresas comuns nos mesmos, dessa forma foi realizado tratamento isolado de cada um deles com correspondentes choques cambiais e de mercados financeiros internacionais. Outro ponto a ser observado diz respeito à correlação da volatilidade próxima a zero do IND2 e as variáveis Ibovespa, IGC-NM e IGC-X, o que demonstra um indicativo da importância do dólar como choque cambial. Isso é corroborado pela alta correlação do dólar e os referidos índices Bovespa. Destacamos ainda a correlação de volatilidade significativa entre o IND3 e os índices Bovespa.

\subsection{Estudo da Dinâmica Temporal}

Nesta seção apresentamos o estudo da dinâmica temporal das variáveis Bovespa e dos índices criados. Inicialmente apresentamos o teste LM para 10 defasagens para os retornos e para as volatilidades das variáveis. $\mathrm{O}$ teste para os retornos caracterizam mais um fato estilizado, o de ausência de autocorrelação para retornos, inclusive para os índices criados. Quando consideramos os retornos ao quadrado, identificamos uma estrutura de correlação pela não rejeição da hipótese nula do teste LM. Novamente, mais uma confirmação de um fato estilizado citado no início do capítulo. 

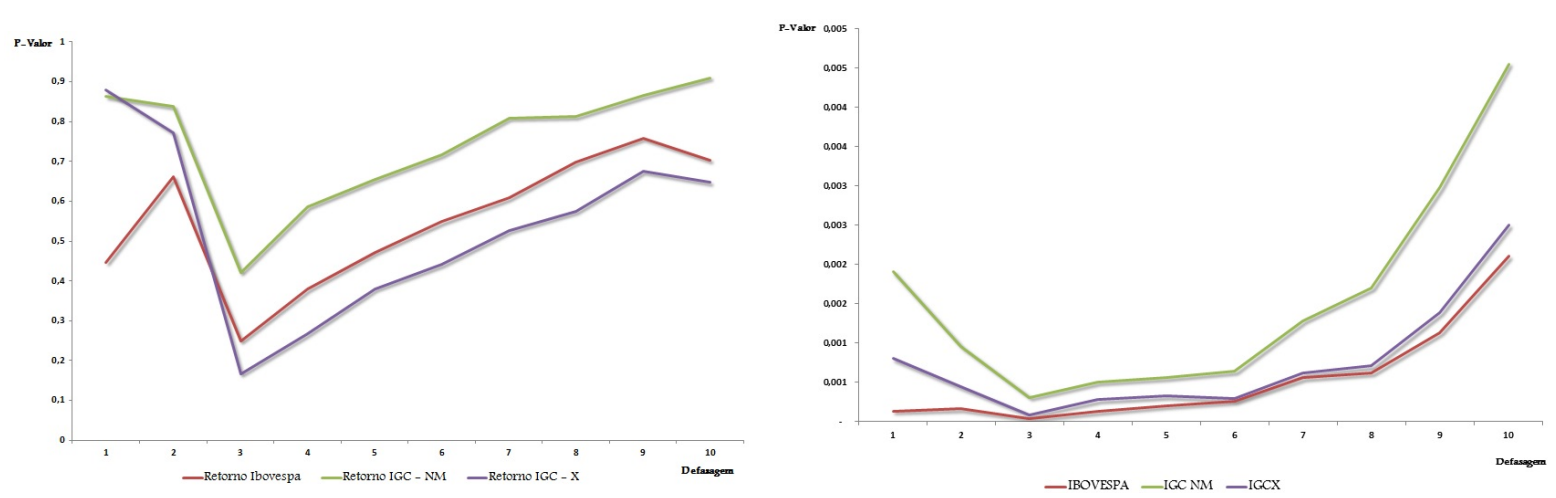

Figura 20 - Teste LM para Autocorrelação de Retornos e Volatilidade - Índices Bovespa
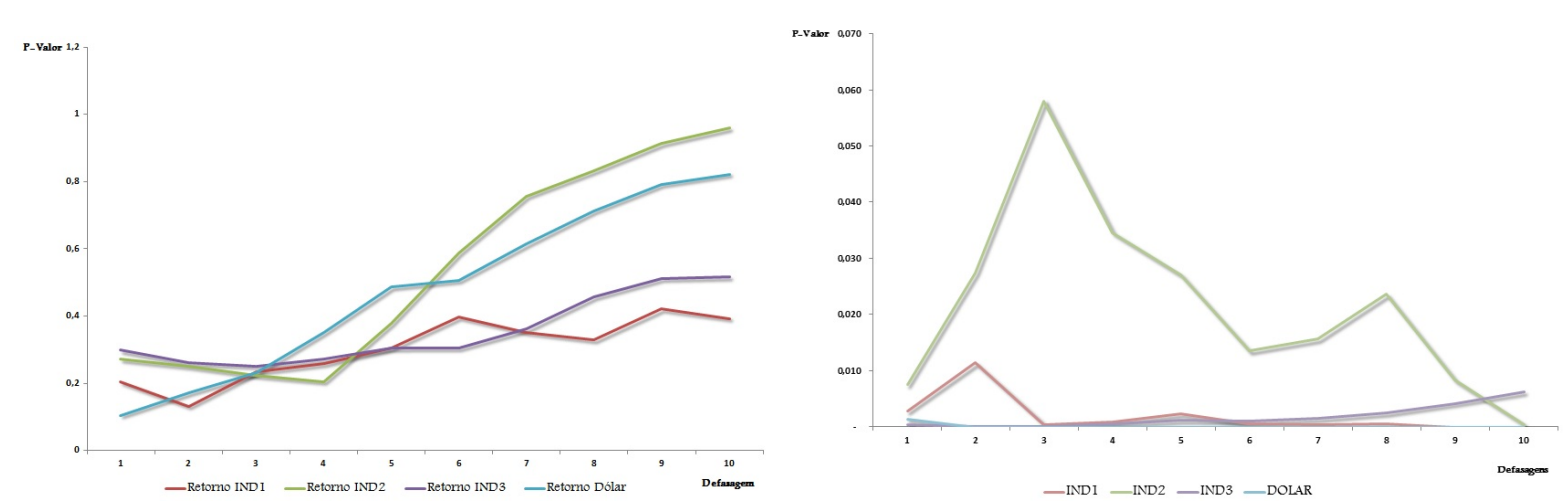

Figura 21 - Teste LM para Autocorrelação de Retornos e Volatilidade - Índices e Dólar

Seguindo no estudo da dinâmica temporal há que se definir a ordem do modelo a ser aplicada. Tendo em vista a incipiente literatura para a definição de ordens para modelos multivariados, optamos por utilizar o que existe na literatura para modelos univariados como indicativo para o multivariado, conforme apresentado na seção 3.5. Assim, utilizamos o estudo das funções de autocorrelação e de autocorrelação parcial das séries, conforme gráficos abaixo, para identificar as possíveis ordens dos modelos a serem estimados (BOX; JENKINS, 1976).
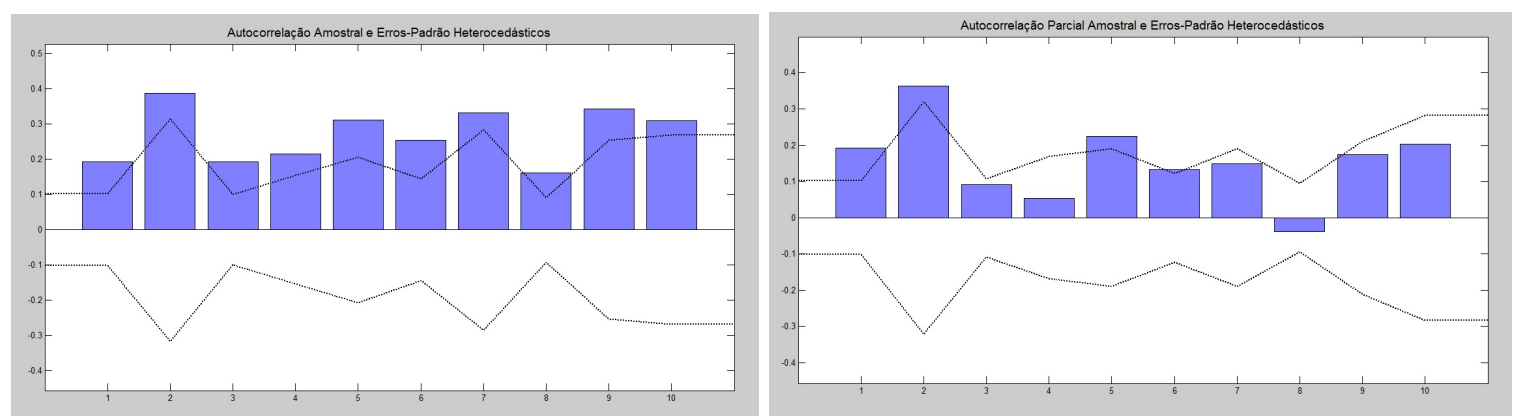

Figura 22 - Funções de Autocorrelação - Ibovespa 

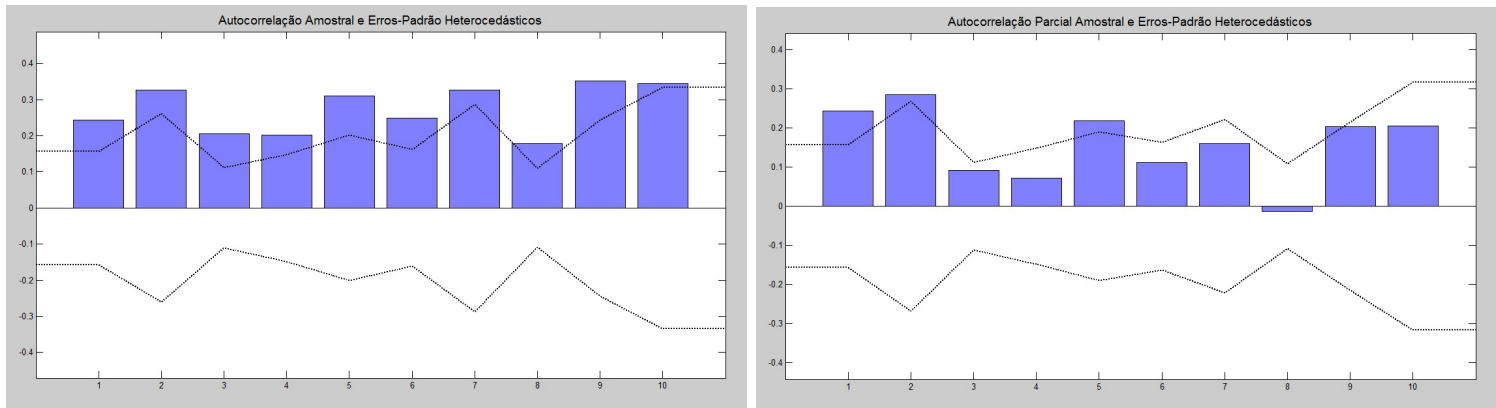

Figura 23 - Funções de Autocorrelação - IGC-NM
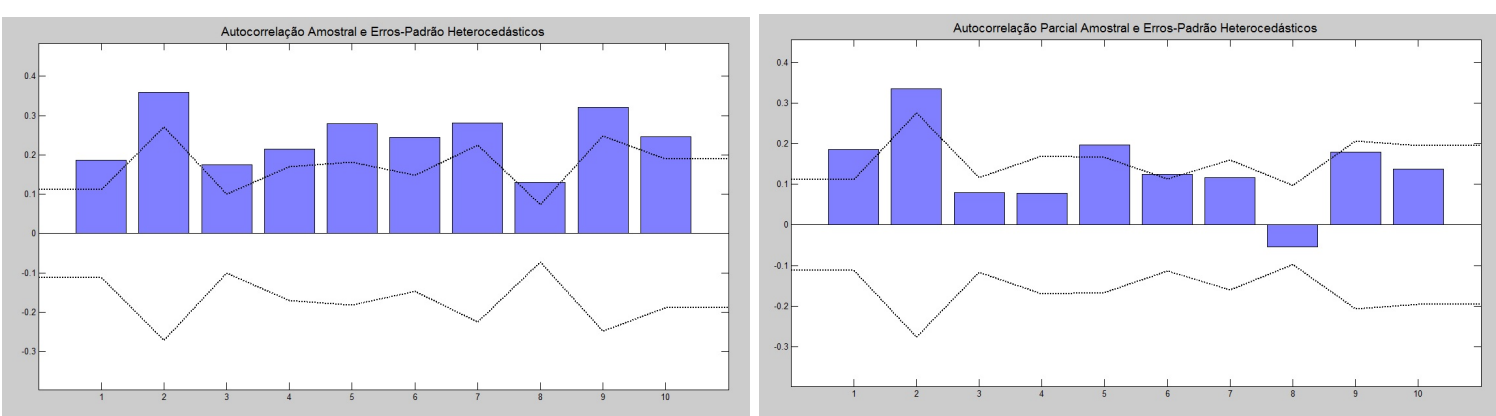

Figura 24 - Funções de Autocorrelação - IGC-X
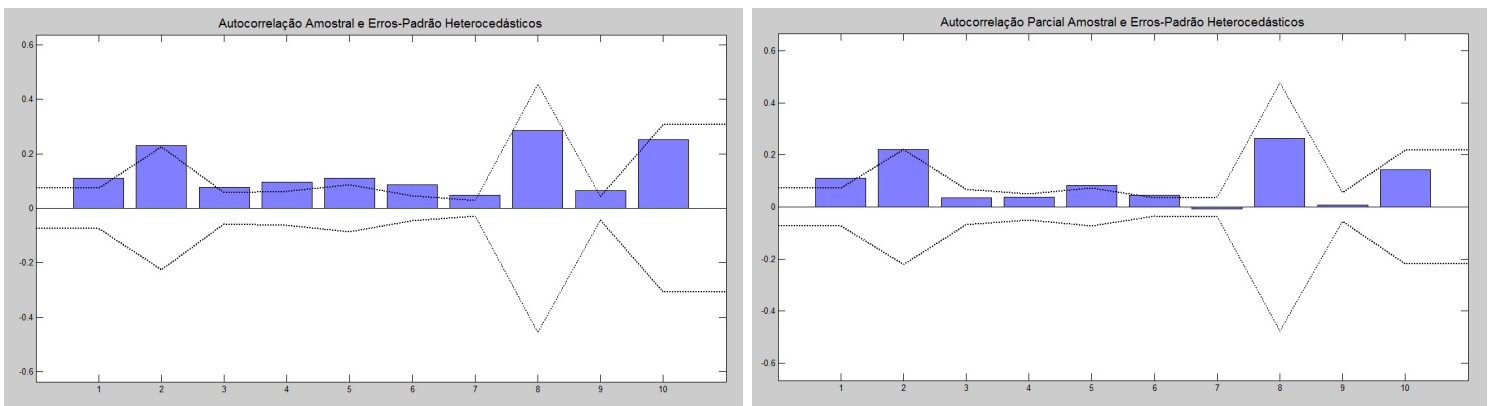

Figura 25 - Funções de Autocorrelação - IND1
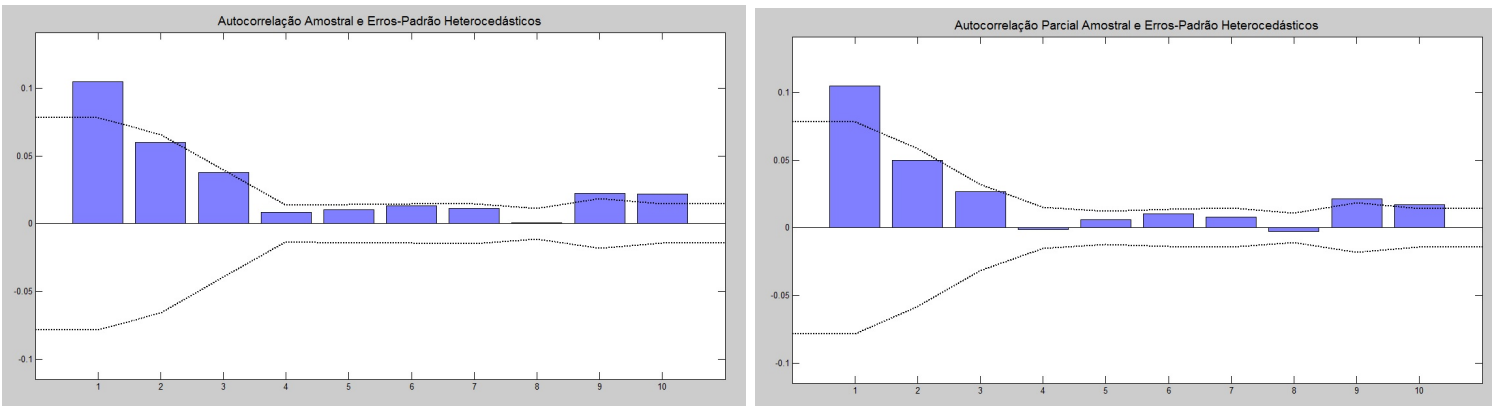

Figura 26 - Funções de Autocorrelação - IND2 

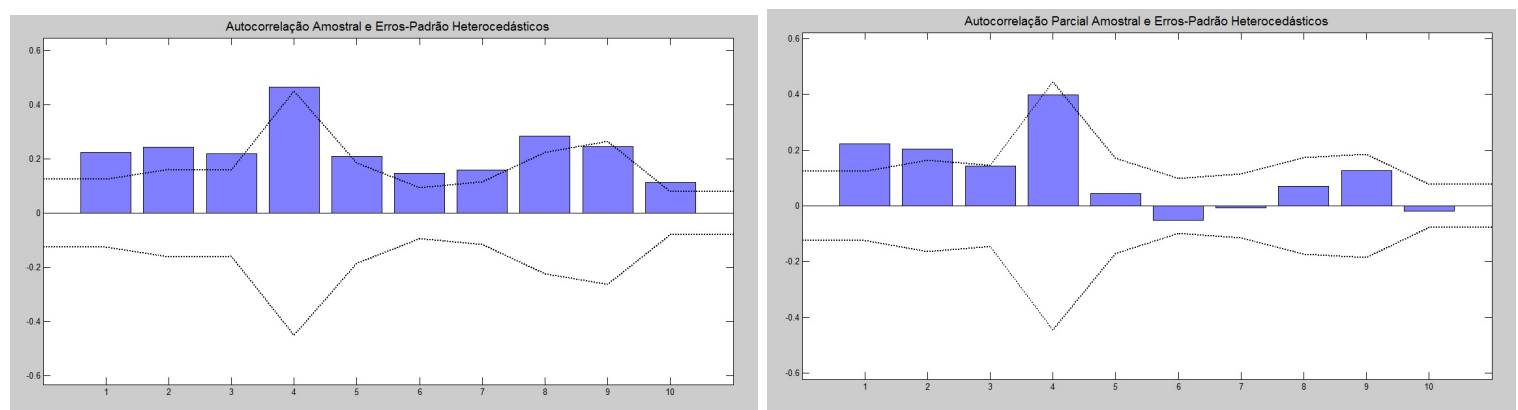

Figura 27 - Funções de Autocorrelação - IND3
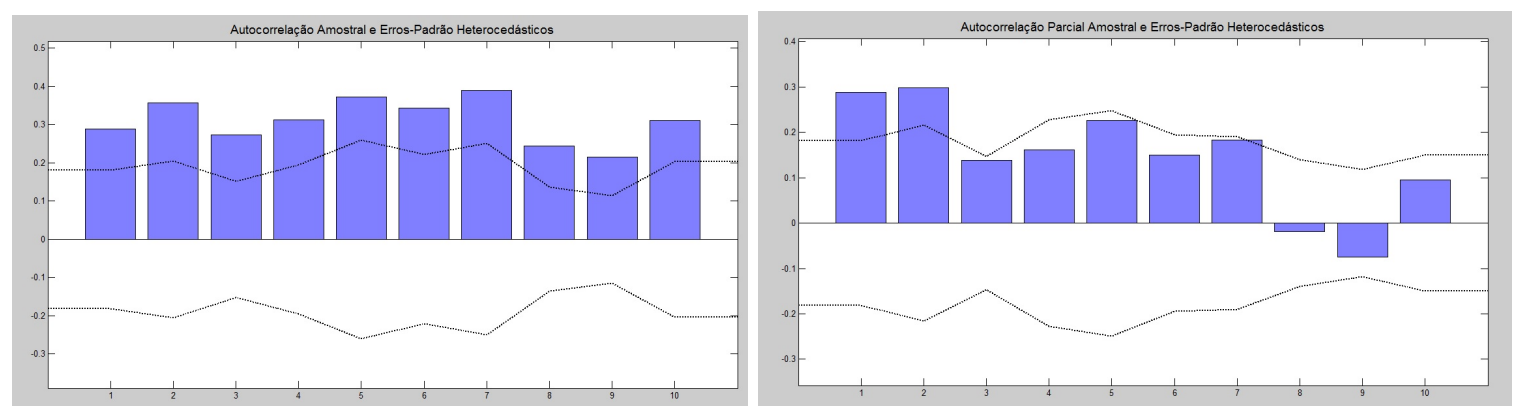

Figura 28 - Funções de Autocorrelação - Dólar

A partir das análises feitas chegamos às conclusões, apresentadas na tabela a seguir, das possibilidade de ordem a serem utilizadas nos modelos, para cada uma das variáveis.

\begin{tabular}{|c|c|c|}
\hline Variáveis & Análise ACF/PACF & Ordem Sugerida \\
\hline Ibovespa & PACF2 & $\begin{array}{c}\text { GARCH }(1,1) \text { ou } \\
\operatorname{GARCH}(1,2)\end{array}$ \\
\hline IGC-NM & PACF2 & $\begin{array}{l}\text { GARCH }(1,1) \text { ou } \\
\text { GARCH }(1,2)\end{array}$ \\
\hline IGC-X & PACF2 & $\begin{array}{l}\text { GARCH }(1,1) \text { ou } \\
\operatorname{GARCH}(1,2)\end{array}$ \\
\hline IND1 & PACF2 & $\begin{array}{l}\text { GARCH }(1,1) \text { ou } \\
\operatorname{GARCH}(1,2)\end{array}$ \\
\hline IND2 & $\begin{array}{c}\text { ACF1 e PACF1 e } \\
\text { Decaimento Exponencial }\end{array}$ & $\begin{array}{c}\text { GARCH }(2,1) \text { ou } \\
\text { GARCH }(1,2)\end{array}$ \\
\hline IND3 & ACF2 e PACF2 & $\operatorname{GARCH}(1,2)$ \\
\hline Dólar & $\mathrm{PACF} 2$ & $\begin{array}{c}\text { GARCH }(1,1) \text { ou } \\
\operatorname{GARCH}(1,2) \text { ou } \\
\operatorname{GARCH}(2,1)\end{array}$ \\
\hline
\end{tabular}

Tabela 3 - Identificação das possíveis ordens dos modelos.

Com base nos resultados na tabela acima obtivemos, para todas as séries, que a ordem univariada sugerida foi de no máximo 2, tanto para o componente de autocorrelação quanto para o componente de média móvel. Assim, tivemos a indicação de que as ordens dos modelos a serem estimados, para o caso multivariado, também fossem de ordem baixa. Contudo, a validação das ordens sugeridas se dará pela eliminação da autocorrelação dos resíduos padronizados e do quadrado dos resíduos padronizados, conforme sequência de passos apresentada na seção 3.5. 


\subsection{Modelos com Ibovespa}

Nesta seção apresentaremos os resultados dos três modelos intermediários estimados com o Ibovespa, ou seja, modelos que não eliminaram autocorrelação dos resíduos padronizados, e de seus quadrados, estão apresentados no apêndice E. Sendo que os modelos aqui apresentados são os com o melhor ajuste de ordem encontrado. Toda a sequência de análise destes modelos seguirá análise dos parâmetros e testes LM para verificar a eliminação de autocorrelação dos resíduos padronizados. Por fim, é apresentado os resultados do teste de causalidade de Granger de segunda ordem e o gráfico das correlações condicionais estimadas.

O Modelo 1 trata da combinação do Ibovespa com IND1 e IND3.

\begin{tabular}{|c|c|c|c|c|}
\hline \multicolumn{5}{|c|}{ Modelo 1} \\
\hline \multicolumn{5}{|c|}{ Modelo $\operatorname{BEKK}(2,1)$} \\
\hline Parâmetros & Estimativa & DP & Estatistica & P Valor \\
\hline$\alpha_{10}$ & 0,199 & 0,036 & 5,480 & 0,000 \\
\hline$\alpha_{20}$ & $-0,036$ & 0,007 & $-4,826$ & 1,000 \\
\hline$\alpha_{\mathbf{s o}}$ & 0,083 & 0,017 & 4,845 & 0,000 \\
\hline$\alpha_{11}$ & 0,058 & 0,009 & 6,233 & 0,000 \\
\hline$\alpha_{22}$ & $-0,008$ & 0,008 & $-1,039$ & 0,850 \\
\hline$\alpha_{33}$ & 0,133 & 0,024 & 5,578 & 0,000 \\
\hline$\beta_{I I}$ & 0,221 & 0,018 & 12,099 & 0,000 \\
\hline$\beta_{z 2}$ & 0,172 & 0,028 & 6,242 & 0,000 \\
\hline$\beta_{s s}$ & 0,947 & 0,034 & 28,001 & 0,000 \\
\hline$\beta_{2 s}$ & 0,173 & 0,185 & 0,94 & 0,174 \\
\hline$A I C$ & 18.782 & & & \\
\hline BIC & 18.833 & & & \\
\hline LOG & $-9381,95$ & & & \\
\hline
\end{tabular}

\begin{tabular}{|c|c|c|c|c|c|c|}
\hline \multirow[b]{2}{*}{ Defasagem } & \multicolumn{5}{|c|}{ Teste LM para Residuos e Quadrado dos Resíduos } & \multirow[b]{2}{*}{$\mathrm{u}_{3, t-\mathrm{p}}^{2}$} \\
\hline & $\mathrm{u}_{1, t-\mathrm{P}}$ & $\mathrm{u}_{2, t-\mathrm{p}}$ & $\mathrm{u}_{\mathrm{s}, \mathrm{t}-\mathrm{p}}$ & $u_{1, t-p}^{2}$ & $u_{2, t-p}^{2}$ & \\
\hline 1 & 0,45 & 0,23 & 0,39 & 0,62 & 0,95 & 0,20 \\
\hline 2 & 0,74 & 0,45 & 0,11 & 0,19 & 0,55 & 0,17 \\
\hline 3 & 0,58 & 0,55 & 0,14 & 0,35 & 0,28 & 0,14 \\
\hline 4 & 0,73 & $0,4 \mathrm{I}$ & 0,50 & 0,49 & 0,38 & 0,89 \\
\hline 5 & 0,85 & $0,5 \mathrm{I}$ & 0,13 & 0,53 & 0,38 & 0,92 \\
\hline 6 & 0,92 & 0,62 & 0,21 & 0,65 & 0,47 & 0,10 \\
\hline 7 & 0,89 & 0,25 & 0,40 & 0,74 & 0,46 & 0,84 \\
\hline 8 & 0,91 & 0,28 & 0,35 & 0,82 & 0,56 & 0,10 \\
\hline 9 & 0,94 & 0,24 & 0,63 & 0,88 & 0,57 & 0,17 \\
\hline 10 & 0,89 & 0,32 & 0,11 & 0,51 & 0,65 & 0,56 \\
\hline
\end{tabular}

Figura 29 - Parâmetros BEKK e Teste LM - Modelo 1
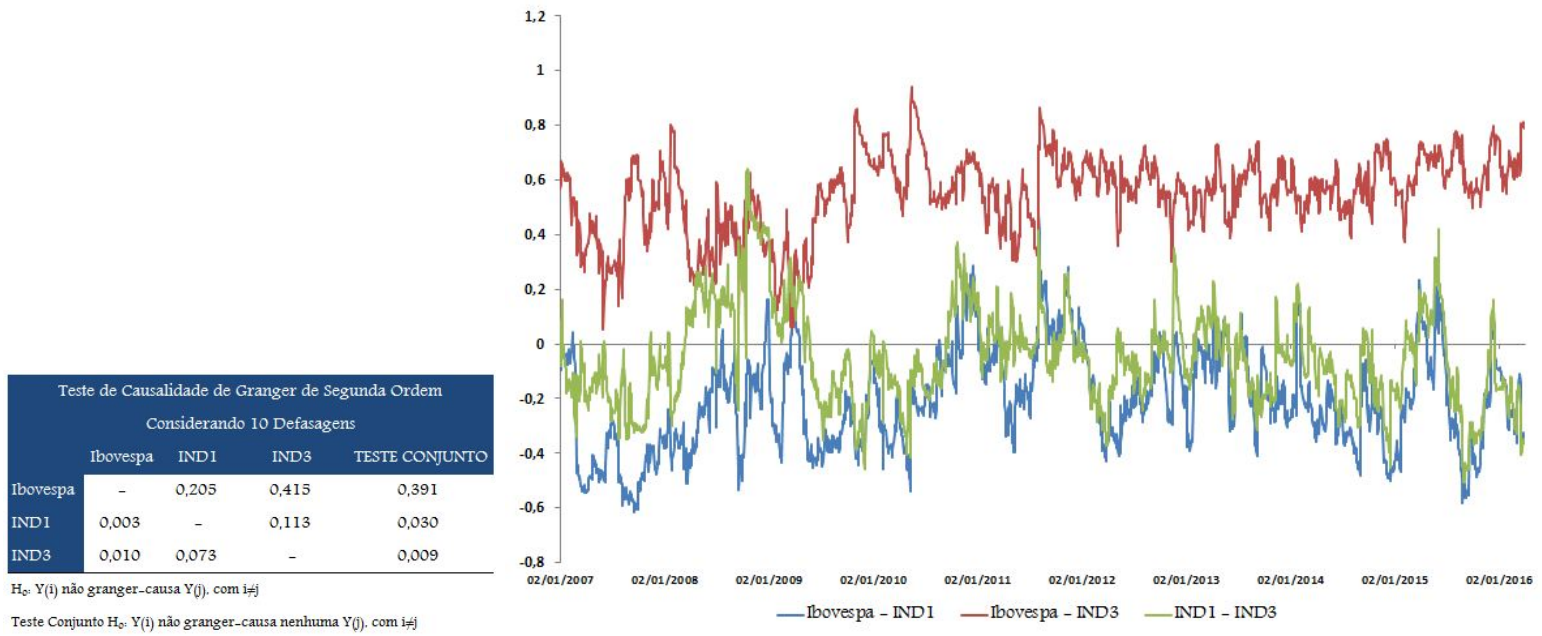

Figura 30 - Teste de Causalidade de Granger de Segunda Ordem e Gráfico de Correlações Condicionais - Modelo 1

O modelo apresenta três parâmetros estatisticamente insignificantes, os quais estão destacados, entretanto com ajuste adequado do processo gerador da série por meio do MGARCH$\operatorname{BEKK}(2,1)$. Os testes de causalidade de Granger de segunda ordem indicam: 
- A volatilidade do IND1 causa, no sentido de Granger, a volatilidade do Ibovespa;

- A volatilidade do IND3 causa, no sentido de Granger, a volatilidade do Ibovespa;

- A volatilidade do IND1 causa, no sentido de Granger, alguma volatilidade estimada no modelo pelo teste conjunto;

- A volatilidade do IND3 causa, no sentido de Granger, alguma volatilidade estimada no modelo pelo teste conjunto.

O gráfico das correlações condicionais mostram que choques cambiais estão negativamente correlacionados com o Ibovespa na maior parte do período amostral. Já a correlação condicional dos choques de mercados financeiros internacionais é positiva em todo o período amostral.

O Modelo 2 trata da combinação do Ibovespa com IND2 e IND3.

\begin{tabular}{|c|c|c|c|c|}
\hline \multicolumn{5}{|c|}{ Modelo 2} \\
\hline \multicolumn{5}{|c|}{ Modelo $\operatorname{BEKK}(\mathrm{I}, \mathrm{I})$} \\
\hline Parâmetros & Estimativa & DP & Estatistica & P Valor \\
\hline$\alpha_{10}$ & 0,229 & 0,040 & 5,711 & 0,000 \\
\hline$a_{20}$ & $-0,046$ & 0,009 & $-5,231$ & 1,000 \\
\hline$\alpha_{30}$ & 0,096 & 0,021 & 4,518 & 0,000 \\
\hline$\alpha_{11}$ & 0,106 & 0,023 & 4,682 & 0,000 \\
\hline$\alpha_{22}$ & $-0,041$ & 0,012 & $-3,372$ & 1,000 \\
\hline$a_{s s}$ & 0,150 & 0,026 & 5,823 & 0,000 \\
\hline$\beta_{I I}$ & 0,210 & 0,032 & 6,559 & 0,000 \\
\hline$\beta_{z z}$ & 0,210 & 0,034 & 6,146 & 0,000 \\
\hline$\beta_{s s}$ & 0,958 & 0,009 & 106,829 & 0,000 \\
\hline$A I C$ & 19.800 & & & \\
\hline$B I C$ & 19.852 & & & \\
\hline$L O G$ & - 9.890,95 & & & \\
\hline
\end{tabular}

\begin{tabular}{|c|c|c|c|c|c|c|}
\hline \multirow[b]{2}{*}{ Defasagem } & \multicolumn{5}{|c|}{ Teste LM para Residuos e Quadrado dos Resíduos } & \multirow[b]{2}{*}{$u_{\text {s.t-p }}^{2}$} \\
\hline & $\mathrm{u}_{1, t-\mathrm{p}}$ & $\mathrm{u}_{2, t-\mathrm{p}}$ & $\mathrm{u}_{3, t-\mathrm{p}}$ & $\mathrm{u}_{1, t-\mathrm{p}}^{2}$ & $u_{2, t-p}^{2}$ & \\
\hline I & 0,47 & 0,22 & 0,00 & 0,73 & 0,27 & 0,03 \\
\hline 2 & 0,77 & 0,29 & 0,00 & 0,25 & 0,27 & 0,03 \\
\hline 3 & 0,57 & 0,46 & 0,00 & 0,42 & 0,18 & 0,03 \\
\hline 4 & 0,72 & 0,43 & 0,00 & 0,58 & 0,09 & 0,02 \\
\hline 5 & 0,85 & 0,57 & 0,00 & 0,67 & 0,09 & 0,02 \\
\hline 6 & 0,91 & 0,63 & 0,00 & 0,78 & 0,09 & 0,02 \\
\hline 7 & 0,89 & 0,57 & 0,00 & 0,84 & 0,10 & 0,01 \\
\hline 8 & 0,91 & 0,59 & 0,00 & 0,90 & 0,10 & 0,02 \\
\hline 9 & 0,93 & 0,67 & 0,00 & 0,94 & 0,11 & 0,03 \\
\hline 10 & 0,89 & 0,74 & 0,01 & 0,63 & 0,15 & 0,01 \\
\hline
\end{tabular}

Figura 31 - Parâmetros BEKK e Teste LM - Modelo 2
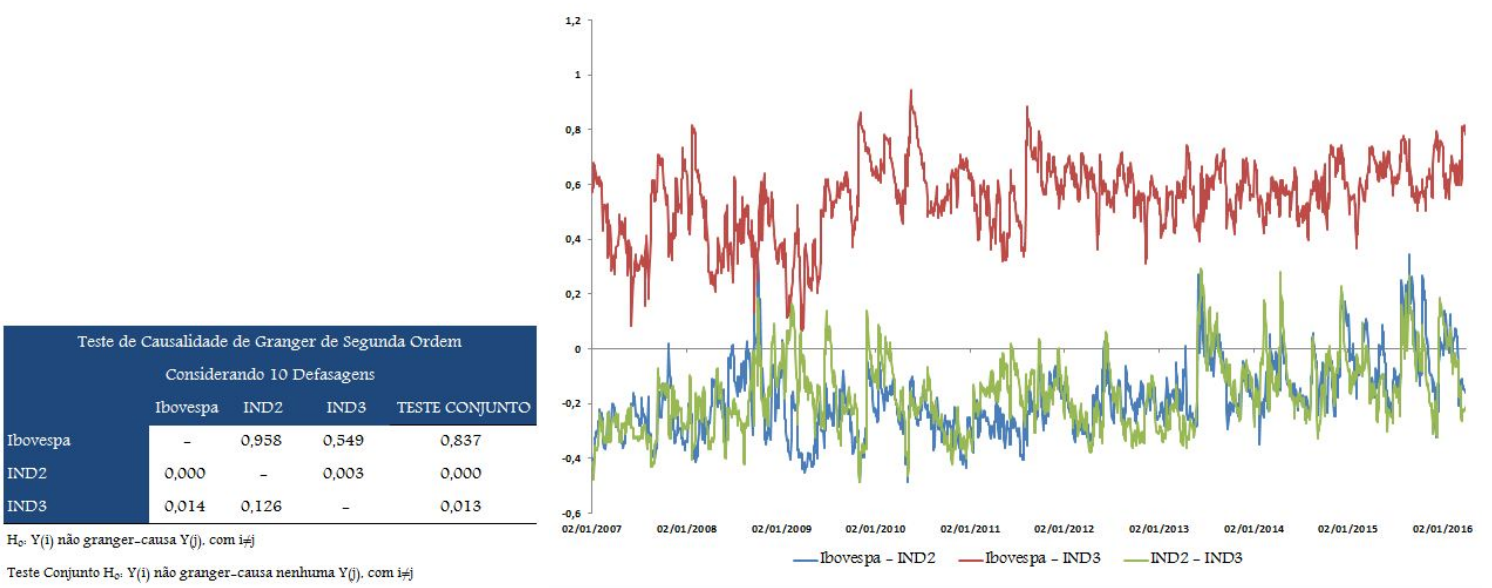

Figura 32 - Teste de Causalidade de Granger de Segunda Ordem e Gráfico de Correlações Condicionais - Modelo 2 
O modelo apresenta dois parâmetros estatisticamente insignificantes, entretanto foi possível ajustar adequadamente o processo gerador da série por meio do $\operatorname{MGARCH-BEKK}(1,1)$. Os testes de causalidade de Granger de segunda ordem indicam:

- A volatilidade do IND2 causa, no sentido de Granger, a volatilidade do Ibovespa;

- A volatilidade do IND3 causa, no sentido de Granger, a volatilidade do Ibovespa;

- A volatilidade do IND2 causa, no sentido de Granger, alguma volatilidade estimada no modelo pelo teste conjunto;

- A volatilidade do IND3 causa, no sentido de Granger, alguma volatilidade estimada no modelo pelo teste conjunto.

Na maior parte do período amostral pode ser observado a partir do gráfico das correlações condicionais que choques cambiais estão negativamente correlacionados com o Ibovespa. Já a correlação condicional dos choques de mercados financeiros internacionais é positiva em todo o período amostral.

O Modelo 3 trata da combinação do Ibovespa com Dólar e IND3.

\begin{tabular}{|c|c|c|c|c|c|c|c|c|c|c|c|}
\hline & & Modelo 3 & & & Defasagem & $\mathrm{u}_{1, \mathrm{t}-\mathrm{p}}$ & $u_{2,-p}$ & $\mathrm{u}_{\text {s,t-p }}$ & $\mathrm{u}_{1, t-\mathrm{p}}^{2}$ & $\mathrm{u}_{2, t-\mathrm{p}}^{2}$ & $\mathrm{u}_{\text {s,t-p }}^{2}$ \\
\hline Parâmetros & Estimativa & DP & Estatistica & P Valor & I & 0,48 & 0,56 & 0,29 & 0,73 & 0,27 & 0,31 \\
\hline$\alpha_{10}$ & 0,235 & 0,023 & 10,181 & 0,000 & 2 & 0,78 & 0,20 & 0,80 & 0,25 & 0,27 & 0,30 \\
\hline$\alpha_{20}$ & $-0,085$ & 0,012 & $-6,839$ & 1,000 & 3 & 0,57 & 0,26 & 0,12 & 0,42 & 0,18 & 0,27 \\
\hline$\alpha_{30}$ & 0,103 & 0,015 & 6,699 & 0,000 & & & & & & & \\
\hline$\alpha_{11}$ & 0,090 & 0,013 & 6,887 & 0,000 & 4 & 0,72 & 0,40 & $0,4 \mathrm{I}$ & 0,58 & 0,09 & 0,19 \\
\hline$\alpha_{22}$ & $-0,026$ & 0,019 & $-1,329$ & 0,908 & 5 & 0,85 & 0,48 & 0,11 & 0,67 & 0,09 & 0,18 \\
\hline$\alpha_{s s}$ & 0,157 & 0,015 & 10,266 & 0,000 & 6 & 0,92 & 0,46 & 0,20 & 0,78 & 0,09 & 0,16 \\
\hline$\beta_{I I}$ & 0,248 & 0,012 & 20,599 & 0,000 & & & & & & & \\
\hline$\beta_{22}$ & 0,149 & 0,021 & 7,002 & 0,000 & 7 & 0,90 & 0,57 & 0,38 & 0,84 & 0,10 & 0,13 \\
\hline$\beta_{s s}$ & 0,955 & 0,004 & 222,583 & 0,000 & 8 & 0,91 & 0,58 & 0,37 & 0,90 & 0,10 & 0,15 \\
\hline $\boldsymbol{A I C}$ & 20.888 & & & & 9 & 0,94 & 0,60 & 0,66 & 0,94 & 0,11 & 0,25 \\
\hline BIC & 20.940 & & & & 10 & 0,89 & 0,64 & 0,11 & 0,63 & 0,15 & 0,11 \\
\hline
\end{tabular}

Figura 33 - Parâmetros BEKK e Teste LM - Modelo 3 


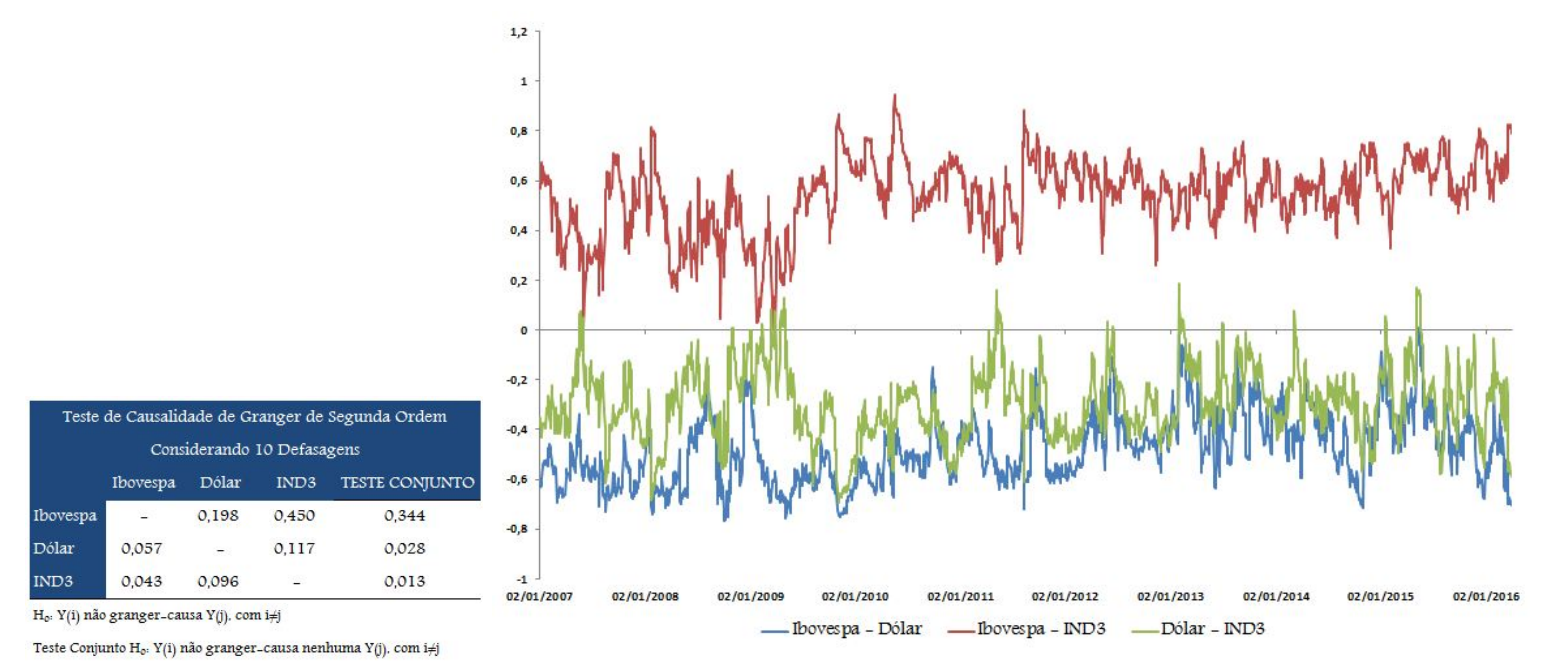

Figura 34 - Teste de Causalidade de Granger de Segunda Ordem e Gráfico de Correlações Condicionais - Modelo 3

Foi possível ajustar adequadamente o processo gerador da série por meio do MGARCH$\operatorname{BEKK}(1,1)$, apesar do modelo ter apresentado dois parâmetros estatisticamente insignificantes. Os testes de causalidade de Granger de segunda ordem indicam:

- A volatilidade do Dólar causa, no sentido de Granger, a volatilidade do Ibovespa;

- A volatilidade do IND3 causa, no sentido de Granger, a volatilidade do Ibovespa;

- A volatilidade do Dólar causa, no sentido de Granger, alguma volatilidade estimada no modelo pelo teste conjunto;

- A volatilidade do IND3 causa, no sentido de Granger, alguma volatilidade estimada no modelo pelo teste conjunto.

Ao longo de todo o período analisado observamos, a partir do gráfico das correlações condicionais, que o Dólar está negativamente correlacionados com o Ibovespa. Já a correlação condicional dos choques de mercados financeiros internacionais é positiva em todo o período amostral.

Em termos gerais os modelos ajustados confirmam a indicação de baixa ordem sugerida na seção 5.3. Os testes de causalidade de Granger de segunda ordem confirmam a existência dos transbordamentos estudados. Sendo a direção verificada sempre das proxies de choques cambiais e de mercados financeiros internacionais para o Ibovespa.

\subsection{Modelos com IGC-NM}

Nesta seção apresentaremos os resultados dos três modelos estimados com o IGC-NM, ou seja, modelos que não eliminaram autocorrelação dos resíduos padronizados, e de seus 
quadrados, estão apresentados no Apêndice E. Lembrando que os modelos aqui apresentados são os com o melhor ajuste de ordem encontrado. Toda a sequência de análise destes modelos seguirá análise dos parâmetros e testes LM para verificar a eliminação de autocorrelação dos resíduos padronizados. Por fim, é apresentado os resultados do teste de causalidade de Granger de segunda ordem e o gráfico das correlações condicionais estimadas.

O Modelo 4 trata da combinação do IGC-NM com IND1 e IND3.

\begin{tabular}{|c|c|c|c|c|}
\hline \multicolumn{5}{|c|}{ Modelo 4} \\
\hline \multicolumn{5}{|c|}{ Modelo $\operatorname{BEKK}(\mathrm{I}, \mathrm{I})$} \\
\hline Parâmetros & Estimativa & DP & Estatistica & P valor \\
\hline$\alpha_{10}$ & 0,148 & 0,028 & 5,233 & 0,000 \\
\hline$\alpha_{20}$ & $-0,033$ & 0,009 & $-3,838$ & 1,000 \\
\hline$\alpha_{30}$ & 0,068 & 0,017 & 4,131 & 0,000 \\
\hline$\alpha_{11}$ & 0,058 & 0,009 & 6,328 & 0,000 \\
\hline$\alpha_{22}$ & $-0,006$ & 0,012 & $-0,528$ & 0,070 \\
\hline$\alpha_{s s}$ & 0,134 & 0,026 & 5,070 & 0,000 \\
\hline$\beta_{I I}$ & 0,222 & 0,017 & 12,958 & 0,000 \\
\hline$\beta_{2 z}$ & 0,162 & 0,026 & 6,256 & 0,000 \\
\hline$\beta_{s s}$ & 0,964 & 0,006 & 158,32 & 0,000 \\
\hline
\end{tabular}

\begin{tabular}{|c|c|c|c|c|c|c|}
\hline \multirow[b]{2}{*}{ Defasagem } & \multicolumn{5}{|c|}{ Teste LM para Resíduos e Quadrado dos Resíduos } & \multirow[b]{2}{*}{$\mathrm{u}^{2}{ }_{\mathrm{s}, \mathrm{t}-\mathrm{p}}$} \\
\hline & $u_{1, t-p}$ & $\mathrm{u}_{2, \mathrm{t}-\mathrm{p}}$ & $u_{s, t-p}$ & $\mathrm{u}_{1, t-\mathrm{p}}^{2}$ & $\mathrm{u}_{2, t-\mathrm{p}}^{2}$ & \\
\hline I & 0,86 & 0,23 & 0,44 & 0,55 & 0,97 & 0,17 \\
\hline 2 & 0,90 & 0,45 & 0,13 & 0,51 & 0,54 & 0,15 \\
\hline 3 & 0,47 & 0,55 & 0,16 & 0,63 & 0,27 & 0,12 \\
\hline 4 & 0,60 & 0,41 & 0,56 & 0,76 & 0,37 & 0,78 \\
\hline 5 & 0,37 & 0,51 & 0,15 & 0,88 & 0,37 & 0,82 \\
\hline 6 & 0,43 & 0,62 & 0,23 & 0,92 & 0,46 & 0,91 \\
\hline 7 & 0,54 & 0,25 & 0,44 & 0,94 & 0,44 & 0,76 \\
\hline 8 & 0,63 & 0,28 & 0,39 & 0,88 & 0,55 & 0,91 \\
\hline 9 & 0,46 & 0,24 & 0,68 & 0,83 & 0,56 & 0,16 \\
\hline 10 & 0,52 & 0,32 & 0,11 & 0,76 & 0,65 & 0,48 \\
\hline
\end{tabular}

Figura 35 - Parâmetros BEKK e Teste LM - Modelo 4
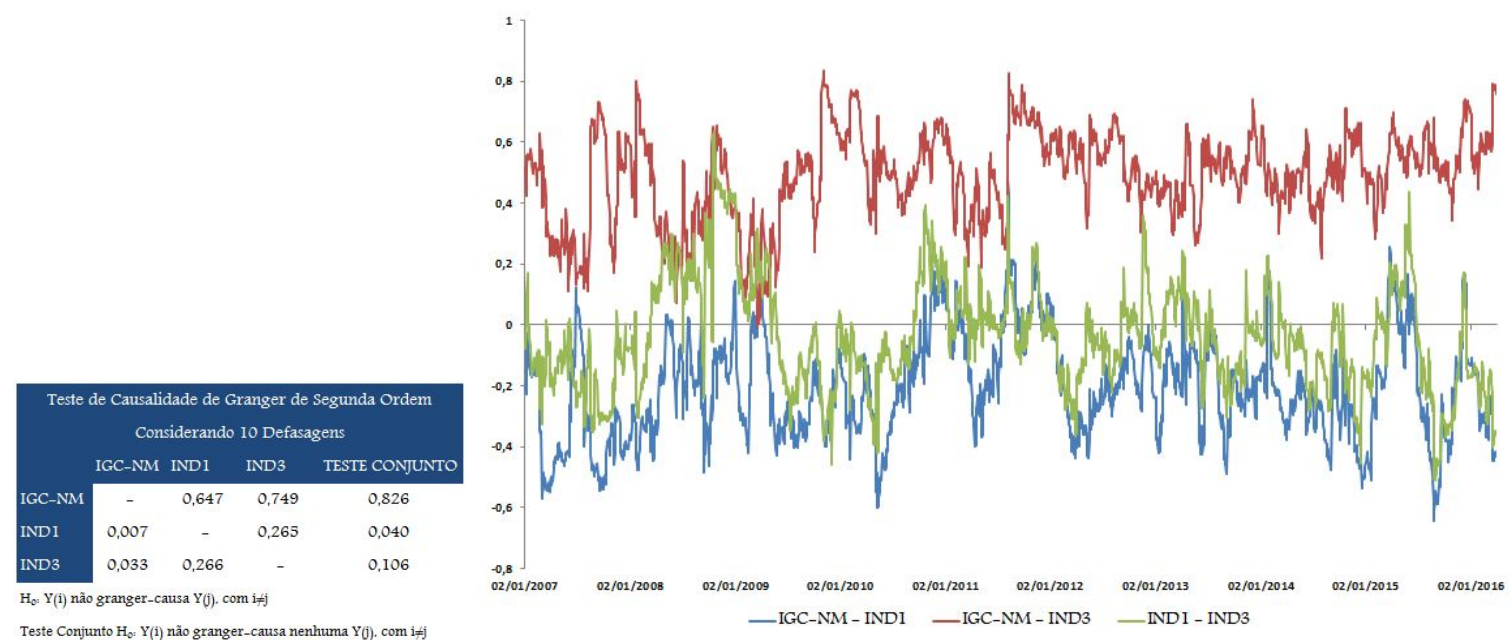

Figura 36 - Teste de Causalidade de Granger de Segunda Ordem e Gráfico de Correlações Condicionais - Modelo 4

O modelo 4 apresenta um parâmetro estatisticamente insignificantes, entretanto foi possível ajustar adequadamente o processo gerador da série por meio do MGARCH-BEKK $(1,1)$. Os testes de causalidade de Granger de segunda ordem indicam:

- A volatilidade do IND1 causa, no sentido de Granger, a volatilidade do IGC-NM;

- A volatilidade do IND3 causa, no sentido de Granger, a volatilidade do IGC-NM; 
- A volatilidade do IND1 causa, no sentido de Granger, alguma volatilidade estimada no modelo pelo teste conjunto;

- A volatilidade do IND3 causa, no sentido de Granger, alguma volatilidade estimada no modelo pelo teste conjunto.

Durante o período amostral observado por meio do gráfico das correlações condicionais percebemos que choques cambiais estão negativamente correlacionados com o IGC-NM na maioria do período. Contudo, em alguns momentos essas correlações condicionais se apresentam bem próximos a zero e em outros momentos chegam a ser positivas. Já a correlação condicional dos choques de mercados financeiros internacionais é positiva em todo o período amostral.

O Modelo 5 trata da combinação do IGC-NM com IND2 e IND3.

\begin{tabular}{|c|c|c|c|c|c|c|c|c|c|c|c|}
\hline \multicolumn{5}{|c|}{ Modelo 5} & \multirow{3}{*}{ Defasagem } & \multirow{3}{*}{$\mathrm{u}_{1, \mathrm{t}-\mathrm{p}}$} & \multirow{3}{*}{$\mathrm{u}_{2, t-\mathrm{p}}$} & \multirow{3}{*}{$\mathrm{u}_{\text {s,t-p }}$} & \multirow{3}{*}{$\mathrm{u}_{1, t-\mathrm{p}}^{2}$} & \multirow{3}{*}{$\mathrm{u}^{2}{ }_{2, t-p}$} & \multirow{3}{*}{$\mathrm{u}_{\text {s.t-p }}^{2}$} \\
\hline \multicolumn{5}{|c|}{ Modelo $\operatorname{BEKK}(2,1)$} & & & & & & & \\
\hline Parâmetros & Estimativa & DP & Estatistica & P Valor & & & & & & & \\
\hline$\alpha_{10}$ & 0,203 & 0,039 & 5,224 & 0,000 & I & 0,84 & 0,93 & 0,00 & 0,63 & 0,32 & 0,10 \\
\hline$\alpha_{20}$ & $-0,047$ & 0,010 & $-4,854$ & 1,000 & 2 & 0,89 & 0,22 & 0,00 & 0,11 & 0,32 & 0,04 \\
\hline$\alpha_{30}$ & 0,090 & 0,026 & 3,517 & 0,000 & 3 & 0,45 & 0,33 & 0,00 & 0,18 & 0,19 & 0,04 \\
\hline$\alpha_{11}$ & $\begin{array}{c}0,122 \\
-0,061\end{array}$ & $\begin{array}{l}0,027 \\
0,016\end{array}$ & $\begin{array}{r}4,506 \\
-3,780\end{array}$ & $\begin{array}{l}0,000 \\
1,000\end{array}$ & 4 & 0,59 & 0,44 & 0,00 & 0,30 & 0,09 & 0,02 \\
\hline $\begin{array}{l}a_{22} \\
a_{35}\end{array}$ & $\begin{array}{r}-0,061 \\
0,177\end{array}$ & $\begin{array}{l}0,016 \\
0,034\end{array}$ & $\begin{array}{r}-3,780 \\
5,184\end{array}$ & $\begin{array}{l}1,000 \\
0,000\end{array}$ & 5 & 0,36 & 0,98 & 0,00 & 0.46 & 0,10 & 0,02 \\
\hline$\beta_{I I}$ & 0,248 & 0,045 & 5,478 & 0,000 & 6 & 0.41 & 0.19 & n? & . & & \\
\hline$\beta_{22}$ & 0,260 & 0,033 & 7,928 & 0,000 & & 0,11 &, 19 & 0,00 & 0,56 &, 09 & 0,02 \\
\hline$\beta_{s s}$ & 0,675 & 0,098 & 6,89 & 0,000 & 7 & 0,52 & 0,33 & 0,00 & 0,67 & 0,09 & 0,01 \\
\hline \multirow[t]{2}{*}{$\beta_{2 s}$} & 0,658 & 0,090 & 7,33 & 0,000 & 8 & 0,62 & 0,44 & 0,00 & 0,56 & 0,09 & 0,02 \\
\hline & & & & & 9 & 0,45 & 0,19 & 0,00 & 0,55 & 0,10 & 0,03 \\
\hline $\begin{array}{l}A I C \\
B I C\end{array}$ & $\begin{array}{l}18.964 \\
19.021\end{array}$ & & & & 10 & 0,51 & 0,16 & 0,00 & 0,49 & 0,14 & 0,01 \\
\hline LOG & $-9472,05$ & & & & 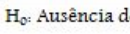 & & & & & & \\
\hline
\end{tabular}

Figura 37 - Parâmetros BEKK e Teste LM - Modelo 5
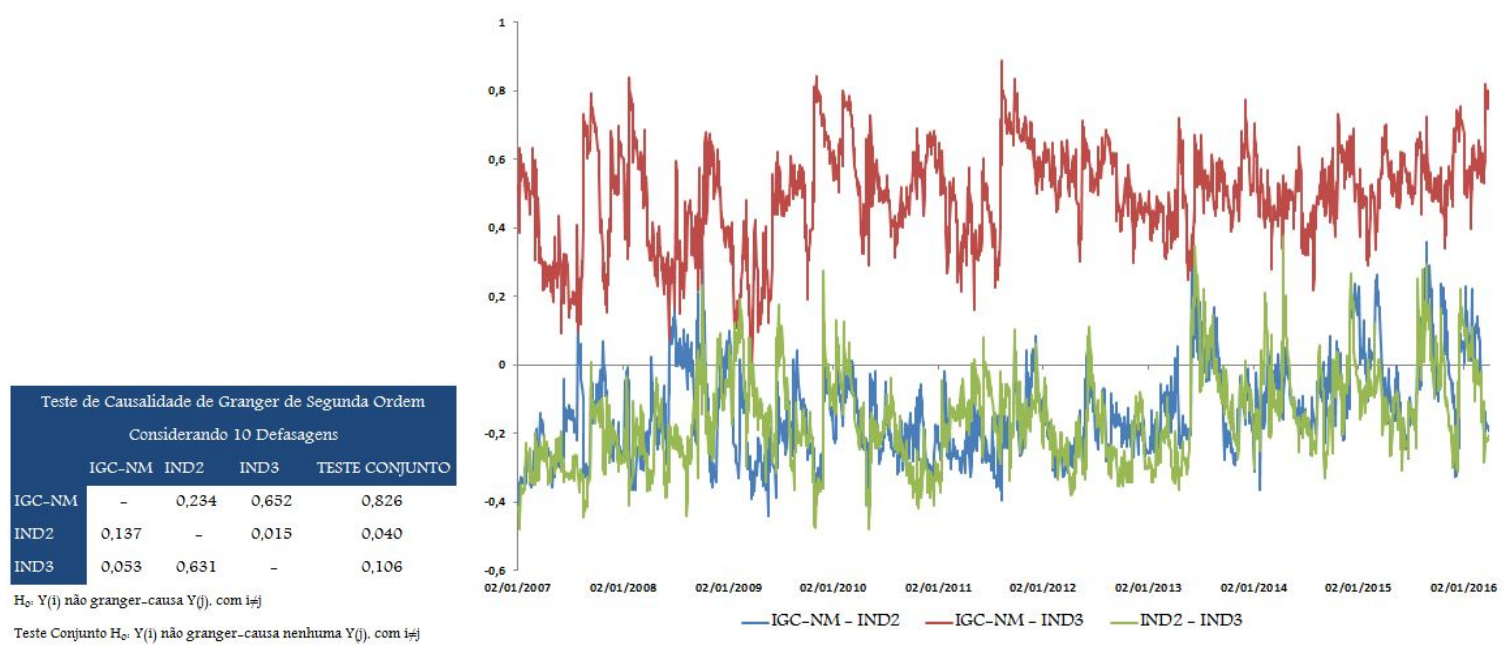

Figura 38 - Teste de Causalidade de Granger de Segunda Ordem e Gráfico de Correlações Condicionais - Modelo 5 
Foi possível ajustar adequadamente o processo gerador da série por meio do MGARCH$\operatorname{BEKK}(2,1)$ ainda que o modelo tenha apresentado dois parâmetros estatisticamente insignificantes. Os testes de causalidade de Granger de segunda ordem indicam:

- A volatilidade do IND2 causa, no sentido de Granger, a volatilidade do IGC-NM;

- A volatilidade do IND3 causa, no sentido de Granger, a volatilidade do IGC-NM;

- A volatilidade do IND2 causa, no sentido de Granger, alguma volatilidade estimada no modelo pelo teste conjunto;

- A volatilidade do IND3 causa, no sentido de Granger, alguma volatilidade estimada no modelo pelo teste conjunto.

Durante o período amostral observado por meio do gráfico das correlações condicionais percebemos que choques cambiais estão negativamente correlacionados com o IGC-NM na maioria do período. Contudo, em alguns momentos essas correlações condicionais se apresentam bem próximos a zero e em outros momentos chegam a ser positivas. Já a correlação condicional dos choques de mercados financeiros internacionais é positiva em todo o período amostral.

O Modelo 6 trata da combinação do IGC-NM com Dólar e IND3.

\begin{tabular}{|c|c|c|c|c|c|c|c|c|c|c|c|}
\hline \\
\hline & & & & & \multirow{4}{*}{ Defasagem } & \multicolumn{5}{|c|}{ Teste LM para Resíduos e Quadrado dos Resíduos } & \multirow{4}{*}{$\mathrm{u}^{2}{ }_{s, t-p}$} \\
\hline \multicolumn{5}{|c|}{ Modelo 6} & & \multirow{3}{*}{$\mathrm{u}_{1, \mathrm{t}-\mathrm{p}}$} & \multirow{3}{*}{$\mathrm{u}_{2, \mathrm{t}-\mathrm{p}}$} & \multirow{3}{*}{$u_{8, t-p}$} & \multirow{3}{*}{$u_{1, t-p}^{2}$} & \multirow{3}{*}{$\mathrm{u}_{2, \mathrm{t}-\mathrm{p}}^{2}$} & \\
\hline & & Elo BEKK & & & & & & & & & \\
\hline Parâmetros & Estimativa & $\mathrm{DP}$ & Estatistica & P valor & & & & & & & \\
\hline$\alpha_{10}$ & 0,183 & 0,020 & 8,995 & 0,000 & I & 0,84 & 0,78 & 0,30 & 0,34 & 0,46 & 0,26 \\
\hline$\alpha_{20}$ & $-0,073$ & 0,014 & $-5,219$ & 1,000 & 2 & 0,90 & 0,21 & 0,83 & 0,44 & 0,46 & 0,28 \\
\hline$\alpha_{\mathbf{s o}}$ & 0,091 & 0,018 & 5,103 & 0,000 & 3 & 0,45 & 0,26 & 0,12 & 0,55 & 0,70 & 0,22 \\
\hline$\alpha_{11}$ & 0,098 & 0,015 & 6,469 & 0,000 & & & & & & & \\
\hline$\alpha_{22}$ & $-0,037$ & 0,023 & $-1,601$ & 0,945 & 4 & 0,58 & 0,40 & 0,42 & 0,70 & 0,16 & 0,13 \\
\hline$a_{s s}$ & 0,162 & 0,019 & 8,401 & 0,000 & 5 & 0,37 & 0,48 & 0,11 & 0,83 & 0,33 & 0,11 \\
\hline$\beta_{I I}$ & 0,258 & 0,017 & 14,795 & 0,000 & 6 & 0,43 & 0,46 & 0,21 & 0,89 & 0,13 & 0,11 \\
\hline$\beta_{2 z}$ & 0,143 & 0,020 & 7,011 & 0,000 & & & & & & & \\
\hline$\beta_{s s}$ & 0,913 & 0,065 & 14,06 & 0,000 & 7 & 0,53 & 0,57 & 0,39 & 0,93 & 0,22 & 0,90 \\
\hline$\beta_{23}$ & 0,274 & 0,202 & 1,36 & 0,087 & 8 & 0,62 & 0,58 & 0,38 & 0,81 & 0,38 & 0,12 \\
\hline$A I C$ & 20.108 & & & & 9 & 0,44 & 0,60 & 0,67 & 0,78 & 0,61 & 0,20 \\
\hline$B I C$ & 20.165 & & & & 10 & 0,50 & 0,64 & 0,11 & 0,72 & 0,24 & 0,55 \\
\hline LOG & -10044 & & & & usên & orrelac & & & & & \\
\hline
\end{tabular}

Figura 39 - Parâmetros BEKK e Teste LM - Modelo 6 


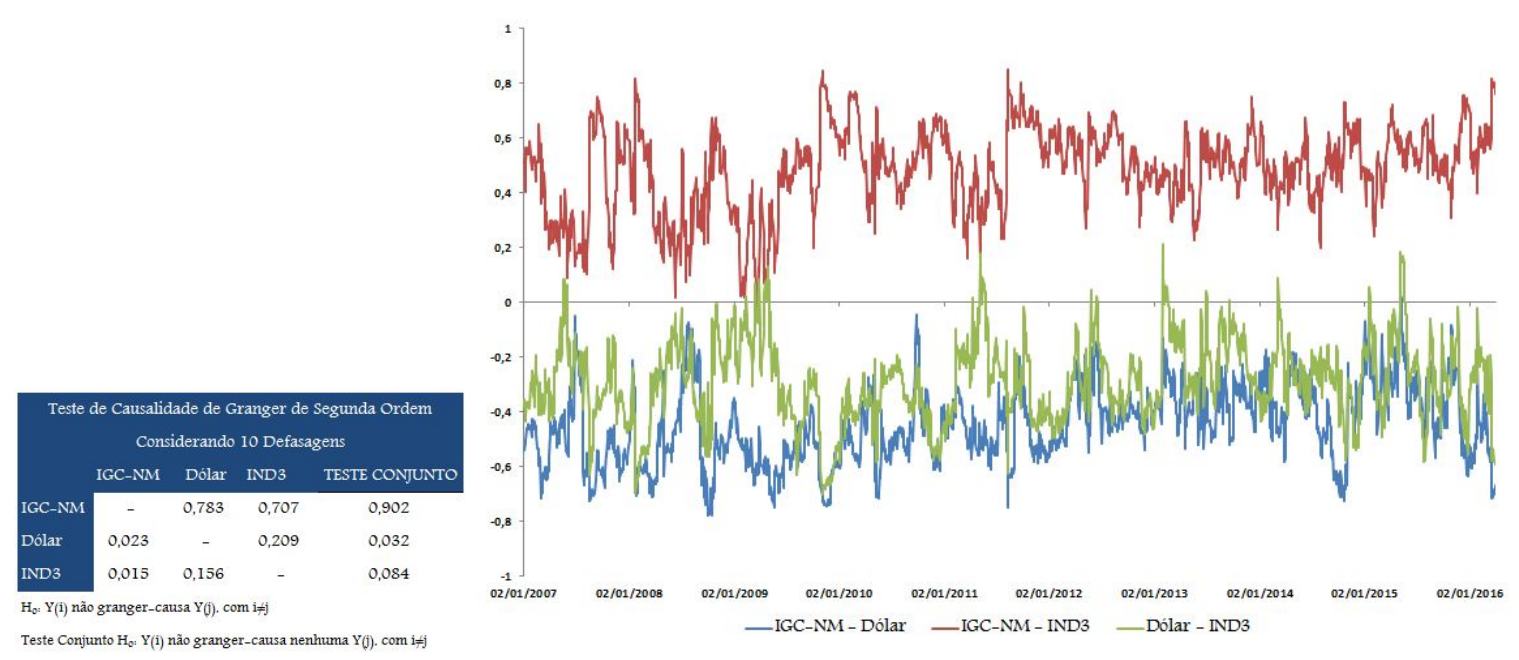

Figura 40 - Teste de Causalidade de Granger de Segunda Ordem e Gráfico de Correlações Condicionais - Modelo 6

O modelo 6 apresenta dois parâmetros estatisticamente insignificantes, entretanto com ajuste adequado do processo gerador da série por meio do MGARCH-BEKK(2,1). Os testes de causalidade de Granger de segunda ordem indicam:

- A volatilidade do Dólar causa, no sentido de Granger, a volatilidade do IGC-NM;

- A volatilidade do IND3 causa, no sentido de Granger, a volatilidade do IGC-NM;

- A volatilidade do Dólar causa, no sentido de Granger, alguma volatilidade estimada no modelo pelo teste conjunto;

- A volatilidade do IND3 causa, no sentido de Granger, alguma volatilidade estimada no modelo pelo teste conjunto.

O gráfico das correlações condicionais mostram que os choques de Dólar estão negativamente correlacionados com o IGC-NM em todo período amostral. Já a correlação condicional dos choques de mercados financeiros internacionais é positiva em todo o período amostral.

Em termos gerais os modelos ajustados confirmam a indicação de baixa ordem sugerida na seção 5.3. Os testes de causalidade de Granger de segunda ordem confirmam a existência dos transbordamentos estudados. Sendo a direção verificada sempre das proxies de choques cambiais e de mercados financeiros internacionais para o IGC-NM.

\subsection{Modelos com IGC-X}

Nesta seção apresentaremos os resultados dos três modelos estimados com o IGC-X, ou seja, modelos que não eliminaram autocorrelação dos resíduos padronizados, e de seus quadrados, 
estão apresentados no Apêndice E. Novamente os modelos apresentados são os com o melhor ajuste de ordem encontrado.

O Modelo 7 trata da combinação do IGC-X com IND1 e IND3.

\begin{tabular}{ccccc}
\hline \multicolumn{5}{c}{ Modelo 7 } \\
\hline \multicolumn{5}{c}{ Modelo BEKK(1, I) } \\
Parâmetros & Estimativa & DP & Estatistica & P Valor \\
\hline $\boldsymbol{\alpha}_{\mathbf{1 0}}$ & 0,150 & 0,028 & 5,305 & 0,000 \\
$\boldsymbol{\alpha}_{\mathbf{2 0}}$ & $-0,036$ & 0,008 & $-4,330$ & 1,000 \\
$\boldsymbol{\alpha}_{\mathbf{3 0}}$ & 0,075 & 0,018 & 4,252 & 0,000 \\
$\boldsymbol{\alpha}_{\mathbf{1 1}}$ & 0,054 & 0,010 & 5,317 & 0,000 \\
$\boldsymbol{\alpha}_{\mathbf{2 2}}$ & $-0,003$ & 0,004 & $-0,791$ & 0,785 \\
$\boldsymbol{\alpha}_{\mathbf{3 3}}$ & 0,131 & 0,025 & 5,233 & 0,000 \\
$\boldsymbol{\beta}_{\boldsymbol{1 1}}$ & 0,220 & 0,017 & 13,247 & 0,000 \\
$\boldsymbol{\beta}_{\mathbf{z 2}}$ & 0,163 & 0,023 & 7,158 & 0,000 \\
$\boldsymbol{\beta}_{\mathbf{s 3}}$ & 0,965 & 0,006 & 174,23 & 0,000 \\
\hline
\end{tabular}

\begin{tabular}{|c|c|c|c|c|c|c|}
\hline Defasagem & $\begin{array}{l}\text { Teste } \\
\mathrm{u}_{1, \mathrm{t}-\mathrm{p}}\end{array}$ & $\begin{array}{l}\text { para Resi } \\
\mathrm{u}_{2, \mathrm{t}-\mathrm{p}}\end{array}$ & $\begin{array}{l}\text { os e Quad } \\
\mathrm{u}_{\text {s:t-p }}\end{array}$ & $\begin{array}{l}\text { do dos } R e \\
\mathrm{u}_{1, t-\mathrm{p}}\end{array}$ & $\begin{array}{l}\text { uos } \\
u^{2}{ }_{2, t-p}\end{array}$ & $u^{2}{ }_{3, t-p}$ \\
\hline I & 0,39 & 0,23 & 0,45 & 0,19 & 0,97 & 0,17 \\
\hline 2 & 0,69 & 0,45 & 0,13 & 0,12 & 0,55 & 0,14 \\
\hline 3 & 0,30 & 0,55 & 0,17 & 0,21 & 0,27 & 0,12 \\
\hline 4 & 0,45 & 0,40 & 0,58 & 0,35 & 0,36 & 0,75 \\
\hline 5 & 0,51 & 0,51 & 0,15 & 0,42 & 0,36 & 0,80 \\
\hline 6 & 0,62 & 0,62 & 0,24 & 0,49 & 0,46 & 0,89 \\
\hline 7 & 0,68 & 0,25 & 0,45 & 0,50 & 0,44 & 0,76 \\
\hline 8 & 0,76 & 0,28 & 0,39 & 0,47 & 0,55 & 0,91 \\
\hline 9 & 0,69 & 0,24 & 0,70 & 0,49 & 0,55 & 0,16 \\
\hline 10 & 0,68 & 0,31 & 0,12 & 0,38 & 0,64 & 0,49 \\
\hline
\end{tabular}

Figura 41 - Parâmetros BEKK e Teste LM - Modelo 7

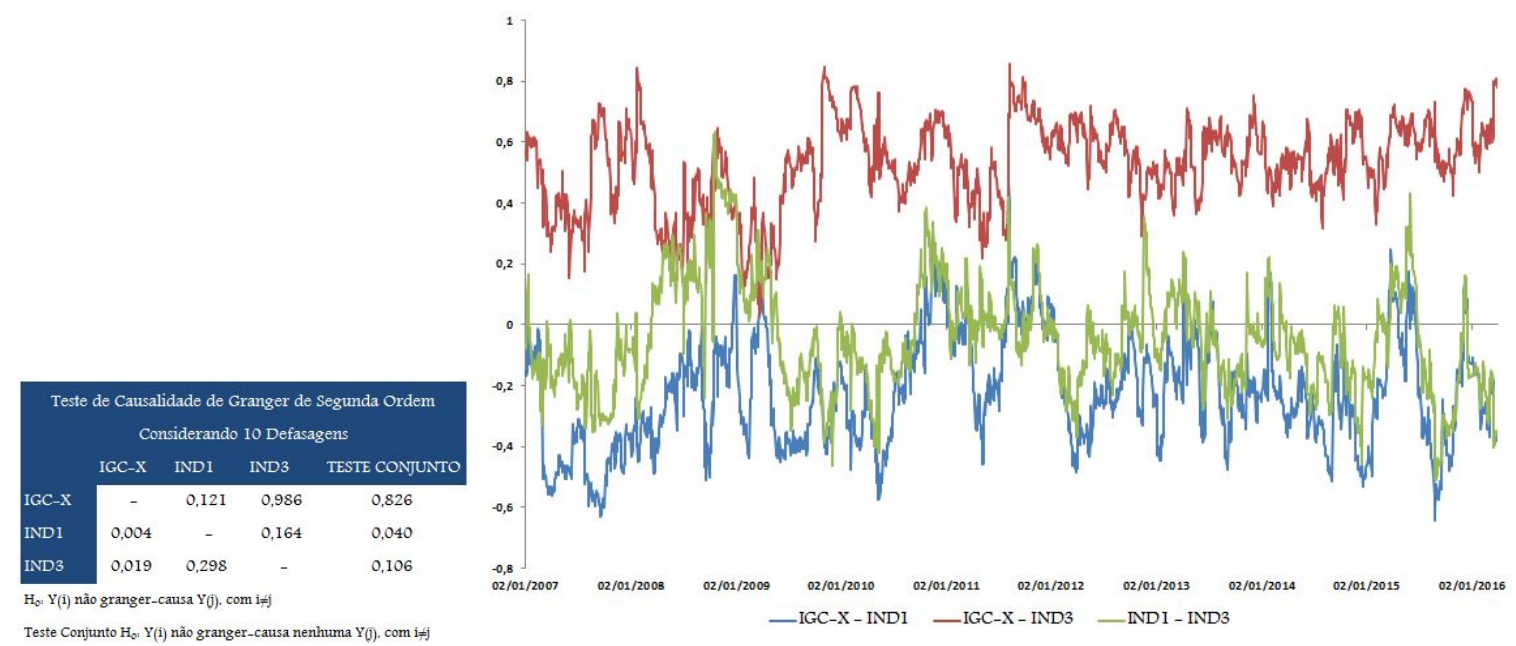

Figura 42 - Teste de Causalidade de Granger de Segunda Ordem e Gráfico de Correlações Condicionais - Modelo 7

O modelo 7 apresenta dois parâmetros estatisticamente insignificantes, mas houve ajuste adequado do processo gerador da série por meio do MGARCH-BEKK(1,1). Os testes de causalidade de Granger de segunda ordem indicam:

- A volatilidade do IND1 causa, no sentido de Granger, a volatilidade do IGC-X;

- A volatilidade do IND3 causa, no sentido de Granger, a volatilidade do IGC-X;

- A volatilidade do IND1 causa, no sentido de Granger, alguma volatilidade estimada no modelo pelo teste conjunto; 
- A volatilidade do IND3 causa, no sentido de Granger, alguma volatilidade estimada no modelo pelo teste conjunto.

Durante o período amostral observado por meio do gráfico das correlações condicionais percebemos que choques cambiais estão negativamente correlacionados com o IGC-X na maioria do período. Contudo, em alguns momentos essas correlações condicionais se apresentam bem próximos a zero e em outros momentos chegam a ser positivas. Já a correlação condicional dos choques de mercados financeiros internacionais é positiva em todo o período amostral.

O Modelo 8 trata da combinação do IGC-X com IND2 e IND3.

\begin{tabular}{|c|c|c|c|c|c|c|c|c|c|c|c|}
\hline \multicolumn{5}{|c|}{ Modelo 8} & \multirow{2}{*}{\multicolumn{7}{|c|}{ Teste LM para Resíduos e Quadrado dos Resíduos }} \\
\hline \multicolumn{5}{|c|}{ Modelo $\operatorname{BEKK}(2,2)$} & & & & & & & \\
\hline Farâmetros & Estimativa & DP & Estatistica & P Valor & Defasagem & $\mathrm{u}_{1, \mathrm{t}-\mathrm{p}}$ & $\mathrm{u}_{2, t-\mathrm{p}}$ & $\mathrm{u}_{\mathrm{s}, \mathrm{t}-\mathrm{p}}$ & $\mathrm{u}_{1, \mathrm{t}-\mathrm{p}}^{2}$ & $\mathrm{u}_{2, t-\mathrm{p}}^{2}$ & $u^{2}{ }_{s, t-p}$ \\
\hline $\begin{array}{l}\alpha_{10} \\
\alpha_{20}\end{array}$ & $\begin{array}{c}0,196 \\
-0,052\end{array}$ & $\begin{array}{l}0,041 \\
0,010\end{array}$ & $\begin{array}{l}4,829 \\
-5,432\end{array}$ & $\begin{array}{l}0,000 \\
1,000\end{array}$ & I & 0,37 & 0,94 & 0,00 & 0,39 & 0,31 & 0,07 \\
\hline$\alpha_{\mathbf{s o}}$ & 0,096 & 0,029 & 3,315 & 0,000 & 2 & 0,67 & 0,23 & 0,00 & 0,56 & 0,32 & 0,03 \\
\hline$\alpha_{11}$ & 0,112 & 0,028 & 3,975 & 0,000 & 3 & 0,27 & 0,35 & 0,00 & 0,15 & 0,20 & 0,03 \\
\hline$\alpha_{2 z}$ & $-0,047$ & 0,015 & $-3,051$ & 0,999 & & & & & & & \\
\hline$\alpha_{s s}$ & 0,166 & 0,034 & 4,895 & 0,000 & 4 & 0,42 & 0,48 & 0,00 & 0,38 & 0,10 & 0,01 \\
\hline$a_{23}$ & 0,241 & 0,048 & 5,037 & 0,000 & 5 & 0,48 & 0,11 & 0,00 & 0,63 & 0,10 & 0,01 \\
\hline$\beta_{I I}$ & 0,000 & 0,000 & 0,971 & 0,166 & 6 & 0,60 & 0,21 & 0,00 & 0,84 & 0,09 & 0,02 \\
\hline$\beta_{22}$ & 0,239 & 0,030 & 7,951 & 0,000 & & & & & & & \\
\hline$\beta_{s s}$ & 0,724 & 0,128 & 5,64 & 0,000 & 7 & 0,67 & 0,36 & 0,00 & 0,11 & 0,10 & 0,01 \\
\hline$\beta_{2 s}$ & 0,611 & 0,137 & 4,47 & 0,000 & 8 & 0,75 & 0,46 & 0,00 & 0,10 & 0,09 & 0,02 \\
\hline $\boldsymbol{A I C}$ & 19.071 & & & & 9 & 0,68 & 0,20 & 0,00 & 0,11 & 0,11 & 0,03 \\
\hline$B I C$ & 19.134 & & & & 10 & 0,67 & 0,17 & 0,01 & 0,10 & 0,14 & 0,01 \\
\hline LOG & $-9524,5$ & & & & & & & & & & \\
\hline
\end{tabular}

Figura 43 - Parâmetros BEKK e Teste LM - Modelo 8
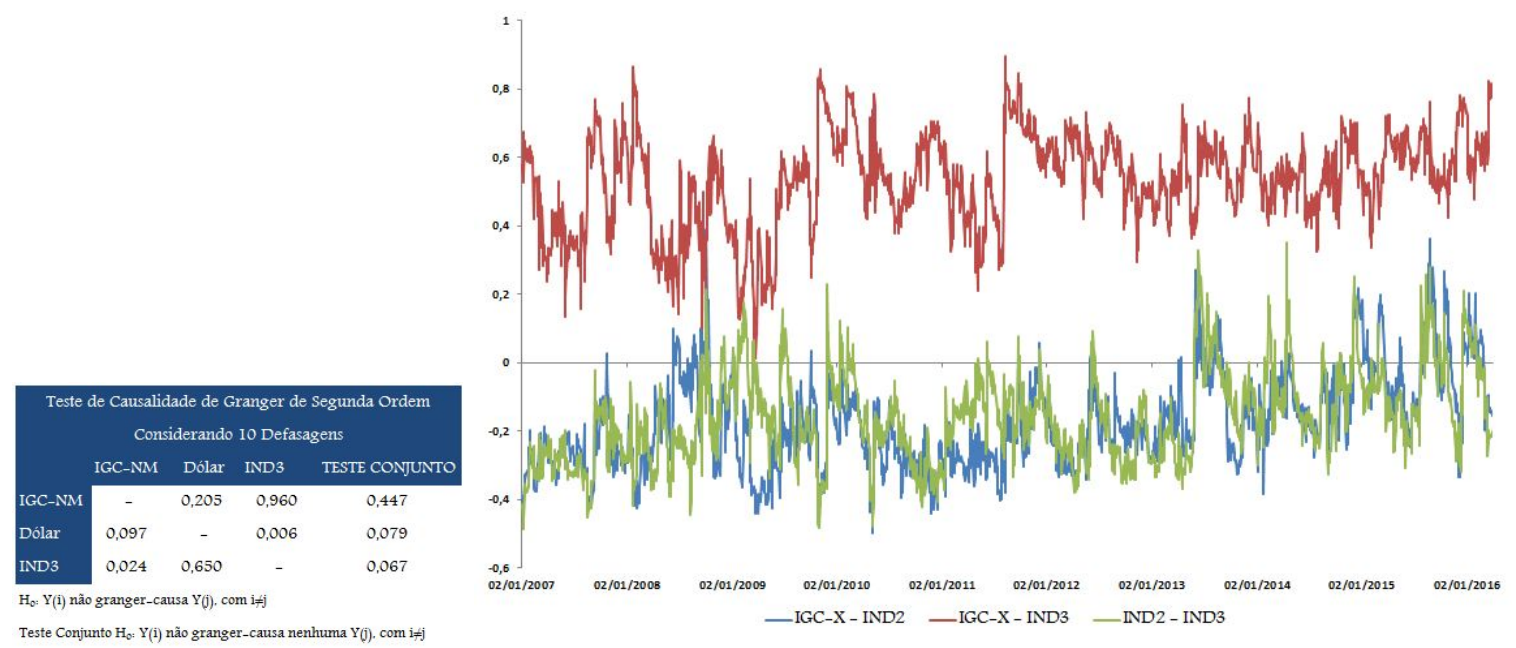

Figura 44 - Teste de Causalidade de Granger de Segunda Ordem e Gráfico de Correlações Condicionais - Modelo 8

O modelo 8 apresenta três parâmetros estatisticamente insignificantes, mas houve ajuste adequado do processo gerador da série por meio do MGARCH-BEKK(2,2). Os testes de causalidade de Granger de segunda ordem indicam: 
- A volatilidade do IND2 causa, no sentido de Granger, a volatilidade do IGC-X;

- A volatilidade do IND3 causa, no sentido de Granger, a volatilidade do IGC-X;

- A volatilidade do IND2 causa, no sentido de Granger, alguma volatilidade estimada no modelo pelo teste conjunto;

- A volatilidade do IND3 causa, no sentido de Granger, alguma volatilidade estimada no modelo pelo teste conjunto.

Durante o período amostral observado por meio do gráfico das correlações condicionais percebemos que choques cambiais estão negativamente correlacionados com o IGC-X na maioria do período. Contudo, em alguns momentos essas correlações condicionais se apresentam bem próximos a zero e em outros momentos chegam a ser positivas. Já a correlação condicional dos choques de mercados financeiros internacionais é positiva em todo o período amostral.

O Modelo 9 trata da combinação do IGC-X com Dólar e IND3.

\begin{tabular}{|c|c|c|c|c|}
\hline \multicolumn{5}{|c|}{ Modelo 9} \\
\hline \multicolumn{5}{|c|}{ Modelo BEKK(1,1) } \\
\hline Farâmetros & Estimativa & DP & Estatistica & P Valor \\
\hline$\alpha_{10}$ & 0,179 & 0,021 & 8,306 & 0,000 \\
\hline$\alpha_{20}$ & $-0,073$ & 0,012 & $-5,965$ & 1,000 \\
\hline$\alpha_{\mathbf{s o}}$ & 0,095 & 0,023 & 4,226 & 0,000 \\
\hline$\alpha_{11}$ & 0,090 & 0,017 & 5,438 & 0,000 \\
\hline$\alpha_{22}$ & $-0,027$ & 0,036 & $-0,743$ & 0,771 \\
\hline$a_{s s}$ & 0,153 & 0,020 & 7,739 & 0,000 \\
\hline$\beta_{1 I}$ & 0,248 & 0,013 & 19,247 & 0,000 \\
\hline$\beta_{22}$ & 0,135 & 0,020 & 6,757 & 0,000 \\
\hline$\beta_{s s}$ & 0,957 & 0,004 & 220,78 & 0,000 \\
\hline
\end{tabular}

\begin{tabular}{ccccccc}
\hline \multicolumn{7}{c}{ Teste LM para Residuos e Quadrado dos Resíduos } \\
Defasagem & $\mathrm{u}_{1, \mathrm{t}-\mathrm{p}}$ & $\mathrm{u}_{2, \mathrm{t}-\mathrm{p}}$ & $\mathrm{u}_{\text {s,t-p }}$ & $\mathrm{u}_{1, \mathrm{t}-\mathrm{p}}$ & $\mathrm{u}_{2, \mathrm{t}-\mathrm{p}}$ & $\mathrm{u}_{\text {3,t-p }}$ \\
\hline $\mathrm{I}$ & 0,38 & 0,77 & 0,00 & 0,10 & 0,03 & 0,02 \\
2 & 0,68 & 0,21 & 0,00 & 0,09 & 0,00 & 0,02 \\
3 & 0,28 & 0,26 & 0,00 & 0,18 & 0,01 & 0,02 \\
4 & 0,44 & 0,39 & 0,00 & 0,30 & 0,01 & 0,01 \\
5 & 0,51 & 0,48 & 0,00 & 0,40 & 0,03 & 0,01 \\
6 & 0,62 & 0,46 & 0,00 & 0,49 & 0,01 & 0,01 \\
7 & 0,69 & 0,57 & 0,00 & 0,54 & 0,02 & 0,01 \\
8 & 0,76 & 0,57 & 0,00 & 0,48 & 0,03 & 0,01 \\
9 & 0,68 & 0,59 & 0,01 & 0,49 & 0,05 & 0,02 \\
10 & 0,66 & 0,63 & 0,01 & 0,40 & 0,02 & 0,00 \\
\hline $\mathrm{H}_{0}$ : Ausência de autocorrelação & & & & &
\end{tabular}

Figura 45 - Parâmetros BEKK e Teste LM - Modelo 9
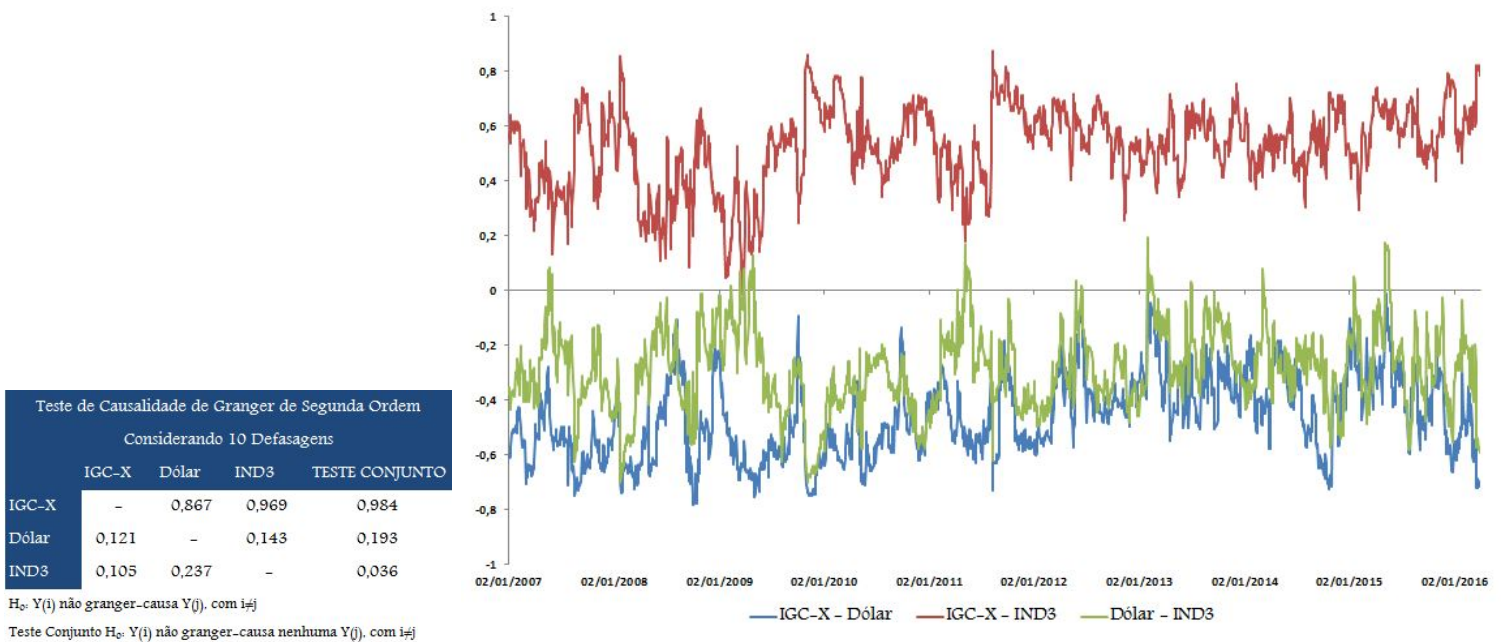

Figura 46 - Teste de Causalidade de Granger de Segunda Ordem e Gráfico de Correlações Condicionais - Modelo 9 
O modelo 9 apresenta dois parâmetros estatisticamente insignificantes, entretanto com ajuste adequado do processo gerador da série por meio do MGARCH-BEKK $(1,1)$. Os testes de causalidade de Granger de segunda ordem indicam:

- A volatilidade do Dólar causa, no sentido de Granger, a volatilidade do IGC-X;

- A volatilidade do IND3 causa, no sentido de Granger, a volatilidade do IGC-X;

- A volatilidade do Dólar causa, no sentido de Granger, alguma volatilidade estimada no modelo pelo teste conjunto;

- A volatilidade do IND3 causa, no sentido de Granger, alguma volatilidade estimada no modelo pelo teste conjunto.

O gráfico das correlações condicionais mostram que choques cambiais estão negativamente correlacionados com o IGC-X na maior parte do período amostral. Já a correlação condicional dos choques de mercados financeiros internacionais é positiva em todo o período amostral.

Em termos gerais os modelos ajustados confirmam a indicação de baixa ordem sugerida na seção 5.3. Os testes de causalidade de Granger de segunda ordem confirmam a existência dos transbordamentos estudados. Sendo a direção verificada sempre das proxies de choques cambiais e de mercados financeiros internacionais para o IGC-X.

\subsection{Análises Comparativas}

Nessa seção apresentamos resultados comparativos das correlações condicionais estimadas. Como foi apresentado na seção anterior, temos pelos testes de Causalidade de Granger de segunda ordem evidências estatisticamente significantes da existência de transbordamentos cambiais e de mercados financeiros internacionais para os índices Bovespa, com esse premissa passamos a estudar as correlações condicionais estimadas com a finalidade de comparar os transbordamentos e sua relação com os aspectos de governança.

Inicialmente, procuramos identificar o comportamento das proxies de choques cambias e do dólar dentro de cada conjunto de modelo estimado. Como o IND1 representa um conjunto de todos os câmbios considerados e IND2 exclui o dólar, foi possível entender a importância do dólar por meio desses dois controles. Os gráficos abaixo evidenciam, que tanto para os modelos com Ibovespa quanto para os modelos com índices de governança corporativa, o dólar apresenta valores de correlação condicional maiores. 

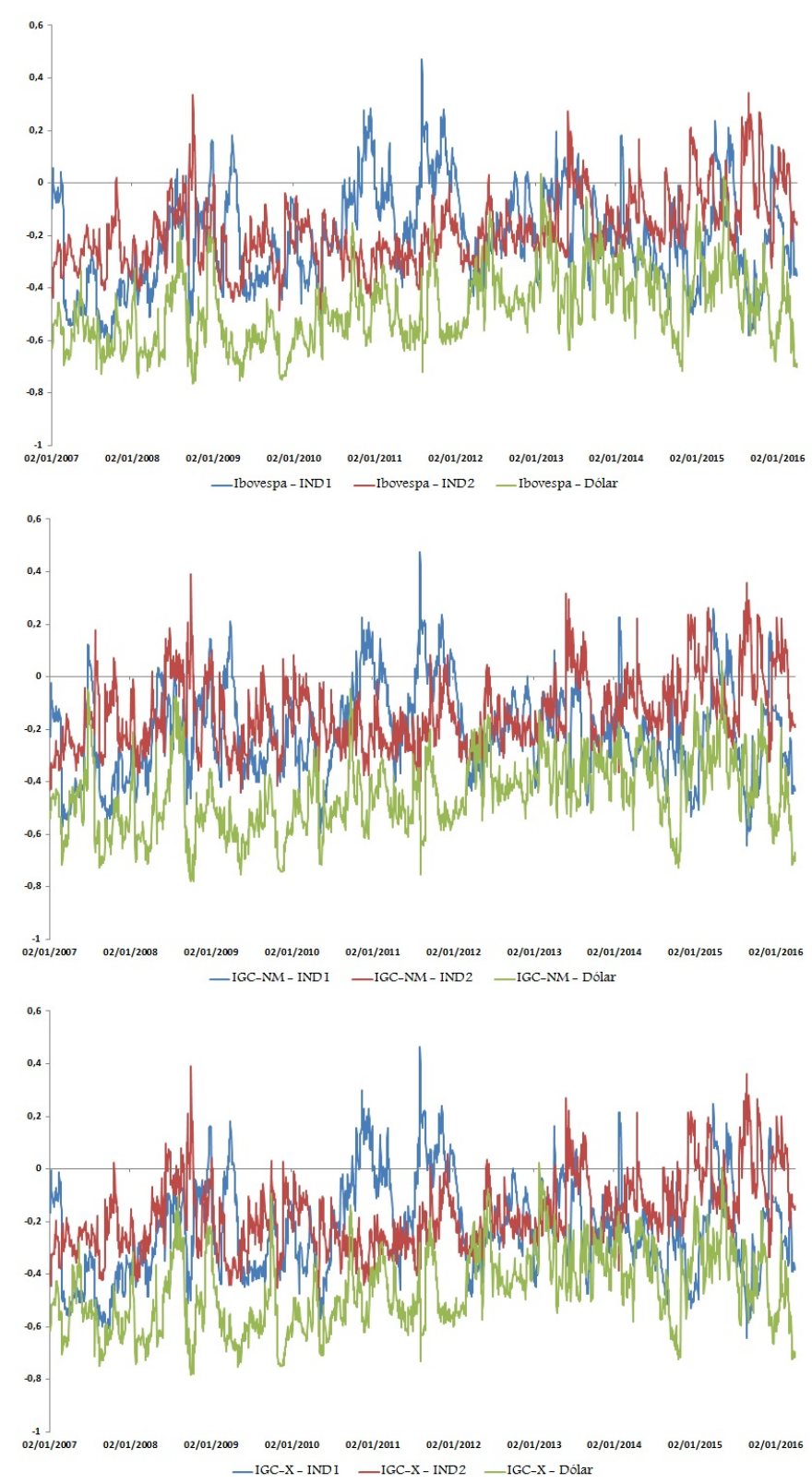

Figura 47 - Comparativos - Correlações Condicionais por Índices Bovespa

A evidência gráfica é corroborada pelos testes T unicaudal com variâncias desiguais. que indicam sempre uma maior correlação condicional associada à presença do dólar, sejam em conjunto com as demais taxas de cambio, seja isoladamente, com a maior correlação condicional observada, conforme está apresentado a seguir. 


\begin{tabular}{c|c}
\hline Resultado do Teste T & Correlação Condicional \\
\hline I & Ibovespa, INDI > Ibovespa, IND2 \\
0 & Ibovespa, INDI $\leq$ Ibovespa, Dólar \\
0 & Ibovespa, IND2 $\leq$ Ibovespa, Dólar \\
\hline I & IGC-NM, INDI > IGC-NM, IND2 \\
0 & IGC-NM, INDI $\leq$ IGC-NM, Dólar \\
0 & IGC-NM, IND2 $\leq$ IGC-NM, Dólar \\
\hline I & IGC-X, INDI > IGC-X, IND2 \\
0 & IGC-X, INDI $\leq$ IGC-X, Dólar \\
0 & IGC-X, IND2 $\leq$ IGC-X, Dólar \\
\hline I : Rejeita-se $\mathrm{H}_{0}$ a nivel de significância de 0.05
\end{tabular}

Figura 48 - Teste T para Correlaçãoes Condicionais

Outra questão relevante é a comparação das correlações condicionais associadas aos choques cambiais e de mercados financeiros internacionais ao Ibovespa que representa um índice negocial e os demais índices que representam diferentes níveis de governança corporativa. Graficamente, não podemos ter um indicativo de diferença relevante quando comparamos as correlações condicionais do dólar e os índices, tanto quanto as correlações condicionais do IND3 e os índices.

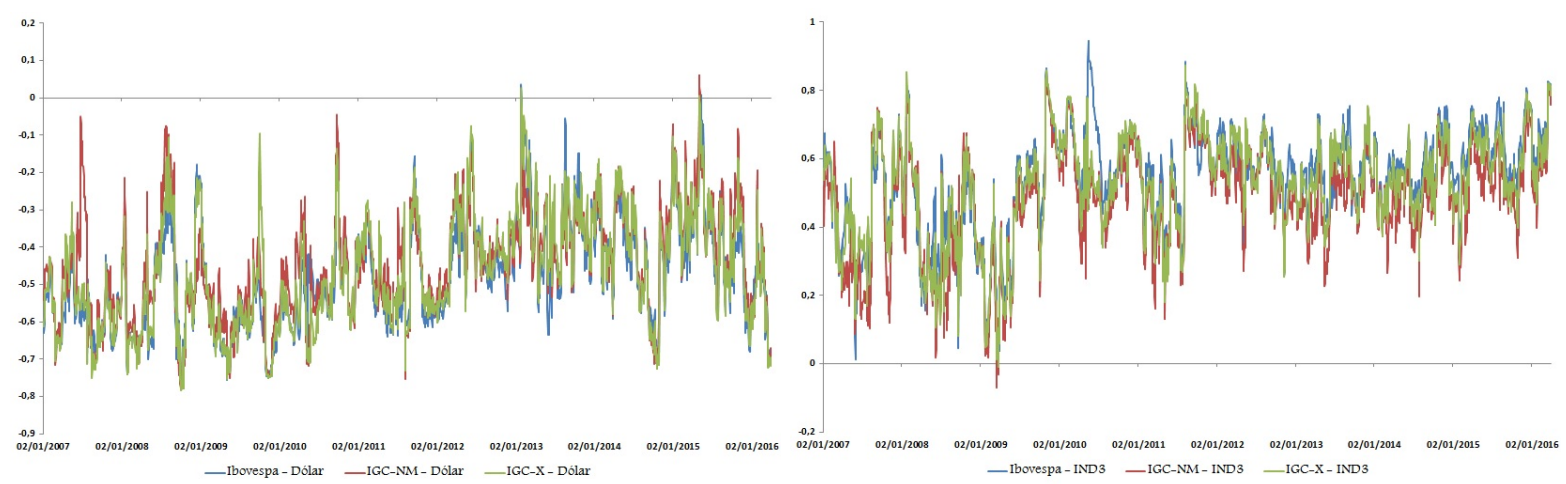

Figura 49 - Comparativos - Correlações Condicionais

Contudo os testes de médias evidenciam que um maior grau de governança está associado a um menor transbordamento de choques de mercados financeiros internacionais, onde a correlação condicional do Ibovespa e o IND3 é maior em relação as correlações condicionais do IND3 e os demais índices. Quando são comparados os dois índices de governança corporativa, o IGC-NM (maior grau de governança corporativa) possui menor transbordamento em relação a correlação condicional IND3 e o IGC-X. 


\begin{tabular}{c|c}
\hline Resultado do Teste T & Correlação Condicional \\
\hline 0 & Ibovespa, Dólar $\leq$ IGC-NM, Dólar \\
0 & Ibovespa, Dólar $\leq$ IGC-X, Dólar \\
I & IGC-NM, Dólar > IGC-X, Dólar \\
\hline
\end{tabular}

$H_{0:} Y_{(i)} \leq Y(j)$. com $i \neq j$

1 : Rejeita-se $\mathrm{H}_{0}$ a nivel de significância de 0.05

\section{Resultado do Teste T Correlação Condicional}

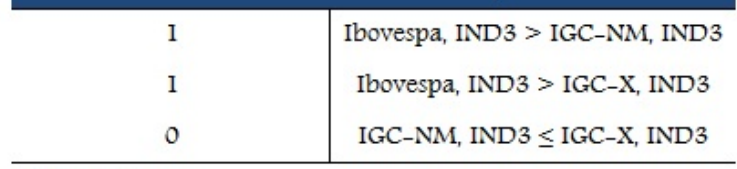

$H_{0:} Y_{(i)} \leq Y(j)$. com $i \neq j$

1 : Rejeita-se $\mathrm{H}_{0}$ a nivel de significância de 0,05

Figura 50 - Teste T para Correlaçãoes Condicionais

Quando consideramos os choques cambiais (medido pela correlação condicional dos índices e o Dólar), e como todos os casos têm valores negativos, uma maior qualidade de governança corporativa, no caso do IGC-NM, está associada a uma maior correlação condicional com choques cambiais (como essa correlação é negativa, será maior quanto mais próximo de zero), indicando que alta qualidade de governança corporativa está associada a um menor transbordamento de choques cambiais, haja vista que essa correlação condicional é maior para o IGC-NM em relação ao IGC-X e ambos são maiores do que essa correlação condicional considerando o Ibovespa.

Apresentamos a seguir as estatísticas exploratórias das correlações condicionais estimadas. Como o dólar apresentou para todos os índices Bovespa impacto de transbordamento mais relevante, assumimos os modelo 3, 6 e 9 como nossas modelos referenciais ${ }^{1}$. Dessa forma, observamos que a magnitude média (ou mediana) das correlações condicionais estimadas, são equivalente próximas de 0,5 sendo positivos em se tratando de choques de mercados financeiros internacionais e negativos para choques cambiais.

\begin{tabular}{ccc|cc|cc} 
& \multicolumn{5}{c}{ Estatísticas - Correlações Condicionais Estimadas } \\
\cline { 2 - 6 } Modelo 3 & \multicolumn{3}{c}{ Modelo 6 } & \multicolumn{2}{c}{ Modelo 9 } \\
\cline { 2 - 6 } Estatísticas & \multicolumn{3}{c}{ Ibovespa - Dólar Ibovespa - IND3 } & IGC-NM - Dólar IGC-NM - IND3 & IGC-X - Dólar IGC-X - IND3 \\
Média & $-0,48$ & 0,54 & $-0,45$ & 0,48 & $-0,46$ & 0,52 \\
Mediana & $-0,50$ & 0,57 & $-0,46$ & 0,50 & $-0,48$ & 0,54 \\
Máximo & 0,04 & 0,95 & 0,06 & 0,85 & 0,03 & 0,87 \\
Minimo & $-0,76$ & 0,00 & $-0,78$ & $-0,07$ & $-0,78$ & $-0,01$ \\
Variância & 0,02 & 0,02 & 0,02 & 0,02 & 0,02 & 0,02 \\
Desvio Padrão & 0,14 & 0,15 & 0,14 & 0,15 & 0,15 & 0,15 \\
Coef. De Variação & $-0,29$ & 0,27 & $-0,31$ & 0,32 & $-0,32$ & 0,28 \\
\hline
\end{tabular}

Figura 51 - Estatísicas Exploratórias - Correlaçãoes Condicionais

Outro ponto de destaque está relacionado a evidência gráfica de que em períodos de crise as correlações condicionais tem uma menor magnitude, essa evidência carece de um estudo de evento para sua total constatação.

$\overline{1}$ As estatísticas dos demais modelos estão apresentados no apêndice $\mathrm{F}$ 



\section{Conclusão}

O presente estudo se propôs em sua primeira parte construir um referencial teórico partindo dos conceitos e origens da governança corporativa e seus impactos nos resultados das empresas. A fim de promover os estudos consideramos esses conceitos traduzindo-os nos índices de governança corporativa utilizados pela Bovespa. Foi feito uma revisão da literatura que tratam dos efeitos de spilloverem suas diferentes abordagens: transbordamentos de câmbios e transbordamentos de mercados financeiros internacionais. Na sequência foram apresentados os conceitos principais de retornos e volatilidades, a base teórica dos modelos GARCH multivariados que foram implementados, além da descrição dos testes e métodos que foram utilizados juntos aos modelos propostos.

O estudo transcorreu de modo a responder as perguntas listadas em sua introdução. Sendo assim, conclui-se primeiramente que foi possível a construção de proxies para choques cambiais e para mercados financeiros internacionais a partir do uso de ACP, de forma que os índices (ou retornos representativos) construídos apresentaram dinâmica temporal consistente com os fatos estilizados de retornos, o que possibilitou seu uso para estimar os efeitos de transbordamento de cada tipo (cambial e de mercados financeiros internacionais).

As estimações de modelos MGARCH BEKK que eliminaram autocorrelação dos resíduos padronizados e de seus quadrados indicam que tais modelos foram capazes de produzir uma boa representação dos processos geradores das séries. Esses modelos produziram correlações condicionais, as quais com dinâmica temporal permitiram concluir que os transbordamentos não são eventos estáticos. Os testes de causalidade de Granger (teste $\mathrm{HH}$ ) de segunda ordem não só validaram a existência de spillover (cambiais e de mercados financeiros internacionais) quanto sua direção. Os resultados mostram que a causalidade no sentido de Granger sempre ocorre dos choques para os índices Bovespa, ou seja, existe uma precedência estatisticamente significante entre transbordamentos cambiais e de mercados financeiros internacionais e os índices Ibovespa, IGC-NM e IGC-X.

As correlações condicionais estimadas apresentam em todos os casos valores positivos quando considerado a proxy para mercados financeiros internacionais e negativos para a proxy de choques cambiais (ou mesmo do Dólar), com magnitudes médias equivalentes quando comparamos com os modelos de referência (modelos 3,6 e 9). Ou seja, as magnitudes dos transbordamentos para os índices Bovespa são equivalentes e significativos, contudo com sentidos opostos. Esses resultados indicam que aumentos da volatilidade cambial estão associados a uma redução da volatilidade dos índices Bovespa e aumentos da volatilidade de mercados financeiros internacionais estão associados a aumentos da volatilidades dos índices Bovespa.

Os testes comparando essas correlações condicionais estimadas permitiram evidenciar 
a importância da volatilidade do Dólar em termos de transbordamento com o uso das outras proxies de choques cambias que combinaram outras moedas.

A conclusão mais importante dos testes comparativos é a de que governança corporativa está associada a menores efeitos de transbordamento. As correlações condicionais estimadas com o IGC-NM, que representa a mais alta qualidade em governança corporativa, apresentaram sempre menores valores que as correlações condicionais estimadas com o IGC-X que, por sua vez, apresentaram valores de correlações condicionais menores do que as estimadas com o Ibovespa. Ou seja, respeitando algumas premissas simplificadores, podemos dizer que alta qualidade de governança pode significar algum efeito mitigador de risco.

As conclusões apresentadas precisam considerar questões não abordadas nesse estudo, para que sejam definitivas. Outros modelos GARCH Multivariados (DVEC, DCC, CCC, etc) devem ser testados e seus resultados de correlações condicionais comparados afim de avaliar a consistência desses valores entre diferentes modelos. Não foi considerado neste estudo a possibilidade de memória longa nas séries do Bovespa e nas séries geradas via ACP. Não foram realizados testes de quebra estruturais tanto para as séries quanto para os testes de causalidade de Granger de segunda ordem Dijk, Osborn e Sensier (2005). Não foram estimados modelos MGARCH Cópulas, pois não há testes de causalidade de Granger de segunda ordem de modelo MGARCH Cópulas o que direcionou o estudo para o modelos MGARCH com possibilidade de aplicação dos testes, além de outros aspectos.

Extensões de pesquisa podem seguir diretamente este estudo, incorporando outros tipos de choques, como por exemplo, choques de commodities, de risco país etc. Outra extensão natural seria a utilização dos modelos MGARCH Fatoriais com versões que já possibilitam tratar questões de memória longa Alessi et al. (2007).

Não obstante as questões salientadas, concluímos o estudo ressaltando seu caráter pioneiro para a investigação de transbordamentos de dois diferentes tipos de choques estimados em um mesmo modelo, e em particular para o caso brasileiro. Cabe o destaque desses resultados como relevantes indagações para outros possíveis estudos de governança corporativa, como por exemplo, as razões teóricas para um menor efeito de transbordamento nas ações de empresas com governança corporativa de alta qualidade. 


\section{Referências}

ABDALLA, I. S.; MURINDE, V. Exchange rate and stock price interactions in emerging financial markets: evidence on india, korea, pakistan and the philippines. Applied financial economics, Taylor \& Francis, v. 7, n. 1, p. 25-35, 1997.

AJAYI, R. A.; FRIEDMAN, J.; MEHDIAN, S. M. On the relationship between stock returns and exchange rates: tests of granger causality. Global finance journal, Elsevier, v. 9, n. 2, p. 241-251, 1999.

AJAYI, R. A.; MOUGOUĖ, M. On the dynamic relation between stock prices and exchange rates. Journal of Financial Research, Wiley Online Library, v. 19, n. 2, p. 193-207, 1996.

ALAGANAR, V.; BHAR, R. Empirical properties of currency risk in country index portfolios. The Quarterly Review of Economics and Finance, Elsevier, v. 47, n. 1, p. 159-174, 2007.

ALESSI, L. et al. Dynamic factor garch: multivariate volatility forecast for a large number of series. Laboratory of Economics and Management (LEM), SantVAnna School of Advanced Studies, -, n. -, p. 1-26, Oct 2007.

AMARE, T.; MOHSIN, M. Stock prices and exchange rates in leading asian economies: short run versus long run dynamics. Singapore Economic Review, v. 45, n. 2, p. 165-181, 2000.

AMIHUD, Y. Exchange rates and the valuation of equity shares. Exchange rates and corporate performance, Irwin New York, v. 11, p. 49-59, 1994.

AMMANN, M.; OESCH, D.; SCHMID, M. M. Corporate governance and firm value: International evidence. Journal of Empirical Finance, v. 18, n. 1, p. 36-55, 2011. ISSN 09275398. Disponível em: <http://www.sciencedirect.com/science/article/pii/S0927539810000757>.

BAE, K.-H.; KAROLYI, G. A. Good news, bad news and international spillovers of stock return volatility between japan and the us. Pacific-Basin Finance Journal, Elsevier, v. 2, n. 4, p. 405-438, 1994.

BAELE, L. Volatility spillover effects in european equity markets. Journal of Financial and Quantitative Analysis, Cambridge Univ Press, v. 40, n. 02, p. 373-401, 2005.

BAHMANI-OSKOOEE, M.; SOHRABIAN, A. Stock prices and the effective exchange rate of the dollar. Applied economics, Taylor \& Francis, v. 24, n. 4, p. 459-464, 1992.

BARNETT, V. The ordering of multivariate data. Journal of the Royal Statistical Society. Series A (General), JSTOR, v. 139, n. 3, p. 318-355, April 1976.

BARTOV, E.; BODNAR, G. M. Firm valuation, earnings expectations, and the exchange-rate exposure effect. The journal of Finance, Wiley Online Library, v. 49, n. 5, p. 1755-1785, 1994.

BLACK, B. S.; CARVALHO, A. G. D.; GORGA, E. What matters and for which firms for corporate governance in emerging markets? evidence from brazil (and other brik countries). Journal of Corporate Finance, v. 18, n. 4, p. 934-952, 2012. ISSN 0929-1199. Special Section: Contemporary corporate finance research on South America. Disponível em: <http://www.sciencedirect.com/science/article/pii/S0929119911001088>. 
BLACK, B. S.; CARVALHO, A. G. de; SAMPAIO, J. O. The evolution of corporate governance in brazil. Emerging Markets Review, v. 20, p. 176-195, 2014. ISSN 1566-0141. Disponível em: <http://www.sciencedirect.com/science/article/pii/S1566014114000193>.

BLACK, B. S.; LOVE, I.; RACHINSKY, A. Corporate governance indices and firms' market values: Time series evidence from russia. Emerging Markets Review, v. 7, n. 4, p. 361-379, 2006. ISSN 1566-0141. Financial market development in the Central and Eastern European countries. Disponível em: <http://www.sciencedirect.com/science/article/pii/S1566014106000495>.

BLACK, F. Studies of stock price volatility changes, proceedings of the 1976 meetings of the business and economic statistics section. 177-191. In: American Statistical association. [S.1.: s.n.], 1976.

BOLLERSLEV. Generalized autoregressive conditional heteroskedasticity. Journal of econometrics, Elsevier, v. 31, n. 3, p. 307-327, 1986.

BOLLERSLEV, T. Modelling the coherence in short-run nominal exchange rates: a multivariate generalized arch model. The review of economics and statistics, JSTOR, v. 72, n. 3, p. 498-505, Aug. 1990.

BOLLERSLEV, T.; ENGLE, R. F.; WOOLDRIDGE, J. M. A capital asset pricing model with time-varying covariances. The Journal of Political Economy, JSTOR, v. 96, n. 1, p. 116-131, Feb. 1988.

BOOTH, L.; ROTENBERG, W. Assessing foreign exchange exposure: Theory and application using canadian firms*. Journal of International Financial Management \& Accounting, Wiley Online Library, v. 2, n. 1, p. 1-22, 1990.

BOTOSAN, C. A.; PLUMLEE, M. A.; XIE, Y. The role of information precision in determining the cost of equity capital. Review of Accounting Studies, Springer, v. 9, n. 2-3, p. 233-259, 2004.

BOX, G. E.; JENKINS, G. M. Time series analysis: forecasting and control. [S.1.]: Holden-Day, 1976.

BOYER, R. S. Commercial policy under alternative exchange rate regimes. Canadian Journal of Economics, JSTOR, v. 10, n. 2, p. 218-232, May 1977.

BRANSON, W. H. A model of exchange-rate determination with policy reaction: evidence from monthly data. The National Bureau of Economic Research, National Bureau of Economic Research Cambridge, Mass., USA, -, n. 1135, p. 1-35, June 1983.

BRENNAN, M. J.; JEGADEESH, N.; SWAMINATHAN, B. Investment analysis and the adjustment of stock prices to common information. Review of Financial Studies, Soc Financial Studies, v. 6, n. 4, p. 799-824, 1993.

BROOKS, C.; REW, A. G.; RITSON, S. A trading strategy based on the lead-lag relationship between the spot index and futures contract for the ftse 100. International Journal of Forecasting, Elsevier, v. 17, n. 1, p. 31-44, 2001.

BROWN, L. D.; CAYLOR, M. L. Corporate governance and firm valuation. Journal of Accounting and Public Policy, Elsevier BV, v. 25, n. 4, p. 409-434, Jul 2006. ISSN 0278-4254. Disponível em: <http://dx.doi.org/10.1016/j.jaccpubpol.2006.05.005>. 
BUSHMAN, R. M.; PIOTROSKI, J. D.; SMITH, A. J. What determines corporate transparency? Journal of accounting research, Wiley Online Library, v. 42, n. 2, p. 207-252, 2004.

BYRNE, A.; BROOKS, M. Behavioral finance: Theories and evidence. CFA Institute, 2008.

CALDEIRA, A. M.; SOUZA, R. C.; MACHADO, M. A. S. Identificação automática das ordens dos modelos garch utilizando redes neurais. ENGEVISTA, v. 11, n. 2, p. 82-89, Dec 2010.

CARRUTH, A.; DICKERSON, A.; HENLEY, A. What do we know about investment under uncertainty? Journal of Economic Surveys, Wiley Online Library, v. 14, n. 2, p. 119-154, 2000.

CARVAlHO, A. G. D. Governança corporativa no brasil em perspectiva. Revista de Administra\&ccdeil; ão da Universidade de São Paulo, v. 37, n. 3, 2002.

CATAPAN, A.; COLAUTO, R. D. Governança corporativa: uma análise de sua relação com o desempenho econômico-financeiro de empresas cotadas no brasil nos anos decorporativa. Contaduria y Administracion, v. 59, n. 3, p. 137-164, 2014. ISSN 0186-1042. Disponível em: <http://www.sciencedirect.com/science/article/pii/S0186104214712689>.

CHEN, J.; NAYLOR, M.; LU, X. Some insights into the foreign exchange pricing puzzle: Evidence from a small open economy. Pacific-Basin Finance Journal, Elsevier, v. 12, n. 1, p. 41-64, 2004.

CHEUNG, Y.-W.; NG, L. K. A causality-in-variance test and its application to financial market prices. Journal of Econometrics, Elsevier, v. 72, n. 1, p. 33-48, 1996.

CHKILI, W.; NGUYEN, D. K. Exchange rate movements and stock market returns in a regime-switching environment: Evidence for brics countries. Research in International Business and Finance, Elsevier, v. 31, p. 46-56, 2014.

CHRISTIE, A. A. The stochastic behavior of common stock variances: Value, leverage and interest rate effects. Journal of financial Economics, Elsevier, v. 10, n. 4, p. 407-432, 1982.

COMTE, F.; LIEBERMAN, O. Second-order noncausality in multivariate garch processes. Journal of Time Series Analysis, Wiley Online Library, v. 21, n. 5, p. 535-557, 2000.

COMTE, F.; LIEBERMAN, O. Asymptotic theory for multivariate garch processes. Journal of Multivariate Analysis, Elsevier, v. 84, n. 1, p. 61-84, 2003.

COSTA, G. d. S. A Influência da governança corporativa no desempenho econômico em empresas de capital aberto no Brasil. Dissertação (Mestrado) - Pontifícia Universidade Católica do Rio Grande do Sul, 2008.

DAIGLER, R. T. Intraday stock index futures arbitrage with time lag effects. 1990.

DARBY, J. et al. The impact of exchange rate uncertainty on the level of investment. The Economic Journal, Wiley Online Library, v. 109, n. 454, p. 55-67, 1999.

DEDU, V.; CHITAN, G. The influence of internal corporate governance on bank performance - an empirical analysis for romania. Procedia - Social and Behavioral Sciences, v. 99, p. 1114-1123, 2013. ISSN 1877-0428. The Proceedings of 9th International Strategic Management Conference. Disponível em: <http://www.sciencedirect.com/science/article/pii/S1877042813040305>. 
DIAMANDIS, P. F.; DRAKOS, A. A. Financial liberalization, exchange rates and stock prices: Exogenous shocks in four latin america countries. Journal of Policy Modeling, Elsevier, v. 33, n. 3, p. 381-394, 2011.

DIEBOLD, F. X.; YILMAZ, K. Measuring financial asset return and volatility spillovers, with application to global equity markets*. The Economic Journal, Wiley Online Library, v. 119, n. 534, p. 158-171, 2009.

DIJK, D. van; OSBORN, D. R.; SENSIER, M. Testing for causality in variance in the presence of breaks. Economics Letters, Elsevier, v. 89, n. 2, p. 193-199, 2005.

DORNBUSCH, R. Exchange rates and fiscal policy in a popular model of international trade. The American Economic Review, JSTOR, v. 65, n. 5, p. 859-871, Dec. 1975.

DUFOUR, J.-M.; RENAULT, E. Short run and long run causality in time series: theory. Econometrica, JSTOR, v. 66, n. 5, p. 1099-1125, Sep. 1998.

EASLEY, D.; O'HARA, M. Information and the cost of capital. The journal of finance, Wiley Online Library, v. 59, n. 4, p. 1553-1583, 2004.

ENDERS, W. Applied econometric time series, by walter. Technometrics, v. 46, n. 2, p. 264, 2004.

ENGLE, R. Dynamic conditional correlation: A simple class of multivariate generalized autoregressive conditional heteroskedasticity models. Journal of Business \& Economic Statistics, Taylor \& Francis, v. 20, n. 3, p. 339-350, 2002.

ENGLE, R. F. Autoregressive conditional heteroscedasticity with estimates of the variance of united kingdom inflation. Econometrica: Journal of the Econometric Society, JSTOR, v. 50, n. 4, p. 987-1007, Jul 1982.

FAMA, E. F. Agency problems and the theory of the firm. Journal of Political Economy, University of Chicago Press, v. 88, n. 2, p. 288-307, Apr 1980. ISSN 1537-534X. Disponível em: <http://dx.doi.org/10.1086/260866>.

FAMA, E. F. Efficient capital markets: Ii. The journal of finance, Wiley Online Library, v. 46, n. 5, p. 1575-1617, 1991.

FEDOROVA, E.; SALEEM, K. Volatility spillovers between stock and currency markets: Evidence from emerging eastern europe. In: 22nd Australasian Finance and Banking Conference. [S.1.: s.n.], 2009. p. 1-25.

FRANCK, P.; YOUNG, A. Stock price reaction of multinational firms to exchange realignments. Financial Management, JSTOR, v. 1, n. 3, p. 66-73, Winter 1972.

FRANSES, P. H.; DIJK, D. V. Non-linear time series models in empirical finance. [S.1.]: Cambridge University Press, 2000.

FUENZALIDA, D. et al. Good corporate governance: Does it pay in peru? Journal of Business Research, v. 66, n. 10, p. 1759-1770, 2013. ISSN 0148-2963. Strategic Thinking in MarketingStrategic Management in Latin AmericaCorporate Social Responsibility and IrresponsibilityManaging Global Innovation and Knowledge. Disponível em: <http://www.sciencedirect.com/science/article/pii/S0148296313000106>. 
GAIO, L. E.; ROLIM, R. C. Interferência dos mercados externos sobre o ibovespa: uma análise utilizando autoregressão vetorial estrutural. In: X Seminários em Administração FEA-USP, conference. [S.1.: s.n.], 2007. p. 9-10.

GARAY, U. et al. Internet-based corporate disclosure and market value: Evidence from latin america. Emerging Markets Review, v. 17, p. 150-168, 2013. ISSN 1566-0141. Disponível em: <http://www.sciencedirect.com/science/article/pii/S1566014113000599>.

GIL, A. C. Métodos e técnicas de pesquisa social. São Paulo: Atlas, 1999.

GLOSTEN, L. R.; JAGANNATHAN, R.; RUNKLE, D. E. On the relation between the expected value and the volatility of the nominal excess return on stocks. The journal of finance, Wiley Online Library, v. 48, n. 5, p. 1779-1801, 1993.

GOLDBERG, L. S. Exchange rates and investment in united states industry. The Review of Economics and Statistics, JSTOR, v. 75, n. 4, p. 575-588, Nov 1993.

GRANGER, C. W.; HUANG, B.-N.; YANG, C. W. A bivariate causality between stock prices and exchange rates: Evidence from recent asia flu. Department of Economics, UCSD, -, n. -, p. 1-24, April 1998.

GRANGER, C. W. J.; ROBINS, R.; ENGLE, R. F. Wholesale and retail prices: Bivariate time series modeling with forecastable error variances. Model reliability, MIT Press Cambridge, MA, -, n. -, p. 1-17, 1986.

HAFNER, C.; HERWARTZ, H. Analytical quasi maximum likelihood inference in multivariate volatility models. Metrika, v. 67, n. 2, p. 219-239, March 2008.

HAFNER, C. M.; HERWARTZ, H. Structural analysis of portfolio risk using beta impulse response functions. Statistica Neerlandica, Wiley Online Library, v. 52, n. 3, p. 336-355, 1998.

HAMAO, Y.; MASULIS, R. W.; NG, V. Correlations in price changes and volatility across international stock markets. Review of Financial studies, Soc Financial Studies, v. 3, n. 2, p. 281-307, 1990.

HERBST, A. F.; MCCORMACK, J. P.; WEST, E. N. Investigation of a lead-lag relationship between spot stock indices and their futures contracts. Journal of Futures Markets, Wiley Online Library, v. 7, n. 4, p. 373-381, 1987.

HERWARTZ, H.; LÜTKEPOHL, H. Multivariate volatility analysis of vw stock prices.

International Journal of Intelligent Systems in Accounting, Finance \& Management, John Wiley \& Sons, Ltd., v. 9, n. 1, p. 35-54, 2000.

HOTI, S. et al. Structure and asymptotic theory for multivariate asymmetric volatility: Empirical evidence for country risk ratings. In: Australasian Meeting of the Econometric Society, Brisbane, Australia. [S.1.: s.n.], 2002. p. 2002.

HUANG, B.-N.; YANG, C.-W.; HU, J. W.-S. Causality and cointegration of stock markets among the united states, japan and the south china growth triangle. International Review of Financial Analysis, Elsevier, v. 9, n. 3, p. 281-297, 2000.

JENSEN, M. C. Some anomalous evidence regarding market efficiency. Journal of financial economics, v. 6, n. 2/3, p. 95-101, 1978. 
JENSEN, M. C.; MECKLING, W. H. Theory of the firm: Managerial behavior, agency costs and ownership structure. Journal of financial economics, Elsevier, v. 3, n. 4, p. 305-360, Oct. 1976. Disponível em: <http://www.sciencedirect.com/science/article/pii/0304405X7690026X>.

JIANG, L.; FUNG, J. K.; CHENG, L. T. The lead-lag relation between spot and futures markets under different short-selling regimes. Financial Review, Wiley Online Library, v. 36, n. 3, p. 63-88, 2001.

JORION, P. The exchange-rate exposure of us multinationals. Journal of business, JSTOR, v. 63, n. 3, p. 331-345, Jul 1990.

JR, R. E. L. Asset prices in an exchange economy. Econometrica: Journal of the Econometric Society, JSTOR, p. 1429-1445, 1978.

KANAS, A. Volatility spillovers across equity markets: European evidence. Applied Financial Economics, Taylor \& Francis, v. 8, n. 3, p. 245-256, 1998.

KANAS, A. Volatility spillovers between stock returns and exchange rate changes: International evidence. Journal of Business Finance \& Accounting, Wiley Online Library, v. 27, n. 3-4, p. 447-467, 2000.

KIM, D.-H. et al. A study on the effect of governance adequacy on the corporate performance. Procedia - Social and Behavioral Sciences, v. 107, p. 59-66, 2013. ISSN 1877-0428. The Proceedings of the 1st Evaluation of Learning for Performance Improvement International Conference 2013. Disponível em: <http://www.sciencedirect.com/science/article/pii/ S1877042813050222>.

KLAPPER, L. F.; LOVE, I. Corporate governance, investor protection, and performance in emerging markets. Journal of Corporate Finance, Elsevier BV, v. 10, n. 5, p. 703-728, Nov 2004. ISSN 0929-1199. Disponível em: <http://dx.doi.org/10.1016/S0929-1199(03)00046-4>.

LÜTKEPOHL, H. Testing for causation between two variables in higher-dimensional var models. In: Studies in Applied Econometrics. [S.1.]: Springer, 1993. p. 75-91.

LÜTKEPOHL, H. New introduction to multiple time series analysis. [S.1.]: Springer Science \& Business Media, 2005.

MADHAVAN, A. Market microstructure: A survey. Journal of financial markets, Elsevier, v. 3, n. 3, p. 205-258, 2000.

MALKIEL, B. G.; FAMA, E. F. Efficient capital markets: A review of theory and empirical work. The journal of Finance, Wiley Online Library, v. 25, n. 2, p. 383-417, 1970.

MEDEIROS, O. R. de; OLIVEIRA, G. R. de. Testando a existência de efeitos lead-lag entre os mercados acionários norte-americano e brasileiro. 2008.

MEESE, R. A.; ROGOFF, K. Empirical exchange rate models of the seventies: Do they fit out of sample? Journal of international economics, Elsevier, v. 14, n. 1, p. 3-24, 1983.

MILLER, S. E. Lead-lag relationships between pork prices at the retail, wholesale, and farm levels. Southern Journal of Agricultural Economics, Cambridge Univ Press, v. 12, n. 01, p. 73-76, 1980. 
MINGOTI, S. Análise de dados atráves de métodos, de estatísticas multivariada: Uma abordagem aplicada. Belo Horizonte-Minas Gerais: Editora UFMG, -, n. -, p. -, - 2005.

MIYAKOSHI, T. Spillovers of stock return volatility to asian equity markets from japan and the us. Journal of International Financial Markets, Institutions and Money, Elsevier, v. 13, n. 4, p. 383-399, 2003.

MOOKERJEE, R.; YU, Q. Macroeconomic variables and stock prices in a small open economy: The case of singapore. Pacific-Basin Finance Journal, Elsevier, v. 5, n. 3, p. 377-388, 1997.

MORALES, L. d. 1. N. Volatility spillovers between equity and currency markets: Eviderice from major latin american countries. Cuadernos de economía, SciELO Chile, v. 45, n. 132, p. 185-215, 2008.

MORETTIN, P. A. Econometria financeira. Second. [S.1.]: Bluncher, 2008.

MUHAMMAD, N.; RASHEED, A.; HUSAIN, F. Stock prices and exchange rates: Are they related? evidence from south asian countries [with comments]. The Pakistan Development Review, JSTOR, v. 41, n. 4, p. 535-550, Winter 2002.

MUNISI, G.; RANDOY, T. Corporate governance and company performance across sub-saharan african countries. Journal of Economics and Business, v. 70, p. 92110, 2013. ISSN 0148-6195. International Corporate Governance. Disponível em: <http://www.sciencedirect.com/science/article/pii/S0148619513000568>.

MURADOGLU, G.; TASKIN, F.; BIGAN, I. Causality between stock returns and macroeconomic variables in emerging markets. Russian \& East European Finance and Trade, JSTOR, v. 36, n. 6, p. 33-53, 2000.

NAKAMURA, R. M. O efeito lead-lag entre o mercado acionário brasileiro e o mercado de adrs: uma revisão metodológica. 2010.

NETO, J. C. d. C. O.; MEDEIROS, O. R. de; QUEIROZ, T. B. de. Governança corporativa e velocidade de incorporação de informações: Lead-lag entre o igc e o ibrx (corporate governance and information incorporation speed: Lead-lag between the igc and ibrx). Revista Brasileira de Finanças, Sociedade Brasileira de Finanças, v. 10, n. 1, p. 149, 2012.

NIEH, C.-C.; LEE, C.-F. Dynamic relationship between stock prices and exchange rates for g-7 countries. The Quarterly Review of Economics and Finance, Elsevier, v. 41, n. 4, p. 477-490, 2002 .

PENA, G. E.; GUELMAN, B.; RABELLO, H. Influência dos índices dow jones industrial avarage e nikkei-225 sobre o ibovespa. Faculdades Ibmec. Disponivel em: $<$ http://www. administradores. com. br/informe-se/producaoacademica/influencia-dos-indices-dow-jones-enikkei-225-sobre-o-ibovespa/785/> Acesso em, v. 9, n. 08, 2010.

PHYLAKTIS, K.; RAVAZZOLO, F. Stock prices and exchange rate dynamics. Journal of International Money and Finance, Elsevier, v. 24, n. 7, p. 1031-1053, 2005.

PLUMLEE, M. A. The effect of information complexity on analysts' use of that information. The Accounting Review, v. 78, n. 1, p. 275-296, 2003.

PORTA, R. L. et al. Law and finance. Journal of Political Economy, v. 106, n. 6, p. 1113-1155, December 1998. 
RANI, N.; YADAV, S. S.; JAIN, P. Impact of corporate governance score on abnormal returns of mergers and acquisitions. Procedia Economics and Finance, v. 5, p. 637-646, 2013. ISSN 2212-5671. International Conference On Applied Economics (ICOAE) 2013. Disponível em: $<$ http://www.sciencedirect.com/science/article/pii/S2212567113000750>.

ROE, M. J. Corporate governance: Politicaland legal prespectives. Edward Elgar Publishing, Edward Elgar Publishing, 2005.

SAATCIOGLU, K.; STARKS, L. T. The stock price-volume relationship in emerging stock markets: the case of latin america. International Journal of forecasting, Elsevier, v. 14, n. 2, p. 215-225, 1998.

SHLEIFER, A.; VISHNY, R. W. A survey of corporate governance. The journal of finance, Wiley Online Library, v. 52, n. 2, p. 737-783, 1997.

SMITH, C. E. Stock markets and the exchange rate: a multi-country approach. Journal of macroeconomics, Elsevier, v. 14, n. 4, p. 607-629, 1992.

SOLNIK, B. Using financial prices to test exchange rate models: A note. The journal of Finance, Wiley Online Library, v. 42, n. 1, p. 141-149, 1987.

SUAREZ, M. M. Análisis de los Precios Contado y Futuro Del IBEX-35 em Intervalos de 1 Y 5 Minutos para El año 2003. DoctoradoemFinazas de Empresas. [S.1.], 2008.

SUSMEL, R.; ENGLE, R. F. Hourly volatility spillovers between international equity markets. Journal of International Money and Finance, Elsevier, v. 13, n. 1, p. 3-25, 1994.

TABAK, B. M. The dynamic relationship between stock prices and exchange rates: Evidence for brazil. International Journal of Theoretical and Applied Finance, World Scientific, v. 9, n. 08, p. 1377-1396, 2006.

THEODOSSIOU, P.; LEE, U. Mean and volatility spillovers across major national stock markets: Further empirical evidence. Journal of Financial Research, Wiley Online Library, v. 16, n. 4, p. 337-350, 1993.

TIMM, N. H. 2 multivariate analysis of variance of repeated measurements. Analysis of Variance, Elsevier BV, v. 1, n. -, p. 41-87, 1980. ISSN 0169-7161. Disponível em: <http://dx.doi.org/10.1016/S0169-7161(80)01004-8>.

TSE, Y. K. Lead-lag relationship between spot index and futures price of the nikkei stock average. Journal of Forecasting, Wiley Online Library, v. 14, n. 7, p. 553-563, 1995.

VEIGA, B.; MCALEER, M. Multivariate volatility and spillover effects in financial markets. Complexity and Integrated Resources Management, Citeseer, -, n. -, p. 1-7, 2003.

WEI, K. J. et al. Volatility and price change spillover effects across the developed and emerging markets. Pacific-Basin Finance Journal, Elsevier, v. 3, n. 1, p. 113-136, 1995.

YANG, S.-Y.; DOONG, S.-C. Price and volatility spillovers between stock prices and exchange rates: empirical evidence from the g-7 countries. International Journal of Business and Economics, International Journal of Business and Economics, v. 3, n. 2, p. 139, 2004.

ZAPATERO, F. Equilibrium asset prices and exchange rates. Journal of Economic Dynamics and Control, Elsevier, v. 19, n. 4, p. 787-811, 1995. 
Apêndices 



\section{APÊNDICE A - Tabela de Câmbios Considerados}

Tabela 4 - Taxas de câmbios utilizadas.

\begin{tabular}{|c|c|c|}
\hline & País & Moeda \\
\hline 1 & Alemanha & Marco/US\$ \\
\hline 2 & Argentina & Peso Argentino/US\$ \\
\hline 3 & Austrália & Dólar Australiano/US\$ \\
\hline 4 & Áustria & Schilling/US\$ \\
\hline 5 & Bolívia & Boliviano/US\$ \\
\hline 6 & Brasil & Real /US\$ \\
\hline 7 & Bulgária & Lev/US\$ \\
\hline 8 & Canadá & Dólar Canadense/US\$ \\
\hline 9 & Chile & Peso Chileno/US\$ \\
\hline 10 & China & Yuan/US\$ \\
\hline 11 & Cingapura & Dólar de Singapura/US\$ \\
\hline 12 & Colômbia & Peso Colombiano/US\$ \\
\hline 13 & Equador & Sucre/US\$ \\
\hline 14 & Eslováquia & Coroa Eslovaca/US\$ \\
\hline 15 & Eslovênia & Dólar da Eslovênia/US\$ \\
\hline 16 & Espanha & Peseta/US\$ \\
\hline 17 & Euro & US\$/Euro \\
\hline 18 & Filipinas & Peso Filipino/US\$ \\
\hline 19 & França & Franco/US\$ \\
\hline 20 & Hong Kong & Dólar de Hong Kong/US\$ \\
\hline 21 & Hungria & Forint/US\$ \\
\hline 22 & Índia & Rúpia da Índia/US\$ \\
\hline 23 & Indonésia & Rúpia da Indonésia/US\$ \\
\hline 24 & Inglaterra & US\$/Libra \\
\hline 25 & Irlanda & Libra Irlandesa (Punts)/US\$ \\
\hline 26 & Israel & Shekel/US\$ \\
\hline 27 & Itália & Lira/US\$ \\
\hline 28 & Japão & Yen/US\$ \\
\hline
\end{tabular}

Continua na próxima página. 
continuação da Tabela4

\begin{tabular}{|c|c|c|}
\hline & País & Moeda \\
\hline 29 & Coreia & Won/US\$ \\
\hline 30 & Malásia & Ringgit/US\$ \\
\hline 31 & México & Peso Mexicano/US\$ \\
\hline 32 & Noruega & Coroa Norueguesa/US\$ \\
\hline 33 & Nova Zelândia & Dólar da Nova Zelândia/US\$ \\
\hline 34 & Paraguai & Guarani/US\$ \\
\hline 35 & Peru & Novo Sol do Peru/US\$ \\
\hline 36 & Polônia & Zloty da Polônia/US\$ \\
\hline 37 & Romênia & Leu/US\$ \\
\hline 38 & Rússia & Rublo/US\$ \\
\hline 39 & Suécia & Coroa Sueca/US\$ \\
\hline 40 & Suíça & US\$/Franco Suiço \\
\hline 41 & Tailândia & Bath/US\$ \\
\hline 42 & Taiwan & Dólar de Taiwan/US\$ \\
\hline 43 & Tcheca & Coroa Tcheca/US\$ \\
\hline 44 & Turquia & Nova Lira da Turquia/US\$ \\
\hline 45 & Ucrânia & Hyvnia da Ucrânia/US\$ \\
\hline 46 & Uruguai & Peso do Uruguai/US\$ \\
\hline 47 & Venezuela & Bolívar/US\$ \\
\hline 48 & Vietnã & Dong/US\$ \\
\hline 49 & África do Sul & US\$/ZAR \\
\hline
\end{tabular}

A Taxa de câmbio da Venezuela, muito embora lista, não foi considerada para o estudo, haja vista ter sido ao longo do período amostral fixa, com apenas dois pontos abruptos de oscilação. 


\section{APÊNDICE B - Tabela de Bolsas Consideradas}

Tabela 5 - Bolsas de valores utilizadas

\begin{tabular}{|c|c|c|}
\hline & País & Índice \\
\hline 1 & Alemanha & DAX \\
\hline 2 & Argentina & Merval \\
\hline 3 & Brasil & Bovespa \\
\hline 4 & Chile & Chile Stock Mkt \\
\hline 5 & Colômbia & IGBC General \\
\hline 6 & França & CAC 40 \\
\hline 7 & Hong Kong & Hang Seng \\
\hline 8 & Londres & FTSE 100 \\
\hline 9 & México & Bolsa do México \\
\hline 10 & Nasdaq & Nasdaq \\
\hline 11 & Nova York & Dow Jones \\
\hline 12 & Peru & Lima General Index \\
\hline 13 & S\&P 500 & S\&P 500 \\
\hline 14 & Japão & Nikkei 225 \\
\hline 15 & Venezuela & Venezuela Stock mkt \\
\hline 16 & Xangai & Shanghai SE \\
\hline 17 & Europa & EU Stoxx \\
\hline
\end{tabular}





\section{APÊNDICE C - Testes de Estacionariedade}

Os resultados apresentados a seguir confirmam a hipótese de estacionariedade tanto de retornos quanto do quadrado dos retornos para os índices Ibovespa, IGC-NM e IGC-X.

\begin{tabular}{|c|c|c|c|}
\hline \multicolumn{4}{|c|}{ RETORNOS } \\
\hline TESTES/ESTATÍSTICAS & IBOVESPA & ICG NM & IGCX \\
\hline $\mathrm{ADF}$ sem termo deterministico & $-\quad 30,05$ & $-8,61$ & $-9,49$ \\
\hline P-Valor & 0,00 & 0,00 & 0,00 \\
\hline Defasagem & 2 & 18 & 19 \\
\hline $\mathrm{ADF}$ com constante & 20,34 & $-8,67$ & $-9,53$ \\
\hline P-Valor & 0,00 & 0,00 & 0,00 \\
\hline Defasagem & 6 & 18 & 19 \\
\hline $\mathrm{ADF}$ com tendência temporal & 20,43 & $-\quad 8,75$ & - 9,62 \\
\hline P-Valor & 0,00 & 0,00 & 0,00 \\
\hline Defasagem & 6 & 18 & 19 \\
\hline $\mathrm{ADF}$ com constante e com tendência temporal & $-\quad 20,40$ & $-\quad 8,75$ & $-9,62$ \\
\hline P-Valor & 0,00 & 0,00 & 0,00 \\
\hline Defasagem & 6 & 18 & 19 \\
\hline
\end{tabular}

\begin{tabular}{|c|c|c|c|}
\hline \multicolumn{4}{|c|}{ VOLATILIDADES } \\
\hline TESTES/ESTATÍSTICAS & IBOVESPA & ICG NM & IGCX \\
\hline $\mathrm{ADF}$ sem termo deterministico & - $\quad 4,44$ & $-\quad 4,71$ & - 4,33 \\
\hline P-Valor & 0,00 & 0,00 & 0,00 \\
\hline Defasagem & 18 & 19 & 18 \\
\hline $\mathrm{ADF}$ com constante & - 5,14 & $-\quad 5,45$ & 5,21 \\
\hline P-Valor & 0,00 & 0,00 & 0,00 \\
\hline Defasagem & 18 & 19 & 18 \\
\hline $\mathrm{ADF}$ com tendência temporal & $-\quad 5,41$ & - $\quad 5,76$ & 5,41 \\
\hline P-Valor & 0,00 & 0,00 & 0,00 \\
\hline Defasagem & 18 & 19 & 18 \\
\hline $\mathrm{ADF}$ com constante e com tendência temporal & $-\quad 5,18$ & $-5,50$ & $-\quad 5,25$ \\
\hline P-Valor & 0,00 & 0,00 & 0,00 \\
\hline Defasagem & 18 & 19 & 18 \\
\hline
\end{tabular}

Figura 52 - Resultados dos Testes ADF para Índices Bovespa

Os resultados apresentados a seguir confirmam a hipótese de estacionariedade tanto de retornos quanto do quadrado dos retornos para os índices criados (IND1, IND2 e IND3) e para o Dólar.

\begin{tabular}{|c|c|c|c|c|}
\hline \multicolumn{5}{|c|}{ RETORNOS } \\
\hline TESTES/ESTATÍSTICAS & IND1 & IND2 & IND3 & DOLAR \\
\hline $\mathrm{ADF}$ sem termo deterministico & $-12,84$ & $-10,73$ & $-16,21$ & $-11,55$ \\
\hline P-Valor & 0,00 & 0,00 & 0,00 & 0,00 \\
\hline Defasagem & 15 & 16 & 8 & 12 \\
\hline $\mathrm{ADF}$ com constante & $-12,92$ & $-10,91$ & $-16,23$ & $-36,48$ \\
\hline P-Valor & 0,00 & 0,00 & 0,00 & 0,00 \\
\hline Defasagem & 15 & 16 & 8 & 1 \\
\hline $\mathrm{ADF}$ com tendências temporal & $-13,04$ & - 11,03 & $-16,30$ & $-36,59$ \\
\hline P-Valor & 0,00 & 0,00 & 0,00 & 0,00 \\
\hline Defasagem & 15 & 16 & 8 & 1 \\
\hline $\mathrm{ADF}$ com constante e com tendêncis tempora & al $-13,01$ & $-11,00$ & $-16,29$ & $-36,51$ \\
\hline P-Valor & 0,00 & 0,00 & 0,00 & 0,00 \\
\hline Defasagem & 15 & 16 & 8 & I \\
\hline
\end{tabular}

$\mathrm{H}_{0}$ : Fresenç̧ de Raiz Unitaris

A seleção da defassagem utilizada nos Teste ADF utilizou $\odot$ Critério de Informação de AIC

\begin{tabular}{|c|c|c|c|c|}
\hline TESTES/ESTATISTICAS & IND1 & IND2 & IND3 & DOLAR \\
\hline $\mathrm{ADF}$ sem termo deterministico & $-5,37$ & $-7,21$ & $-5,53$ & $-4,97$ \\
\hline P-Valor & 0,00 & 0,00 & 0,00 & 0,00 \\
\hline Defasagem & 20 & 13 & 20 & 18 \\
\hline $\mathrm{ADF}$ com constante & $-6,71$ & $-8,56$ & $-6,52$ & $-6,00$ \\
\hline P-Valor & 0,00 & 0,00 & 0,00 & 0,00 \\
\hline Defasagem & 20 & 13 & 20 & 18 \\
\hline $\mathrm{ADF}$ com tendência temporal & $-6,78$ & $-8,62$ & $-6,86$ & $-6,08$ \\
\hline P-Valor & 0,00 & 0,00 & 0,00 & 0,00 \\
\hline Defasagem & 20 & 13 & 20 & 18 \\
\hline $\mathrm{ADF}$ com constante e com tendência temporal & $-\quad 6,77$ & $-8,61$ & $-6,59$ & $-6,05$ \\
\hline P-Valor & 0,00 & 0,00 & 0,00 & 0,00 \\
\hline Defasagem & 20 & 13 & 20 & 18 \\
\hline
\end{tabular}

A seleção da defasagem utilizada nos Teste ADF utilizou $\odot$ Critério de Informaçăo de AIC

Figura 53 - Resultados dos Testes ADF para os Índices Criados 



\section{APÊNDICE D - Análise de Componentes Principais}

\begin{tabular}{|c|c|c|c|c|c|c|c|}
\hline \multicolumn{8}{|c|}{ CÂMBIO VOLATILIDADE } \\
\hline \multirow[t]{2}{*}{ CÂMBIO } & \multirow[t]{2}{*}{ FESOS } & \multirow[t]{2}{*}{ AUTOVALORES } & VARIÂNCIA & \multirow[t]{2}{*}{ CÂMBIO } & \multirow[t]{2}{*}{ FESOS } & \multirow[t]{2}{*}{ AUTOVALORES } & \multirow{2}{*}{$\begin{array}{l}\text { VARIÂNCLA } \\
\text { EXFLICADA }\end{array}$} \\
\hline & & & EXPLICADA & & & & \\
\hline 1 & 0,13 & 17,99 & 0.88 & 25 & $-0,04$ & 0.49 & 0,00 \\
\hline 2 & $-0,17$ & 4,21 & 0.05 & 26 & -0.24 & 0,48 & 0.00 \\
\hline 3 & -0.26 & 2,36 & 0.02 & 27 & -0.42 & 0.45 & 0.00 \\
\hline 4 & -0.08 & 1.23 & 0.00 & 28 & -0.40 & 0.42 & 0.00 \\
\hline 5 & -0.02 & 1.14 & 0.00 & 29 & 0.30 & 0.42 & 0.00 \\
\hline 6 & 0.00 & 1,13 & 0.00 & 30 & 0,10 & 0.38 & 0.00 \\
\hline 7 & -0.01 & 1.09 & 0.00 & 31 & -0.07 & 0.35 & 0.00 \\
\hline 8 & 0.02 & 1.04 & 0.00 & 32 & -0.03 & 0.34 & 0.00 \\
\hline 9 & 0.09 & 1.03 & 0.00 & 33 & 0.19 & 0.30 & 0.00 \\
\hline 10 & 0.05 & 1.00 & 0.00 & 34 & -0.09 & 0.29 & 0.00 \\
\hline 11 & -0.02 & 0.97 & 0.00 & 35 & -0.01 & 0.24 & 0.00 \\
\hline 12 & -0.03 & 0.97 & 0.00 & 36 & 0.02 & 0.19 & 0.00 \\
\hline 13 & 0.02 & 0.90 & 0.00 & 37 & 0.03 & 0,18 & 0.00 \\
\hline 14 & 0.02 & 0.89 & 0.00 & 38 & 0.01 & 0.17 & 0.00 \\
\hline 15 & 0.05 & 0.87 & 0.00 & 39 & 0.01 & 0.15 & 0.00 \\
\hline 16 & -0.10 & 0.80 & 0.00 & 40 & 0.04 & 0.13 & 0.00 \\
\hline 17 & 0.05 & 0.75 & 0.00 & 41 & 0.00 & 0.10 & 0.00 \\
\hline 18 & -0.09 & 0.73 & 0.00 & 42 & 0.01 & 0.05 & 0.00 \\
\hline 19 & 0,25 & 0,68 & 0.00 & 43 & 0,00 & 0.02 & 0,00 \\
\hline 20 & 0.06 & 0.64 & 0.00 & 44 & 0.00 & 0.00 & 0.00 \\
\hline 21 & -0.04 & 0.61 & 0.00 & 45 & 0.00 & 0.00 & 0.00 \\
\hline 22 & -0.02 & 0.60 & 0.00 & 46 & 0.00 & 0.00 & 0,00 \\
\hline 23 & -0.22 & 0.53 & 0.00 & 47 & 0.00 & 0.00 & 0.00 \\
\hline 24 & -0.13 & 0,50 & 0,00 & 48 & 0.00 & 0.00 & 0,00 \\
\hline
\end{tabular}

Figura 54 - Resultados da ACP - Câmbio

\begin{tabular}{|c|c|c|c|c|c|c|c|}
\hline \multicolumn{8}{|c|}{ CÂMBIO VOLATILIDADE SEM DOLLAR } \\
\hline \multirow[t]{2}{*}{ CÂMBIO } & \multirow{2}{*}{ PESOS } & \multirow{2}{*}{ AUTOVALORES } & VARIÂNCIA & \multirow[t]{2}{*}{ CÂMBIO } & \multirow{2}{*}{ PESOS } & \multirow{2}{*}{ AUTOVALORES } & \multirow{2}{*}{$\begin{array}{l}\text { VARIÂNCIA } \\
\text { EXPLICADA }\end{array}$} \\
\hline & & & & & & & \\
\hline 1 & 0.22 & 17,72 & 0.89 & 25 & -0.01 & 0,49 & 0.00 \\
\hline 2 & 0,14 & 4,10 & 0.03 & 26 & -0.03 & 0.47 & 0.00 \\
\hline 3 & 0.07 & 2.41 & 0.02 & 27 & 0.02 & 0.44 & 0.00 \\
\hline 4 & 0.02 & 1.22 & 0.00 & 28 & -0.03 & 0.42 & 0.00 \\
\hline 5 & -0.04 & 1,14 & 0.00 & 29 & -0.06 & 0,38 & 0.00 \\
\hline 6 & -0.01 & 1,13 & 0.00 & 30 & -0.01 & 0.35 & 0.00 \\
\hline 7 & -0.02 & 1.09 & 0.00 & 31 & 0.03 & 0.34 & 0.00 \\
\hline 8 & 0.01 & 1.04 & 0.00 & 32 & 0.10 & 0.30 & 0.00 \\
\hline 9 & -0.01 & 1.02 & 0.00 & 33 & -0.05 & 0.30 & 0.00 \\
\hline 10 & -0.02 & 0.99 & 0.00 & 34 & 0.01 & 0.24 & 0.00 \\
\hline 11 & 0.01 & 0.97 & 0.00 & 35 & 0.06 & 0.20 & 0.00 \\
\hline 12 & 0.00 & 0.97 & 0.00 & 36 & 0.03 & 0.18 & 0,00 \\
\hline 13 & 0.04 & 0.90 & 0.00 & 37 & -0.01 & 0.17 & 0.00 \\
\hline 14 & -0.01 & 0.89 & 0.00 & 38 & 0.01 & 0.15 & 0.00 \\
\hline 15 & 0.00 & 0.87 & 0.00 & 39 & -0.06 & 0.15 & 0.00 \\
\hline 16 & 0.01 & 0,80 & 0.00 & 40 & -0.12 & 0,10 & 0.00 \\
\hline 17 & 0.00 & 0.75 & 0.00 & 41 & 0,13 & 0.05 & 0.00 \\
\hline 18 & 0.00 & 0.72 & 0.00 & 42 & 0.15 & 0.02 & 0.00 \\
\hline 19 & -0.04 & 0.66 & 0.00 & 43 & 0.20 & 0.00 & 0.00 \\
\hline 20 & 0.02 & 0.64 & 0.00 & 44 & $-0,38$ & 0.00 & 0.00 \\
\hline 21 & 0.01 & 0.61 & 0,00 & 45 & 0.08 & 0,00 & 0.00 \\
\hline 22 & 0.04 & 0.60 & 0.00 & 46 & -0.67 & 0.00 & 0.00 \\
\hline 23 & -0.02 & 0.32 & 0.00 & 47 & 0.02 & 0.00 & 0.00 \\
\hline 24 & 0.01 & 0.30 & 0.00 & 48 & 0.02 & 0.00 & 0.00 \\
\hline
\end{tabular}

Figura 55 - Resultados da ACP - Câmbio sem Dólar 


\begin{tabular}{cccc} 
BOLSAS & PONDERAÇÕES & AUTOVALORES & $\begin{array}{c}\text { VARIÂNCIA } \\
\text { EXPLICADA }\end{array}$ \\
\hline 1 & 0.27 & 8.21 & 0.89 \\
2 & 0.10 & 1,85 & 0.04 \\
3 & 0.25 & 1,16 & 0.02 \\
4 & 0.05 & 1,00 & 0.01 \\
5 & -0.10 & 0.93 & 0.01 \\
6 & 0.05 & 0.80 & 0.01 \\
7 & 0.04 & 0.68 & 0.01 \\
8 & 0.08 & 0.56 & 0.00 \\
9 & 0.16 & 0.51 & 0.00 \\
10 & -0.58 & 0.39 & 0.00 \\
11 & -0.35 & 0.33 & 0.00 \\
12 & 0.58 & 0.27 & 0.00 \\
13 & 0.10 & 0.14 & 0.00 \\
14 & 0.02 & 0.08 & 0.00 \\
15 & 0.03 & 0.07 & 0.00 \\
16 & -0.01 & 0.01 & 0.00 \\
17 & 0.02 & 0.01 & 0.00 \\
\hline
\end{tabular}

Figura 56 - Resultados da ACP - Bolsas 


\section{APÊNDICE E - Modelos Estimados}

Apresentamos neste apêndice os modelos intermediários estimados. São apresentados os modelos que não eliminaram a autocorrelação dos resíduos padronizados e de seus quadrados. A sequência dos modelos estimados sempre seguiu a seguinte ordem até a eliminação de autocorrelação dos resíduos padronizados:

1. MGARCH-BEKK $(1,1)$;

2. $\operatorname{MGARCH-BEKK}(2,1)$;

3. $\operatorname{MGARCH-BEKK}(2,2)$.

\begin{tabular}{|c|c|c|c|c|c|c|c|c|c|c|c|}
\hline \multicolumn{5}{|c|}{ Modelo I } & & & & & & & \\
\hline \multicolumn{5}{|c|}{ Modelo BEKK(I,I) } & & & & & & & \\
\hline Parâmetros & Estimativa & DP & Estatistica & P Valor & & & & & & & \\
\hline$\alpha_{10}$ & 0,197 & 0,124 & 1,584 & 0,057 & \multicolumn{7}{|c|}{ Teste LM para Resíduos e Quadrado dos Resíduos } \\
\hline$\alpha_{20}$ & $-0,035$ & 0,038 & $-0,915$ & 0,820 & Defasagem & $\mathrm{u}_{1, t-\mathrm{p}}$ & $\mathrm{u}_{2, \mathrm{t}-\mathrm{p}}$ & $\mathrm{u}_{\text {8,t-p }}$ & $\mathrm{u}_{1, \mathrm{t}-\mathrm{p}}^{2}$ & $\mathrm{u}_{2, t-\mathrm{p}}^{2}$ & $\mathrm{u}^{2}{ }_{3, t-\mathrm{p}}$ \\
\hline$a_{\mathbf{s o}}$ & 0,082 & 0,132 & 0,626 & 0,266 & 1 & 0,44 & 0,23 & 0,00 & 0,61 & 0,96 & 0,02 \\
\hline$\alpha_{11}$ & 0,058 & 0,062 & 0,925 & 0,177 & 2 & 0,74 & 0,45 & 0,00 & 0,19 & 0,55 & 0,02 \\
\hline$\alpha_{22}$ & $-0,008$ & 0,199 & $-0,040$ & 0,516 & 3 & 0,58 & 0,55 & 0,00 & 0,35 & 0,28 & 0,01 \\
\hline$\alpha_{33}$ & 0,131 & 0,072 & 1,812 & 0,035 & 4 & 0,73 & 0,41 & 0,00 & 0,50 & 0,38 & 0,01 \\
\hline$\beta_{I I}$ & 0,219 & 0,063 & 3,495 & 0,000 & 5 & 0,85 & $0,5 \mathrm{I}$ & 0,00 & 0,54 & 0,38 & 0,01 \\
\hline$\beta_{22}$ & 0,170 & 0,087 & 1,956 & 0,025 & 6 & 0,92 & 0,63 & 0,00 & 0,66 & 0,47 & 0,01 \\
\hline \multirow[t]{2}{*}{$\beta_{s s}$} & 0,964 & 0,015 & 66,17 & 0,000 & 7 & 0,89 & 0,25 & 0,00 & 0,75 & 0,45 & 0,01 \\
\hline & & & & & 8 & 0,91 & 0,28 & 0,00 & 0,83 & 0,56 & 0,01 \\
\hline$A I C$ & 18.784 & & & & 9 & 0,94 & 0,24 & 0,01 & 0,88 & 0,56 & 0,02 \\
\hline$B I C$ & $18.84 \mathrm{I}$ & & & & 10 & 0,89 & 0,32 & 0,01 & 0,51 & 0,65 & 0,01 \\
\hline
\end{tabular}

Figura 57 - MGARCH-BEKK(1,1) - Modelo 1

\begin{tabular}{ccccc}
\hline \multicolumn{5}{c}{ Modelo 5 } \\
Parâmetros & Estimativa & DP & Estatistica & P Valor \\
\hline $\boldsymbol{\alpha}_{\mathbf{1 0}}$ & 0,170 & 0,031 & 5,534 & 0,000 \\
$\boldsymbol{\alpha}_{\mathbf{2 0}}$ & $-0,038$ & 0,008 & $-4,514$ & 1,000 \\
$\boldsymbol{\alpha}_{\mathbf{3 0}}$ & 0,076 & 0,019 & 4,040 & 0,000 \\
$\boldsymbol{\alpha}_{\mathbf{1 1}}$ & 0,105 & 0,022 & 4,843 & 0,000 \\
$\boldsymbol{\alpha}_{\mathbf{2 2}}$ & $-0,050$ & 0,014 & $-3,640$ & 1,000 \\
$\boldsymbol{\alpha}_{\mathbf{3 s}}$ & 0,150 & 0,027 & 5,492 & 0,000 \\
$\boldsymbol{\beta}_{\mathbf{1 1}}$ & 0,207 & 0,031 & 6,791 & 0,000 \\
$\boldsymbol{\beta}_{\mathbf{2 z}}$ & 0,215 & 0,034 & 6,307 & 0,000 \\
$\boldsymbol{\beta}_{\boldsymbol{s 3}}$ & 0,960 & 0,009 & 112,01 & 0,000 \\
\hline
\end{tabular}

\begin{tabular}{|c|c|c|c|c|c|c|}
\hline \multirow[b]{2}{*}{ Defasagem } & \multicolumn{5}{|c|}{ Teste LM para Resíduos e Quadrado dos Resíduos } & \multirow[b]{2}{*}{$\mathrm{u}_{\text {s.t-p }}^{2}$} \\
\hline & $\mathrm{u}_{1, t-\mathrm{p}}$ & $\mathrm{u}_{2, \mathrm{t}-\mathrm{p}}$ & $u_{s, t-p}$ & $\mathrm{u}_{1, t-\mathrm{p}}^{2}$ & $\mathrm{u}_{2, t-\mathrm{p}}^{2}$ & \\
\hline I & 0,83 & 0,01 & 0,00 & 0,31 & 0,27 & 0,03 \\
\hline 2 & 0,89 & 0,00 & 0,00 & 0,46 & 0,27 & 0,03 \\
\hline 3 & 0,47 & 0,00 & 0,00 & 0,60 & 0,18 & 0,03 \\
\hline 4 & 0,62 & 0,01 & 0,00 & 0,76 & 0,09 & 0,02 \\
\hline 5 & 0,37 & 0,01 & 0,00 & 0,88 & 0,10 & 0,02 \\
\hline 6 & 0,42 & 0,03 & 0,00 & 0,93 & 0,09 & 0,02 \\
\hline 7 & 0,53 & 0,04 & 0,00 & 0,96 & 0,10 & 0,01 \\
\hline 8 & 0,62 & 0,06 & 0,00 & 0,88 & 0,10 & 0,02 \\
\hline 9 & 0,45 & 0,02 & 0,00 & 0,85 & 0,11 & 0,02 \\
\hline 10 & 0,52 & 0,02 & 0,01 & 0,78 & 0,15 & 0,01 \\
\hline
\end{tabular}

Figura 58 - MGARCH-BEKK $(1,1)$ - Modelo 5 


\begin{tabular}{|c|c|c|c|c|c|c|c|c|c|c|c|}
\hline \multicolumn{5}{|c|}{ Modelo 6} & & & & & & & \\
\hline \multicolumn{5}{|c|}{ Modelo $\operatorname{BEKK}(\mathrm{I}, \mathrm{I})$} & & & & & & & \\
\hline Parâmetros & Estimativa & DP & Estatistica & P Valor & & & & & & & \\
\hline$\alpha_{10}$ & 0,177 & 0,018 & 9,958 & 0,000 & \multicolumn{7}{|c|}{ Teste LM para Resíduos e Quadrado dos Resíduos } \\
\hline$\alpha_{20}$ & $-0,071$ & 0,014 & $-5,162$ & 1,000 & \multirow[b]{2}{*}{ Defasagem } & \multirow[b]{2}{*}{$\mathrm{u}_{1, \mathrm{t}-\mathrm{p}}$} & \multirow[b]{2}{*}{$u_{2, t-p}$} & \multirow[b]{2}{*}{$\mathrm{u}_{\text {st,-p }}$} & \multirow[b]{2}{*}{$u_{1, t-p}^{2}$} & \multirow[b]{2}{*}{$\mathrm{u}_{2, \mathrm{t}-\mathrm{p}}^{2}$} & \multirow[b]{2}{*}{$\mathrm{u}_{\text {st.-p }}^{2}$} \\
\hline$\alpha_{\text {so }}$ & 0,088 & 0,015 & 5,749 & 0,000 & & & & & & & \\
\hline$\alpha_{11}$ & 0,095 & 0,013 & 7,323 & 0,000 & I & 0,84 & 0,77 & 0,00 & 0,42 & 0,03 & 0,02 \\
\hline$\alpha_{22}$ & $-0,036$ & 0,023 & $-1,539$ & 0,938 & 2 & 0,90 & 0,21 & 0,00 & 0,51 & 0,00 & 0,02 \\
\hline$\alpha_{33}$ & 0,158 & 0,016 & 9,591 & 0,000 & 3 & 0,45 & 0,26 & 0,00 & 0,63 & 0,01 & 0,02 \\
\hline$\beta_{I I}$ & 0,250 & 0,013 & 19,539 & 0,000 & 4 & 0,58 & 0,40 & 0,00 & 0,77 & 0,01 & 0,01 \\
\hline$\beta_{z z}$ & 0,138 & 0,020 & 6,808 & 0,000 & 5 & 0,37 & 0,48 & 0,00 & 0,88 & 0,03 & 0,01 \\
\hline \multirow[t]{3}{*}{$\beta_{s 3}$} & 0,956 & 0,004 & 246,78 & 0,000 & 6 & 0,42 & 0,46 & 0,00 & 0,93 & 0,01 & 0,01 \\
\hline & & & & & 7 & 0,53 & 0,57 & 0,00 & 0,95 & 0,02 & 0,01 \\
\hline & & & & & 8 & 0,62 & 0,57 & 0,00 & 0,84 & 0,03 & 0,01 \\
\hline$A I C$ & 20.106 & & & & 9 & 0,44 & 0,59 & 0,01 & 0,81 & 0,05 & 0,02 \\
\hline$B I C$ & 20.158 & & & & 10 & 0,49 & 0,63 & 0,01 & 0,76 & 0,02 & 0,00 \\
\hline$L O G$ & $-10044,1$ & & & & Ausência & rre & & & & & \\
\hline
\end{tabular}

Figura 59 - MGARCH-BEKK(1,1) - Modelo 6

\begin{tabular}{|c|c|c|c|c|}
\hline \multicolumn{5}{|c|}{ Modelo 8} \\
\hline \multicolumn{5}{|c|}{ Modelo BEKK(I,I) } \\
\hline Parâmetros & Estimativa & DP & Estatistica & P Valor \\
\hline$\alpha_{10}$ & 0,169 & 0,030 & 5,642 & 0,000 \\
\hline$\alpha_{20}$ & $-0,044$ & 0,009 & $-4,971$ & 1,000 \\
\hline$\alpha_{30}$ & 0,084 & 0,020 & 4,116 & 0,000 \\
\hline$\alpha_{11}$ & 0,099 & 0,022 & 4,439 & 0,000 \\
\hline$\alpha_{22}$ & $-0,040$ & 0,014 & $-2,873$ & 0,998 \\
\hline$\alpha_{33}$ & 0,144 & 0,026 & 5,643 & 0,000 \\
\hline$\beta_{I I}$ & 0,206 & 0,030 & 6,840 & 0,000 \\
\hline$\beta_{22}$ & 0,205 & 0,033 & 6,162 & 0,000 \\
\hline$\beta_{s s}$ & 0,961 & 0,008 & 123,46 & 0,000 \\
\hline
\end{tabular}

\begin{tabular}{|c|c|c|c|c|c|c|}
\hline \multirow[b]{2}{*}{ Defasagem } & \multicolumn{5}{|c|}{ Teste LM para Resíduos e Quadrado dos Residuos } & \multirow[b]{2}{*}{$\mathrm{u}_{\text {s.t-p }}^{2}$} \\
\hline & $\mathrm{u}_{1, \mathrm{t}-\mathrm{p}}$ & $\mathrm{u}_{2, t-\mathrm{p}}$ & $\mathrm{u}_{\text {s:t-p }}$ & $\mathrm{u}_{1, t-\mathrm{p}}^{2}$ & $\mathrm{u}_{2, \mathrm{t}-\mathrm{p}}^{2}$ & \\
\hline I & 0,38 & 0,01 & 0,00 & 0,07 & 0,26 & 0,03 \\
\hline 2 & 0,68 & 0,00 & 0,00 & 0,07 & 0,28 & 0,02 \\
\hline 3 & 0,30 & 0,00 & 0,00 & 0,14 & 0,19 & 0,02 \\
\hline 4 & 0,46 & 0,01 & 0,00 & 0,26 & 0,09 & 0,01 \\
\hline 5 & 0,51 & 0,01 & 0,00 & 0,35 & 0,10 & 0,01 \\
\hline 6 & 0,62 & 0,03 & 0,00 & 0,43 & 0,10 & 0,01 \\
\hline 7 & 0,68 & 0,04 & 0,00 & 0,47 & 0,11 & 0,01 \\
\hline 8 & 0,76 & 0,06 & 0,00 & 0,44 & 0,10 & 0,01 \\
\hline 9 & 0,68 & 0,02 & 0,00 & 0,46 & 0,11 & 0,02 \\
\hline 10 & 0,67 & 0,02 & 0,01 & 0,36 & 0,15 & 0,01 \\
\hline
\end{tabular}

\begin{tabular}{c|c} 
AIC & 19.079 \\
BIC & 19.130 \\
LOG & $-9530,41$ \\
\hline
\end{tabular}
$\mathrm{H}_{0}$ : Ausência de autocorrelaçăa

\begin{tabular}{|c|c|}
\hline Parâmetros & Estimativa \\
\hline$\alpha_{10}$ & 0,196 \\
\hline$\alpha_{20}$ & $-0,052$ \\
\hline$\alpha_{30}$ & 0,096 \\
\hline$\alpha_{11}$ & 0,112 \\
\hline$\alpha_{22}$ & $-0,047$ \\
\hline$\alpha_{33}$ & 0,166 \\
\hline$\beta_{I I}$ & 0,241 \\
\hline$\beta_{2 z}$ & 0,239 \\
\hline$\beta_{s s}$ & 0,724 \\
\hline$\beta_{23}$ & 0,611 \\
\hline$A I C$ & 19.069 \\
\hline$B I C$ & 19.126 \\
\hline LOG & $-9524,5$ \\
\hline
\end{tabular}

Modelo 8

odelo $\operatorname{BEKK}(2,1)$

Figura 60 - MGARCH-BEKK(1,1) e MGARCH-BEKK(2,1) - Modelo 8 


\section{APÊNDICE F - Estatísticas Exploratórias - Correlações Condicionais}

Apresentamos nesse apêndice as estatísticas exploratórias referentes aos demais modelos estimados. Os resultados gerais dos modelos de referencia, são vistos nos resultados desses demais modelos, ou seja, magnitude de spillovers equivalentes em média para choques cambiais nos diferentes modelos, contudo com menor magnitude quando comparado em modulo com os valores médios dos choques de mercados financeiros internacionais.

\begin{tabular}{|c|c|c|c|c|c|c|c|c|c|c|c|c|}
\hline \multirow[b]{3}{*}{ Estatisticas } & \multicolumn{12}{|c|}{ Estatisticas - Correlaçôes Condicionais Estimadas } \\
\hline & \multicolumn{2}{|c|}{ Modelo 1} & \multicolumn{2}{|c|}{ Modelo 2} & \multicolumn{2}{|c|}{ Modelo 4} & \multicolumn{2}{|c|}{ Modelo 5} & \multicolumn{2}{|c|}{ Modelo 7} & \multicolumn{2}{|c|}{ Modelo 8} \\
\hline & Ibovespa - IND1 & Tbovespa - $\mathbb{N N D} 3$ & Ibovespa - IND2 & Tbovespa - IND3 & IGC-NM - IND1 & IGC-NM- IND3 & IGC-NM - IND2 & IGC-NM - IND3 & IGC-X - IND 1 & IGC-X - IND3 & IGC-X - IND2 & $\mathrm{IGC}-\mathrm{X}-\mathrm{IND} 3$ \\
\hline Média & $-0,21$ & 0,55 & $-0,18$ & 0,55 & $-0,21$ & 0,49 & $-0,14$ & 0,49 & $-0,23$ & 0,53 & $-0,18$ & 0,53 \\
\hline Mediana & $-0,22$ & 0,57 & $-0,20$ & 0,57 & $-0,22$ & 0,50 & $-0,16$ & 0,50 & $-0,24$ & 0,54 & $-0,20$ & 0,54 \\
\hline Máximo & 0,47 & 0,94 & 0,34 & 0,94 & 0,48 & 0,83 & 0,39 & 0,89 & 0,46 & 0,85 & 0,39 & 0,89 \\
\hline Minimo & $-0,62$ & 0,05 & $-0,49$ & 0,07 & $-0,64$ & $-0,01$ & $-0,44$ & $-0,01$ & $-0,64$ & 0,03 & $-0,50$ & 0,01 \\
\hline Variância & 0,03 & 0,02 & 0,02 & 0,02 & 0,03 & 0,02 & 0,02 & 0,02 & 0,03 & 0,02 & 0,02 & 0,02 \\
\hline Desvio Padrão & 0,18 & 0,14 & 0,13 & 0,14 & 0,17 & 0,15 & 0,13 & 0,14 & 0,18 & 0,14 & 0,14 & 0,14 \\
\hline Coef. De Variação & $-0,87$ & 0,26 & $-0,73$ & 0,25 & $-0,81$ & 0,30 & $-0,95$ & 0,29 & $-0,80$ & 0,27 & $-0,77$ & 0,26 \\
\hline
\end{tabular}

Figura 61 - Estatísticas Exploratórias - Correlações Condicionais 